\title{
Effects of pesticide exposure on the humoral immune response following Streptococcus pneumoniae vaccination
}

\author{
Keith Douglas Salazar \\ West Virginia University
}

Follow this and additional works at: https://researchrepository.wvu.edu/etd

\footnotetext{
Recommended Citation

Salazar, Keith Douglas, "Effects of pesticide exposure on the humoral immune response following Streptococcus pneumoniae vaccination" (2006). Graduate Theses, Dissertations, and Problem Reports. 2420.

https://researchrepository.wvu.edu/etd/2420

This Dissertation is protected by copyright and/or related rights. It has been brought to you by the The Research Repository @ WVU with permission from the rights-holder(s). You are free to use this Dissertation in any way that is permitted by the copyright and related rights legislation that applies to your use. For other uses you must obtain permission from the rights-holder(s) directly, unless additional rights are indicated by a Creative Commons license in the record and/ or on the work itself. This Dissertation has been accepted for inclusion in WVU Graduate Theses, Dissertations, and Problem Reports collection by an authorized administrator of The Research Repository @ WVU. For more information, please contact researchrepository@mail.wvu.edu.
} 


\title{
Effects of pesticide exposure on the humoral immune response following Streptococcus pneumoniae vaccination
}

\author{
Keith Douglas Salazar \\ Dissertation submitted to the School of Medicine at West Virginia University in partial \\ fulfillment of the requirements for the degree of: \\ Doctor of Philosophy \\ In \\ Microbiology, Immunology, and Cell Biology \\ Rosana Schafer, Ph.D. Chair \\ John B. Barnett, Ph.D. \\ Michael R. Miller, Ph.D. \\ Christopher F. Cuff, Ph.D. \\ David N. Weissman, M.D. \\ Department of Microbiology, Immunology, and Cell Biology \\ Morgantown, West Virginia \\ 2006
}




\section{ABSTRACT \\ Effects of pesticide exposure on the humoral immune response following Streptococcus pneumoniae vaccination}

Keith Douglas Salazar

As pesticide use rises in the US annually, the need for extensive characterization of the risks associated with these substances also increases. Herbicides represent the most frequently used type of pesticides. 3,4-dichloropropionanilide (propanil) and 2,4dicholorophenoxyacetic acid (2,4-D) are two of the most commonly used herbicides. These experiments evaluated the effects of propanil and 2,4-D on the humoral immune response in C57BL/6 mice following heat-killed Streptococcus pneumoniae (HKSP) immunization. Intraperitoneal exposure of $150 \mathrm{mg} / \mathrm{kg}$ propanil on the same day as HKSP immunization enhances the splenic T-independent type 2 antibody response to phosphorylcholine (PC) antigen 4-6-fold. Maximal PC enhancement occurs 7 days postexposure. Propanil exposure 9 days following HKSP immunization enhances the Tdependent antibody response to the pneumococcal surface protein A (PspA). 2,4-D exposure decreases the $\mathrm{PC}$-specific antibody response in the bone marrow and the antibody serum titers 10 days post-exposure. Mixture exposure to the herbicides did not produce any synergistic effects. In addition, aspiration of the mixture of herbicides did not affect the antibody response. Ovariectomy and inhibition of ovarian steroid synthesis abrogates the PC-specific antibody enhancement in propanil-treated mice. Several studies examined the direct and indirect estrogenic activity of propanil. Interestingly, propanil enhances the PC-specific splenic antibody response independent of an estrogenic mechanism. Although male mice also had enhanced antibody responses following propanil exposure, orchiectomy did not affect the enhancement. Finally, propanil exposure did not enhance survival following a suboptimal immunization to a virulent strain of $S$. pneumoniae. Altogether, these results provide a number of findings that contribute to our understanding of the regulation of the humoral response to HKSP. 


\section{ACKNOWLEDGEMENTS}

I would like to thank my advisor, Rosana Schafer, for her steady guidance and support. Rosana excelled at knowing which of my ideas might prove fertile and which ideas would be fruitless distractions. I would also like to thank the members of my committee John Barnett, Mike Miller, Chris Cuff, and David Weissman for their helpful insight that focused my efforts on worthwhile endeavors. I also thank my fellow immunotoxicology graduate students, Alex and Irina, for being there to take my frustrations out and discuss all things unrelated to science. Finally, I thank Cheryl and Lennie for the countless ways they made my life easier. 


\section{TABLE OF CONTENTS}

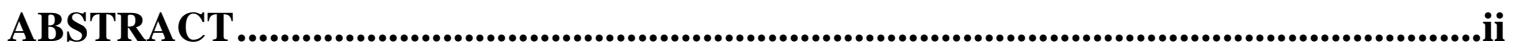

ACKNOWLEDGEMENTS .................................................................................... iii

LIST OF FIGURES...................................................................................

LIST OF TABLES ............................................................................................................viii

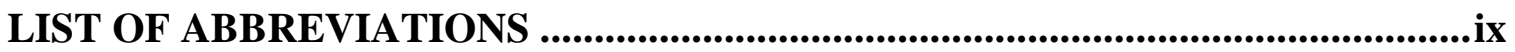

CHAPTER 1: GENERAL INTRODUCTION ...........................................................1

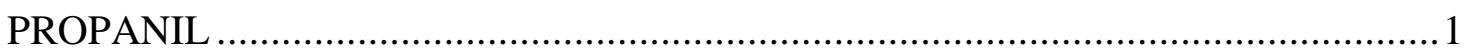

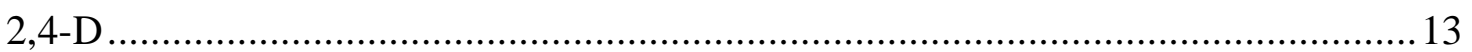

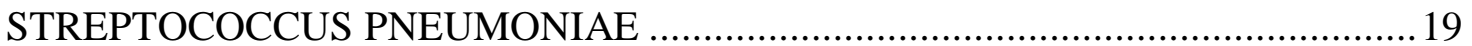

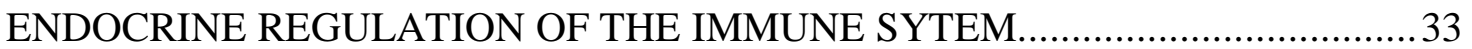

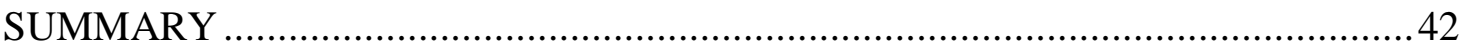

CHAPTER 2: COMPARISON BETWEEN ASPIRATION AND IP ROUTES OF

HERBICIDE EXPOSURE ON THE IMMUNE SYSTEM ........................................44

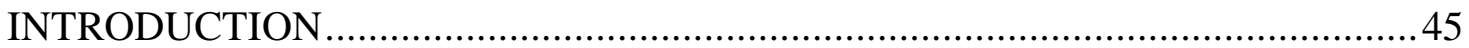

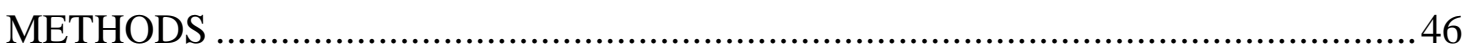

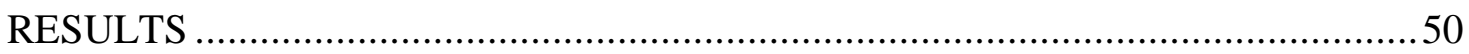

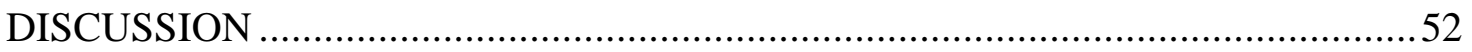

CHAPTER 3: THE POLYSACCHARIDE ANTIBODY RESPONSE AFTER STREPTOCOCCUS PNEUMONIAE VACCINATION IS DIFFERENTIALLY ENHANCED OR SUPPRESSED BY 3,4-DICHLOROPROPIONANILIDE AND 2,4-DICHLOROPHENOXYACETIC ACID .....................................................58

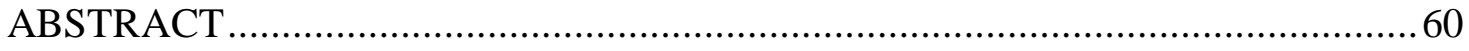

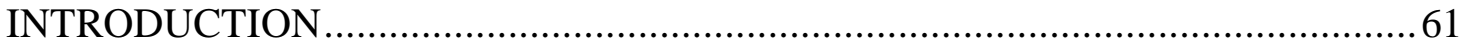

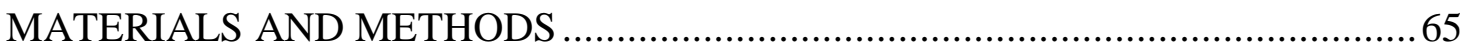

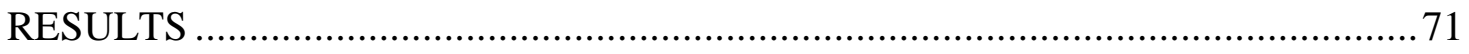

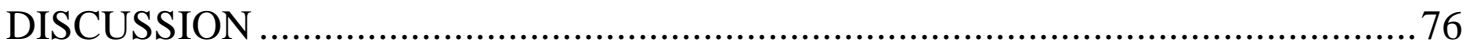

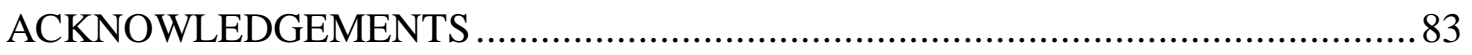

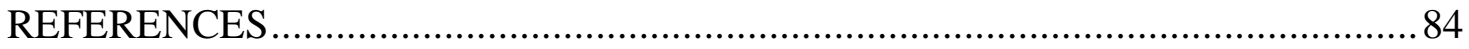

CHAPTER 4: FURTHER CHARACTERIZATION OF THE EFFECT OF

PROPANIL EXPOSURE ON THE HUMORAL IMMUNE RESPONSE ...............98

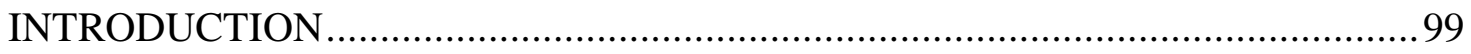

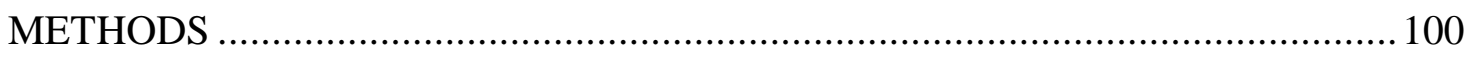

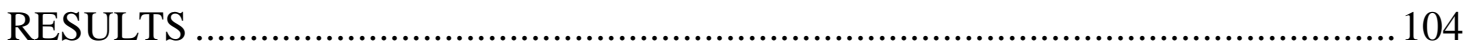

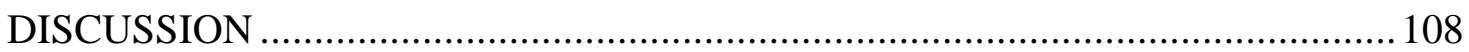

CHAPTER 5: EVIDENCE FOR A NOVEL ENDOCRINE DISRUPTOR: THE PESTICIDE PROPANIL REQUIRES THE OVARIES AND STEROID

SYNTHESIS TO ENHANCE HUMORAL IMMUNITY ........................................120

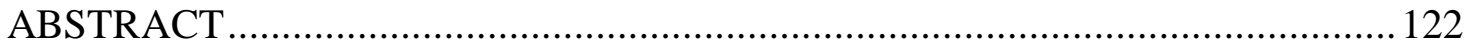

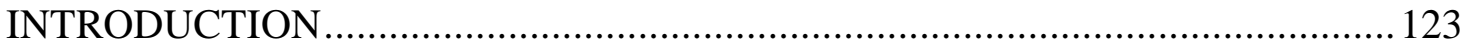

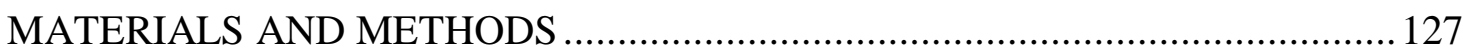

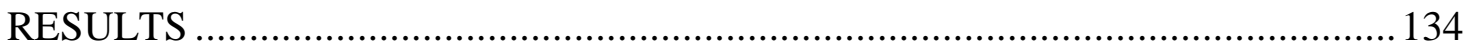

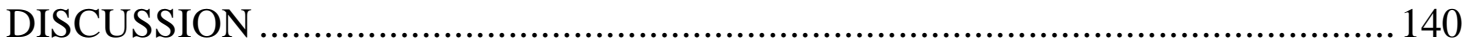

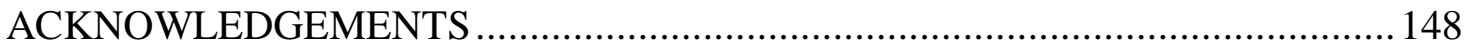


REFERENCES.

149

CHAPTER 6: PROPANIL EXPOSURE DOES NOT ENHANCE SURVIVAL TO A VIRULENT S. PNEUMONIAE CHALLENGE FOLLOWING A SUBOPTIMAL

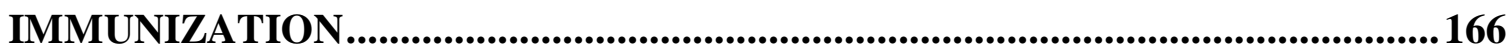

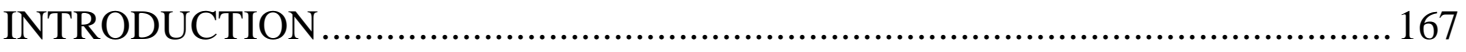

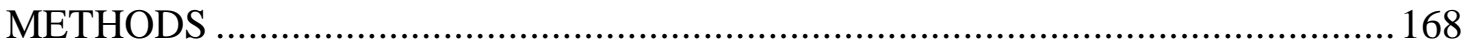

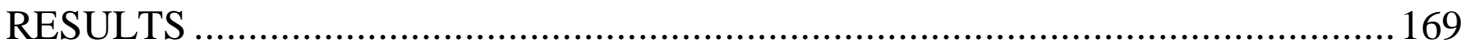

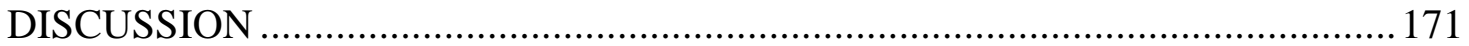

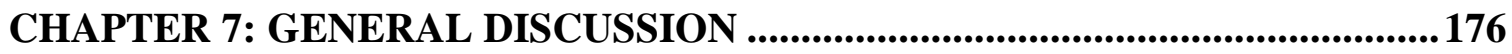

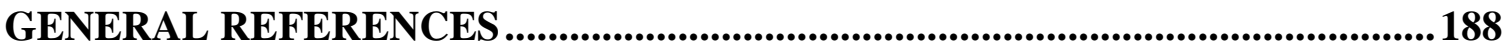




\section{LIST OF FIGURES}

\section{Chapter 2. Comparison between ip and aspiration routes of herbicide exposure on the immune system.}

Figure 1. Aspirated herbicides decrease thymic weight similarly to ip injection............54

Figure 2. Aspirated herbicides decrease the number of thymocytes similarly to ip injection. .55

Figure 3. Aspirated herbicides decrease thymocyte subpopulations similar to ip injection.

Figure 4. Aspirated herbicides do not affect the number of PC-specific ASC................5

Chapter 3. The polysaccharide antibody response after Streptococcus pneumoniae vaccination is differentially enhanced or suppressed by 3,4-dichloropropionanilide and 2,4-dichlorophenoxyacetic acid

Figure 1. Propanil and mixture exposure increases the number of PC-specific ASC in the spleen.

Figure 2. Propanil and mixture exposure increase spleen weight...............................91

Figure 3. Propanil increases the number of splenic ASC in a dose dependent manner...93

Figure 4. Propanil and mixture exposure increases ex vivo antibody production by splenocytes following HKSP vaccination.

Figure 5. 2,4-D and mixture exposure decreases the number of PC-specific bone marrow ASC

Figure 6. 2,4-D and mixture exposure decreases PC-specific titers.

Figure 7. Herbicide exposure has no effect on the number of splenic PspA-specific ASC.

Chapter 4. Further characterization of the effect of propanil exposure on the humoral immune response.

Figure 1. Propanil exposure increases the number of PC-specific ASC following PC-

Ficoll immunization.

Figure 2. Propanil does not affect PC-specific serum titers following PC-Ficoll immunization.

Figure 3. Propanil exposure does not affect PC-specific ASC in suboptimally HKSP immunized mice.

Figure 4. Day 14 propanil exposure increases the number of PC-specific and PspAspecific ASC following a HKSP boost on day 14.

Figure 5. Propanil exposure does not affect serum titers following secondary HKSP immunization.

Figure 6. Day 9 propanil exposure increases the number of PC and PspA-specific ASC.

Figure 7. Propanil exposure does not affect the number of PC-specific ASC following PC-KLH. 
Chapter 5. Evidence for a novel endocrine disruptor: the pesticide propanil requires the ovaries and steroid synthesis to enhance humoral immunity.

Figure 1. Ovariectomy abrogates the propanil-induced increase in PC-specific splenic ASC

Figure 2. Propanil does not increase uterine weights in OVX mice. ........................... 158

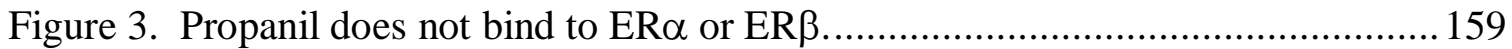

Figure 4. Propanil does not increase estrogen-inducible alkaline phosphatase activity in

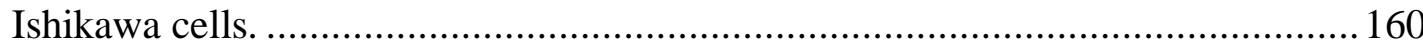

Figure 5. Addition of exogenous E2 does not restore the increase in PC-specific ASC of

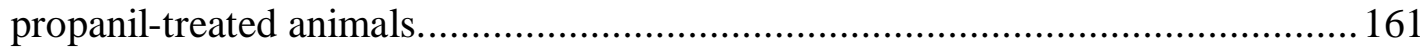

Figure 6. Addition of the ER antagonist ICI 182,780 does not block the increase in ASC in propanil-treated animals......

Figure 7. Antide treatment abrogates the propanil-induced increase in PC-specific ASC.

Figure 8. Treatment with the progesterone antagonist RU486 does not inhibit the increase in ASC in propanil-treated animals.

Figure 9. Propanil enhances the antibody response in both normal and orchiectomized males.

Chapter 6. Propanil exposure does not enhance survival to a virulent S. pneumoniae challenge following supoptimal immunization.

Figure 1. IP oil injection increases survival to a lethal ip $S$. pneumoniae challenge. .... 173 Figure 2. IP oil injection does not affect survival to a lethal iv $S$. pneumoniae challenge.

Figure 3. Propanil exposure does not increase survival to a lethal challenge following a suboptimal immunization. 


\section{LIST OF TABLES}

Chapter 3. The polysaccharide antibody response after Streptococcus pneumoniae vaccination is differentially enhanced or suppressed by 3,4-dichloropropionanilide and 2,4-dichlorophenoxyacetic acid

Table 1. Spleen cell populations 7 days after herbicide exposure and HKSP vaccination. 


\section{LIST OF ABBREVIATIONS}

$\begin{array}{ll}\text { 2,4-D } & \text { 2,4-dichlorophenoxyacetic acid } \\ \text { 2,4-DCP } & \text { 2,4-dichlorophenol } \\ \text { ANOVA } & \text { one-way analysis of variance } \\ \text { AP } & \text { alkaline phosphatase } \\ \text { APC } & \text { antigen presenting cell } \\ \text { ASC } & \text { antibody secreting cell } \\ \text { asp } & \text { aspiration } \\ \text { BCR } & \text { B-cell receptor } \\ \text { BFU-E } & \text { erythroid burst-forming units } \\ \text { BM } & \text { bone marrow } \\ \text { BPA } & \text { bisphenol A } \\ \text { CFU } & \text { colony forming unit } \\ \text { CFU-E } & \text { erythroid colony forming units } \\ \text { CFU-G } & \text { neutrophils } \\ \text { CFU-M } & \text { macrophages } \\ \text { CFU-S } & \text { myeloid stem cells } \\ \text { CHR } & \text { contact hypersensitivity reaction } \\ \text { CNS } & \text { central nervous system } \\ \text { ConA } & \text { concanavalin A } \\ \text { CpG-ODN } & \text { unmethylated cytidyl guanosyl-oligodeoxynucleotide } \\ \text { CR1 } & \text { complement receptor 1 } \\ \text { CR2 } & \text { complement receptor 2 } \\ \text { DAG } & \text { diacylgylcerol } \\ \text { DCA } & \text { 3,4-dichloroaniline } \\ \text { DES } & \text { diethylstilbesterol } \\ \text { E2 } & \text { 17ß-estradiol } \\ \text { EDC } & \text { endocrine disrupting chemical } \\ \text { ELISA } & \text { enzyme linked immunosorbent assay } \\ \text { ELISPOT } & \text { enzyme linked immunosorbent spot assay } \\ \text { EPA } & \text { Environmental Protection Agency } \\ \text { ER } & \text { estrogen receptor } \\ \text { FDC } & \text { follicular dendritic cell } \\ \text { FSH } & \text { follicle stimulating hormone } \\ \text { GM-CFU } & \text { granulocyte/macrophage progenitor cell } \\ \text { GnRH } & \text { gonadotropin-releasing hormone } \\ \text { GR } & \text { glucocorticoid receptor } \\ \text { HEV } & \text { high endothelial venules } \\ \text { HKLM } & \text { heat-killed Listeria monocytogenes } \\ \text { HKSP } & \text { heat-killed Streptococcus pneumoniae } \\ \text { IC } & \text { immune complex } \\ \text { Ip } & \text { intraperitoneal } \\ \text { Iv } & \text { intravenous } \\ \text { LD } 50 & \text { lethal dose causing death in 50\% of exposed animals } \\ \text { LH } & \text { luteinizing hormone } \\ & \end{array}$




$\begin{array}{ll}\text { LOAEL } & \text { lowest observed affect effect level } \\ \text { LPS } & \text { lipopolysaccharide } \\ \text { MHC } & \text { major histocompatibility complex } \\ \text { MLR } & \text { mixed lymphocyte reaction } \\ \text { MZ } & \text { marginal zone } \\ \text { NK } & \text { natural killer cell } \\ \text { OVX } & \text { ovariectomized } \\ \text { PAMPS } & \text { pathogen associated molecular patterns } \\ \text { PBMC } & \text { peripheral blood mononuclear cells } \\ \text { PC } & \text { phosphorylcholine } \\ \text { PFC } & \text { plaque-forming colony } \\ \text { PKC } & \text { protein kinase C } \\ \text { Po } & \text { peanut oil } \\ \text { PPS } & \text { pneumococcal polysaccharide } \\ \text { PspA } & \text { pneumococcal surface protein A } \\ \text { SC } & \text { subcutaneous } \\ \text { SCE } & \text { sister chromatid exchange } \\ \text { SLE } & \text { systemic lupus erythematosus } \\ \text { SRBC } & \text { sheep red blood cells } \\ \text { TCR } & \text { T cell receptor } \\ \text { TD } & \text { T-dependent } \\ \text { TH1 } & \text { T-helper 1 antibody reponse } \\ \text { TH2 } & \text { T-helper 2 antibody response } \\ \text { TI-2 } & \text { T-independent type 2 antibody response } \\ \text { TLR } & \text { Toll-like receptor } \\ \text { WHO } & \text { World Health Organization } \\ & \end{array}$




\section{CHAPTER 1: GENERAL INTRODUCTION}

\section{PROPANIL}

\section{Background and General Toxicity}

The pesticide 3,4-dichloropropionanilide (propanil) is an herbicide that is predominantly used for the control of weeds on commercial rice crops. Numerous studies have investigated the toxicological potential of propanil. It has been established in the literature that propanil has a number of immunotoxic effects. This report will provide a brief background of the general toxic effects of propanil exposure and primarily focus on the immunotoxicity studies that have been performed in both in vivo and in vitro models. In addition, epidemiological reports examining the immunotoxic effects of propanil on professional applicators and people living in areas of propanil use will be summarized.

Propanil is in the acetanilide chemical family (U.S. EPA OFFICE OF PESTICIDE PROGRAMS, 2003). Approximately 99\% of the propanil used in the United States is for the control of weeds on rice crops (U.S. EPA OFFICE OF PESTICIDE PROGRAMS, 2003). Roughly $50-70 \%$ of all rice grown in the U.S. is treated with propanil (U.S. EPA OFFICE OF PESTICIDE PROGRAMS, 2003). A 2001 estimate by the Environmental Protection Agency (EPA) ranks propanil as the $17^{\text {th }}$ most used pesticide in the U.S. The range of propanil application extends throughout the lower southern states along the Mississippi River and in some areas of California. Propanil is restricted exclusively to commercial use and it is readily degraded in the soil and water. The half-life in the soil is 1-3 days and 2-3 days in the water (Wauchope et al., 1992). Given the lack of residential use of propanil and the short half-life, exposure of the 
chemical is primarily restricted to applicators and residents who live near the treated farms. The preferred method of application is via groundboom sprayers and aerial methods (U.S. EPA OFFICE OF PESTICIDE PROGRAMS, 2003).

The most common routes of propanil exposure include inhalational, dermal, orbital, and to a lesser extent, oral. Upon entry into the organism, propanil is rapidly metabolized in the liver by the enzyme acylamidase into the major metabolite 3,4dichloroaniline (DCA) (Williams et al., 1966). Other metabolites of propanil include 2'hydroxypropanil and 6'-hydroxypropanil (McMillan et al., 1990a). DCA is subsequently metabolized to 6-hydroxy-3, 4-dichloroaniline and N-hydroxy-3, 4-dichloroaniline. Due to the rapid metabolism of the parent compound, propanil remains at detectable concentrations in the blood of rats for approximately 48 hours following exposure (Izmerov, 1984).

Following exposure to propanil, a number of toxic side effects are induced including hemolytic anemia, methemoglobinemia, and myelotoxicity. In vivo studies in Sprague-Dawley rats have shown that inhibition of the acylamidase activity with triorthotolyl phosphate decreased the amount of methemoglobinemia formed following a $400 \mathrm{mg} / \mathrm{kg}$ intraperitoneal (i.p.) exposure to propanil (Singleton et al., 1973). In addition, i.p. injections of the metabolite N-hydroxy-3, 4-dichloroaniline into rats was found to induce the same amount of hemolytic anemia as the parent compound (McMillan et al., 1991). In vitro studies analyzing the ability of propanil metabolites to oxidize hemoglobin in erythrocyte suspensions confirmed that N-hydroxy-3, 4-dichloroaniline was the most potent oxidizing metabolite (McMillan et al., 1990a). Altogether, theses studies indicate that metabolism of the parent compound is necessary for anemia. 
Duration of the anemic effects differ according to the exposure concentration of propanil (McMillan et al., 1990b). Analysis of blood samples from acutely exposed Sprague-Dawley rats treated with $300 \mathrm{mg} / \mathrm{kg}$ of propanil showed that methemoglobinemia effects peak at 4.5 hours post-exposure and these effects can be detected for as long as 24 hours (McMillan et al., 1990b). However, $100 \mathrm{mg} / \mathrm{kg}$ of propanil induced a peak in methemoglobin levels at 1.5 hours and could be detected for 12 hours (McMillan et al., 1990b). These data indicate that the anemic effects induced by propanil are brief and these effects do not persist following the clearance of propanil from the blood.

More recently, myelotoxic effects have also been established following propanil exposure (Malerba et al., 2002; Blyler et al., 1994). Ex vivo colony-forming assays from the bone marrow of acutely exposed C57B1/6 mice demonstrated that the early stem cell progenitors, myeloid stem cells (CFU-S) and erythroid burst-forming units (BFU-E), are decreased in number following $200 \mathrm{mg} / \mathrm{kg}$ propanil exposure (Blyler et al., 1994). However, the more differentiated cell types such as erythroid colony-forming units (CFU-E), granulocyte/macrophage progenitor cells (GM-CFU), macrophages (CFU-M), and neutrophils (CFU-G) are not reduced in number following propanil treatment (Blyler et al., 1994). Similar effects on the early erythroid stem cells are seen with human cord progenitor cells following propanil treatment (Malerba et al., 2002). In vitro exposure to cord blood demonstrated that the CFU-E and BFU-E progenitors had 50\% of their growth inhibited $\left(\mathrm{IC}_{50}\right)$ by 234 and $441 \mu \mathrm{M}$ of propanil, respectively (Malerba et al., 2002). The more differentiated CFU-GM progenitors had an $\mathrm{IC}_{50}$ of greater than $500 \mu \mathrm{M}$, indicating similar susceptibility to the effects of propanil on the more immature progenitors in both 
humans and mice (Malerba et al., 2002). However, unlike mice, DCA is far less toxic to human CFU/BFU-E progenitors than its parent compound (Malerba et al., 2002).

Initial chronic and acute exposure studies found that secondary immune organs are also affected after exposure to propanil (Barnett et al., 1989; Ambrose et al., 1972). Female and male rats exposed for 2 years to $400 \mathrm{ppm}$ of propanil mixed in their feed have increased spleen weights, but the heart, kidney, liver and testes weights are unaffected (Ambrose et al., 1972). In a subchronic study, female and male rats treated for 3 months with 1000 and 3300 ppm of propanil, respectively, did not have altered organ weights except increased spleen sizes (Ambrose et al., 1972). Additionally, acutely exposed C57Bl/6 mice treated i.p. with $200 \mathrm{mg} / \mathrm{kg}$ of propanil had decreased thymus weights and increased spleen weights (Barnett and Gandy, 1989). These studies suggest that propanil may be more toxic to secondary immune organs than other nonimmune organs. The relevance of these immunotoxic effects will be discussed in more detail in later sections.

Other studies using common toxic endpoints such as mutagenicity, reproductive toxicity, and carcinogenicity have yielded negative results. Propanil has not been found to be mutagenic as determined in Salmonella reversion assays (McMillan et al., 1988). The EPA has determined that propanil is not a carcinogen in humans (U.S. EPA OFFICE OF PESTICIDE PROGRAMS, 2003). Reproductive studies in rats have shown that chronic oral propanil exposure does not cause any abnormalities in the fertility of the parents nor does it affect the health of the offspring (Ambrose et al., 1972). Propanil is classified in the "slightly toxic" toxicity class III for oral exposures and toxicity class IV 
for inhalation and dermal exposures (U.S. EPA OFFICE OF PESTICIDE PROGRAMS, 2003).

Assessment of the effects of propanil on humans demonstrates that the greatest risk of toxic exposure is most hazardous with applicators and manufacturing workers. Examination of immune changes in farm-families exposed to propanil observed decreases in IL-2 ${ }^{+}$cells and natural killer (NK) cell counts (McClure et al., 2001). However, these lower counts were associated with the preseason measurements and the cell counts rebounded during the spray season (McClure et al., 2001). This could be due to the low particulate concentration of propanil in family homes lying adjacent to the spray fields (Richards et al., 2001). Non-applicator personnel working in adjacent propanil-treated fields were also exposed to very low concentrations of propanil (Barnes et al., 1987). These personnel were exposed to concentrations that were several orders of magnitude lower than the concentrations shown to be toxic (Barnes et al., 1987). However, $61 \%$ of production workers exposed to propanil had chloracne indicating the higher risk of toxicity (Morse et al., 1979).

\section{Innate immune studies}

The innate immune system is responsible for not only rapidly eliminating pathogens, but also initiating adaptive immune responses. Immunotoxic effects on cells of this system may also compromise the ability of an organism to control initial infections until an adaptive immune response can be generated. Two important effector cells of the innate immune system are macrophages and NK cells.

Propanil has been demonstrated to inhibit macrophage function. LPS-stimulated peritoneal macrophages harvested from mice 7 days following i.p. propanil exposure 
(200 mg/kg) have reduced production of IL-6 (32\% of control) and TNF- $\alpha$ (55\% of control) (Xie et al., 1997b). In addition, oral exposure to propanil (400 mg/kg) also reduced the production of IL-6 (40\% of control) (Xie et al., 1997b). However, macrophage TNF- $\alpha$ production is more sensitive to the effects of an oral exposure to propanil. Forty $\mathrm{mg} / \mathrm{kg}$ of propanil reduced the levels of TNF- $\alpha$ approximately the same amount as an i.p. exposure of $200 \mathrm{mg} / \mathrm{kg}$ of propanil (Xie et al., 1997b). This data suggests that different routes of exposure can affect the extent of immunotoxicity on macrophages. However, the sensitivity of macrophages to the effects of propanil varies depending on the endpoint studied and the route of exposure.

Both $\mathrm{Ca}^{2+}$ release and NF- $\kappa \mathrm{B}$ regulate the production of IL- 6 and TNF- $\alpha$ in macrophages. $\mathrm{Ca}^{2+}$, in combination with diacylgylcerol (DAG), stimulates protein kinase $\mathrm{C}(\mathrm{PKC})$. At the cytoplasmic membrane, PKC enhances the phosphorylation of some transcription factors for cytokine transcription, such as NF- $\kappa B$. Macrophages treated in vitro with propanil have a significant reduction in intracellular $\mathrm{Ca}^{2+}$ release (Xie et al., 1997a). In addition, NF-кB p65 subunit is decreased in the nucleus of propanil-treated macrophages (Frost et al., 2001). The binding of NF- $\kappa \mathrm{B}$ to the TNF- $\alpha$ promoter is reduced in propanil-treated cells after 18 hours of in vitro exposure (Frost et al., 2001). These data suggest the mechanism regulating the reduction in inflammatory cytokine production in propanil-treated macrophages is an effect on NF- $\kappa \mathrm{B}$ and $\mathrm{Ca}^{2+}$.

NK cell function is also inhibited following propanil exposure. Mice treated i.p. with propanil and DCA have reduced NK cell cytotoxicity. NK cells harvested from the spleens of mice treated i.p. with $50 \mathrm{mg} / \mathrm{kg}$ of propanil have an approximate $20 \%$ reduction in their ability to lyse a target cell (Barnett et al., 1992). The metabolite, DCA, 
also inhibits the cytolytic ability of NK cells similar to the parent compound (Barnett $e t$ al., 1992). The data suggests that propanil may reduce the capacity of cells of the innate immune system to fight new infections.

\section{T cell toxicity}

One of the first studied immunotoxic effects induced by propanil was observed on T cells (Barnett and Gandy, 1989). T cells are essential in facilitating a potent adaptive immune response. Briefly, $\mathrm{CD}^{+} \mathrm{T}$ cells are responsible for activating and coordinating the humoral immune response as well as cell-mediated immune responses. $\mathrm{CD}^{+} \mathrm{T}$ cells function primarily in executing cell-mediated immune responses. The thymus is the organ responsible for $\mathrm{T}$ cell development and maturation.

As mentioned previously, propanil induces thymic atrophy. Thymic atrophy is seen in acutely exposed mice approximately 2-4 days post-exposure (Cuff et al., 1996). Thymic weight is reduced in these mice for up to 7 days following an i.p. dose of 200 $\mathrm{mg} / \mathrm{kg}$ of propanil (Barnett and Gandy, 1989). By day 7, the thymus has begun to recover from the initial atrophy (Cuff et al., 1996). After 14 days post-exposure, the thymus has fully recovered from the original insult (Cuff et al., 1996). Analysis of the circulating $\mathrm{T}$ cell populations in the mesenteric lymph nodes and the spleen 7 days postexposure shows that mature $\mathrm{T}$ cell numbers are unaffected as a result of the thymic atrophy (Zhao et al., 1995). Failure to detect decreases in the mature T cell populations of immune organs may indicate that thymic atrophy is an endpoint to determine the extent of propanil exposure rather than a direct measure of damage to immune function.

The decrease in thymic weight is accompanied by a loss in total thymic cellularity, as well as an overall decline in the number of $\mathrm{T}$ cells in the various 
developmental stages of maturation (Zhao et al., 1995). Exposure doses as low as 100 $\mathrm{mg} / \mathrm{kg}$ decrease the number of all the $\mathrm{CD}^{+}$and $\mathrm{CD}^{-}{ }^{-}$subpopulations (Zhao et al., 1995). Mice treated i.p. with $200 \mathrm{mg} / \mathrm{kg}$ propanil have the largest decrease in the percentage of $\mathrm{CD}^{+} \mathrm{CD}^{+} \mathrm{CD}^{+}$(DP) thymocytes 4 days post-exposure (Cuff et al., 1996). This data indicates that the DP cells are the most sensitive of the thymocyte populations (Cuff $e t$ $a l ., 1996)$. The decrease observed in the immature population results in a downstream effect of decreasing the number of the more mature $\mathrm{CD}^{+}$single positive (SP) and $\mathrm{CD} 8^{+}$ SP cells (Zhao et al., 1995; Cuff et al., 1996).

The primary mechanism by which propanil induces thymic atrophy is a result of increased levels of glucocorticoids (Cuff et al., 1996; de la Rosa et al., 2005). Acute i.p. propanil exposure with doses of $50 \mathrm{mg} / \mathrm{kg}$ in C57Bl/6 mice increases the levels of corticosterone in the serum to approximately $1000 \mathrm{ng} / \mathrm{ml}$ compared to approximately 60 ng/ml for control mice (de la Rosa et al., 2005). The increase in corticosterone serum levels peaks within one hour following propanil exposure and returns to baseline levels within 24 hours (de la Rosa et al., 2005). Inhibition of the glucocorticoid receptors (GR) with the GR antagonist RU486 or removal of the adrenal glands, the primary site for glucocorticoid production, abrogates the thymic atrophy induced by propanil (Cuff et al., 1996; de la Rosa et al., 2005). In response to the sudden loss in the thymocyte populations, the recovery of the thymocyte population is generated by an increase in the percentage of cycling DP and CD8 ${ }^{+}$SP cells 4 days post-exposure (Cuff et al., 1996). However, the percentage of cycling thymocyte subpopulations returns to normal by day 7, indicating that recovery is initiated rapidly after exposure (Cuff et al., 1996). 
The extent of thymic atrophy induced by propanil can also be increased when combined with other herbicides (de la Rosa et al., 2005). The herbicide 2,4dichlorophenoxyacetic acid (2,4-D) does not decrease the number of DP or $\mathrm{CD}^{+} \mathrm{SP}$ cells following a $150 \mathrm{mg} / \mathrm{kg}$ i.p. exposure (de la Rosa et al., 2005). However, the addition of $150 \mathrm{mg} / \mathrm{kg}$ of 2,4-D combined with a $150 \mathrm{mg} / \mathrm{kg}$ dose of propanil can induce a greaterthan-additive decrease in the number of both the DP and $\mathrm{CD}^{+} \mathrm{SP}$ cell populations (de la Rosa et al., 2005). This data demonstrates the potential for other chemicals to enhance the toxicity of propanil (de la Rosa et al., 2005).

Analysis of $\mathrm{T}$ cell function after in vivo exposure to propanil has indicated that $\mathrm{T}$ cells are relatively resistant to the toxic effects of propanil. As mentioned previously, propanil exposure causes splenomegaly (Barnett and Gandy et al., 1989; Ambrose et al., 1972). The spleen is also an important secondary lymphoid organ. Therefore, the spleen was chosen for early immunotoxic characterization studies. Mixed lymphocyte reactions (MLR) are typically used to characterize $\mathrm{CD}^{+}$function. MLR of spleen cells from mice treated with an acute i.p. dose of propanil 1 week prior to harvest demonstrated that only at the highest doses tested of $400 \mathrm{mg} / \mathrm{kg}$ was there a significant decrease in the MLR (Barnett and Gandy, 1989). In vivo cell mediated immune responses were assessed using the contact hypersensitivity reaction (CHR) (Barnett and Gandy, 1989). The CHR was also decreased in animals treated with only the highest tested dose of $400 \mathrm{mg} / \mathrm{kg}$ (Barnett and Gandy, 1989). Finally, proliferation of splenocytes from mice treated in vivo with propanil was determined following ex vivo stimulation with the T cell mitogen, Concanavalin A (ConA). Again, only animals treated with the highest tested dose had significant reductions in proliferation (Barnett and Gandy, 1989). However, ConA 
stimulated splenocytes from animals treated i.p. with $200 \mathrm{mg} / \mathrm{kg}$ of propanil had a significant reduction in IL-2 production (27\% of control) and IL-6 production ( $45 \%$ of control) (Zhao et al., 1998). Altogether, the studies characterizing the T cell toxicity of propanil indicate that several endpoints are required to establish an accurate inference of propanil's toxicity.

Mechanistic studies on the regulation of IL-2 in T cells demonstrated that in vitro propanil treatment decreases IL-2 transcription rate as well as IL-2 message stability (Zhao et al., 1999). DNA binding of the IL-2 transcription factor, AP-1, is also reduced for up to 4 hours post-exposure in propanil-treated cells (Brundage et al., 2004). In addition, propanil reduces the phosphorylation and the total protein levels of the subunit of AP-1, c-jun (Brundage et al., 2004). These data suggest that propanil decreases the Tcell production of IL-2 by suppressing the activity of one of the subunits of a key transcription factor, however, the molecular mechanism by which propanil reduces phosphorylation is unknown.

\section{B cell toxicity and the humoral response}

As mentioned previously, propanil was found to be myelotoxic and induce splenomegaly. The bone marrow microenvironment is the site of B cell maturation prior to release into circulation. The spleen is an important site for early and late antibody production to bacterial pathogens (Martin et al., 2001; Zandvoort et al., 2002; Manz et al., 2002). Approximately $40 \%$ of the lymphocytes in the spleen are B lymphocytes (Salazar et al., 2005). Altogether, these organs represent two important sites for evaluating the immunotoxic effects of propanil on B cells. 
Propanil exposure decreases the number of developing B cells in the bone marrow available for maturation. B cell maturation proceeds from the pro-B cell to pre-B cell and finally to the immature $\operatorname{IgM}^{+} \mathrm{B}$ cell (Rosenberg et al., 1994). In vivo i.p. propanil exposure at the lowest studied dose of $50 \mathrm{mg} / \mathrm{kg}$ decreased the number of murine pre-B cells in the bone marrow ( $\sim 50 \%$ of control) 7 days post-exposure (de la Rosa et al., 2003). Immature IgM $\mathrm{Ig}^{+} \mathrm{B}$ cells are also decreased in number ( $\sim 50 \%$ of control) at doses of $150 \mathrm{mg} / \mathrm{kg}$ (de la Rosa et al., 2003). However, this decrease in immature B cells does not result in a loss of circulating B cells as determined by an analysis of splenocyte populations (Salazar et al., 2005). Total splenic B cell numbers, as well as the circulating follicular B cell population, remain unchanged following propanil exposure (Salazar et al., 2005).

Although propanil exposure does not effect the number of B cells in the periphery, it can suppress B cell function. Exposure to $400 \mathrm{mg} / \mathrm{kg}$ of propanil suppresses splenic B cell proliferation after ex vivo stimulation with the B cell mitogen lipopolysaccharide (LPS) (Barnett and Gandy, 1989). Analysis of the antibody response to both T-independent type 2 (TI-2) and T-dependent (TD) model antigens found that these responses are more sensitive to propanil's toxic effects than B cell proliferation (Barnett and Gandy, 1989; Barnett et al., 1992). Exposure to propanil on day 0 followed by immunization with sheep red blood cells (SRBC) on day 4 decreased the number of SRBC plaque forming cells (PFC) in a dose dependent fashion (Barnett and Gandy, 1989). Fifty $\mathrm{mg} / \mathrm{kg}$ of propanil was the lowest dose to significantly reduce the number of SRBC PFC (67.5\% of control) (Barnett and Gandy, 1989). Higher doses of propanil and DCA, $200 \mathrm{mg} / \mathrm{kg}$ and $150 \mathrm{mg} / \mathrm{kg}$, respectively, were found to decrease the number of 
PFC in animals immunized with DNP-Ficoll 4 days following propanil exposure $(75 \%$ of control) (Barnett et al., 1992). Altogether, these reports suggest that propanil exerts immunotoxic effects either directly on B cells or their supporting microenvironment critical for their normal function.

\section{Adaptive immune response to bacterial challenges}

In general, the collective in vivo studies on immune function indicate that propanil has suppressive effects on the immune system. Challenging the immune system with live bacteria provides important information toward understanding the relevance of altered immune function on individual lymphocyte populations. Live bacterial challenge studies provide information demonstrating the effect of decreased immune cell function on clearing infections caused by common pathogens. These studies are important for predicting risk of infection that is associated with a specific level of immunotoxicity.

The toxic effects of propanil on the cell-mediated immune response were studied using a Listeria monocytogenes infection model in C57BL/6 mice (Watson et al., 2000). L. monocytogenes is an intracellular pathogen that requires an effective cell-mediated immune response to clear the infection. Animals were exposed to propanil and challenged with live L. monocytogenes. Ex vivo Con A and heat-killed L. monocytogenes (HKLM) stimulated splenocyte and liver cultures from the propanil-treated and $L$. monocytogenes challenged animals had an approximate $50 \%$ reduction in IFN- $\gamma$ production (Watson et al., 2000). However, analysis of spleen and liver endogenous cytokine levels from propanil-treated and L. monocytogenes infected animals showed no significant differences in IL-6, IFN- $\gamma$, TNF- $\alpha$, and IL-1 $\beta$ when compared to $L$. monocytogenes-infected control animals (Watson et al., 2000). Additionally, animals 
treated with $200 \mathrm{mg} / \mathrm{kg}$ of propanil and $\mathrm{LD}_{50}$ of $L$. monocytogenes did not demonstrate any greater susceptibility to infection than control animals (Watson et al., 2000). This indicates that a $200 \mathrm{mg} / \mathrm{kg}$ exposure to propanil produces immunotoxic effects on cellmediated immunocytes measured in vitro, but does not significantly affect the host's ability to mount an effective immune response. A limitation of this study is that $L$. monocytogenes infections can be initially controlled in mice lacking an adequate cytotoxic T cell response (Bancroft et al., 1991). However, there have been no studies reported to date characterizing the effect of an acute propanil exposure on the immune response to a pathogen that predominantly requires a competent cytotoxic $\mathrm{T}$ cell response to clear the infection.

\section{2,4-D}

\section{Background}

2,4-D is a chlorinated phenoxy herbicide used for the control of broadleaf weeds throughout the year in both the public and private sector. 2,4-D is the most used pesticide ingredient in the home and garden sector in the United States and is the fifth most used active ingredient in the agricultural sector. 2,4-D is predominantly used in the Midwest, Great Plains, and the Northwest (U.S. EPA OFFICE OF PESTICIDE PROGRAMS, 2005).

2,4-D is readily metabolized in both the soil and the water. The half-life of 2,4-D in the water under aerobic and anaerobic conditions is 15 and 312 days, respectively. The half-life in the soil is approximately 59 days. Aerobic microbial metabolism is the major mechanism by which 2,4-D is degraded in both the water and soil. The major 
metabolite of aerobic aquatic degradation is 2-chlorohydroquinone. Minor metabolites from aerobic microbial degradation include 2,4-dichlorophenol (2,4-DCP) and carbon dioxide. Conversely, anaerobic aquatic degradation results in the predominant formation of 2,4-DCP and carbon dioxide. The major metabolite of microbial degradation of 2,4-D in the soil yields 2,4-DCP (Veeh et al., 1996).

The most common routes of exposure for 2,4-D include dermal and oral exposure, and to a lesser extent, inhalation (Garabrant et al., 2002). Despite the rapid degradation of 2,4-D in the environment, exposure to humans is widespread. An analysis of 1000 randomly selected adults residing in the U.S. found that $12 \%$ had measurable levels of 2,4-D in the urine and $64 \%$ had detectable concentrations of the metabolite 2,4-DCP (Hill et al., 1995). The median and maximum concentration of 2,4-D in the urine was 1.8 $\mu \mathrm{g} /$ liter and $37 \mu \mathrm{g} /$ liter, respectively (Hill et al., 1995). Following oral exposure in Fischer 344 rats, 2,4-D concentrations peak within the blood in 10-20 minutes (Pelletier et al., 1989). Dermal exposures in rats demonstrates that 2,4-D is rapidly absorbed similarly to oral exposure and peaks 30 minutes post-exposure (Pelletier et al., 1989). Upon entry into humans, 2,4-D is not metabolized (Knopp et al., 1992). 2,4-D is widely distributed throughout the body due to its water solubility and does not accumulate to any specific organ (Pelletier et al., 1989). The half-life of 2,4-D in the urine is approximately 17 hours and 11 hours in the plasma (Sauerhoff et al., 1977). Due to the rapid clearance, inability to be metabolized, or locate to a particular tissue, 2,4-D is not believed to accumulate in repeatedly exposed humans (Garabrant and Philbert, 2002).

\section{General toxicity}


The toxicity of 2,4-D has been extensively studied. Numerous reports have evaluated the potential of 2,4-D to cause reproductive, carcinogenic, neurological, endocrinological and immunotoxic effects. The acceptable daily intake for 2,4-D as established by the World Health Organization (WHO) is .013 mg/kg/day (Zeljezic et al., 2004). The conclusions from these studies have suggested that 2,4-D has very little overall toxicity (Munro et al., 2002).

A number of genotoxic assays performed in a fibroblastic cell line found that 2,4D does not increase the amount of DNA repair (Jacobi et al., 1991; Clausen et al., 1990; Galloway et al., 1987). However, lymphocytes from human donors were exposed to a commercial formulation of 2,4-D in vitro and demonstrated that chromosomal aberrations were increased at concentrations that have been established by the WHO to lack any associated health risks (Zeljezic and Garaj-Vrhovac, 2004). The duration and concentration of lymphocyte exposure to 2,4-D has not been determined, thereby preventing an accurate assessment of genotoxic risks for lymphocytes (Zeljezic and Garaj-Vrhovac, 2004). Lymphocytes from humans exposed to 2,4-D in an occupational setting were analyzed for sister chromatid exchange (SCE) frequency and found no significant changes in SCE frequency in 2,4-D workers (Linnainmaa, 1983). Altogether, the literature supports the hypothesis that 2,4-D does not increase the risk for developing cancer (Munro et al., 2002).

Adverse neurotoxic effects such as myotonia, characterized by difficulty relaxing skeletal muscles, can be observed in animals treated with high doses of 2,4-D (50-500 $\mathrm{mg} / \mathrm{kg}$ ) (Elo et al., 1989). Locomotor effects have also been observed in rats at doses as low as $15 \mathrm{mg} / \mathrm{kg} /$ day, but these effects were transient (Mattsson et al., 1997). Other 
potentially lasting effects such as demyelination in the CNS have not been observed in animals (Garabrant and Philbert, 2002). Since the concentration of 2,4-D required to induce neurotoxic effects also causes systemic toxicity, 2,4-D is considered to be mildly toxic to the nervous system (Garabrant and Philbert, 2002).

Reproductive toxicity following 2,4-D exposure has been assessed in a number of animal studies. Maternal rats and rabbits exposed to doses in excess of $90 \mathrm{mg} / \mathrm{kg} / \mathrm{day}$ had litters with reduced fetal weights and increased fetal variations (Charles et al., 2001). Male mice and rats exposed chronically to 2,4-D did not produce any changes in the testes and did not affect reproductivity (Charles et al., 2001; Charles et al., 1996). There have been no published studies demonstrating that 2,4-D exposure induces reproductive or teratogenic effects in humans (Garabrant and Philbert, 2002; Munro et al., 2002).

The ability of 2,4-D to disrupt the endocrine system is of recent interest and less studied compared with more common toxicological endpoints. The ability of 2,4-D to bind to the estrogen receptor was studied using an in vitro model in MCF-7 breast cancer cells (Lin and Garry, 2000). 2,4-D was found to induce estrogen receptor mediated growth at concentrations of $1 \mu \mathrm{g} / \mathrm{ml}$ (Lin and Garry, 2000). This concentration was roughly 500-fold less efficacious than E2 and is not considered to be estrogenic (Lin and Garry, 2000). Another approach analyzing the enzymes responsible for metabolizing E2 found that rats exposed to $375 \mathrm{mg} / \mathrm{kg}$ of 2,4-D had elevated amounts of CYP1A and CYP1B in the liver, kidney, and the mammary gland (Badawi et al., 2000). These increased enzyme levels corresponded to a marked increase in estradiol and estrone (Badawi et al., 2000). However, further dose response studies are needed to appropriately quantify the sensitivity for this effect. Finally, a preliminary study in 
amphibians found that 2,4-D inhibited progesterone-dependent oocyte maturation, as well as, disrupt the actin cytoskeleton of oocytes (Lin and Garry, 2000). Additional studies are required to determine if $2,4-\mathrm{D}$ is able to affect the progesterone pathway in mammals.

\section{Immunotoxicity}

Immunotoxic studies have suggested that 2,4-D has modest toxicity. Exposure to 2,4-D in CD-1 mice via a dermal administration and an ip immunization of sheep red blood cells (SRBC) on the following day decreased the number of SRBC-specific plaque forming cells (PFC) on day 5 post-immunization (Blakley et al., 1986). The decrease in SRBC-specific PFC was dose dependent (Blakley and Schiefer, 1986). The lowest measured dose of 2,4-D to decrease SRBC-specific PFC was $100 \mathrm{mg} / \mathrm{kg}$, which decreased the PFC 10\% from controls (Blakley and Schiefer, 1986). In addition, acute dermal exposure did not affect the ex vivo proliferative responses of splenocytes to either the T cell mitogen, ConA, or the B cell mitogen, LPS (Blakley and Schiefer, 1986). Conversely, an acute oral exposure of 2,4-D in $\mathrm{BDF}_{1}$ mice via gastric intubation and followed by an ip vaccination to SRBC on the next day, demonstrated that the number of SRBC-specific PFC was increased when measured on the fifth day of immunization (Blakley, 1986). The effect on PFC was not dose dependent and increased the number of SRBC PFC 1.5 to 2.4-fold following exposures of 50 to $200 \mathrm{mg} / \mathrm{kg}$ (Blakley, 1986). Animals treated with 2,4-D had normal proliferative responses in splenic T cells following ConA stimulation (Blakley, 1986). This suggests that the variation in SRBC PFC responses after oral or dermal exposure to $2,4-\mathrm{D}$ is not likely due to changes in $\mathrm{T}$ cell function (Blakley, 1986). A proposed hypothesis for enhancement versus suppression of the antibody response in 2,4-D exposed animals is that 2,4-D acts as a 
hapten when given orally (Blakley, 1986). However, this hypothesis has not been experimentally tested.

Since 2,4-D is widely used for many different commercial and private applications, it is often applied in mixtures. Examining the effect of mixture interactions on the immune response is a more relevant method for evaluating immunotoxicity of 2,4D. Initial studies demonstrate that mixture exposure with 2,4-D can enhance the immunotoxic effect of a single 2,4-D exposure.

A common commercial mixture of 2,4-D is Tordon 202C, which contains a 1:16 ratio of the herbicide picloram and 2,4-D (Blakley, 1997). The lowest tested dose of 2.5 $\mathrm{mg}$ picloram/kg/day and $50 \mathrm{mg}$ 2,4-D/kg/day decreased the antibody response to SRBC $33 \%$ after 26 days of daily oral exposure (Blakley, 1997). An analysis of the effects of a single picloram or 2,4-D exposure was not performed, thereby preventing an interpretation of the mixture interaction. Another commonly occurring herbicide mixture includes propanil and 2,4-D. An acute ip exposure to 2,4-D did not affect pre-B or immature IgM $\mathrm{I}^{+} \mathrm{B}$ cells 2 days post-exposure (de la Rosa et al., 2003). However, a 50 $\mathrm{mg} / \mathrm{kg}$ mixture decreased both the pre- $\mathrm{B}$ and $\operatorname{IgM}^{+} \mathrm{B}$ cells. When the propanil and 2,4-D mixture effect was analyzed on thymocytes, $200 \mathrm{mg} / \mathrm{kg}$ of 2,4-D decreased the number of $\mathrm{CD}^{+} \mathrm{CD}^{+}$and $\mathrm{CD} 4{ }^{-} \mathrm{CD} 8^{+}$. However, a $150 / 150$ mixture decreased these thymocyte populations the same magnitude as a single $200 \mathrm{mg} / \mathrm{kg}$ exposure of 2,4-D. These findings suggest that the immunotoxic effects of 2,4-D may be enhanced when combined with other active herbicide ingredients.

There is little direct evidence that 2,4-D exposure affects human immune function. A published study on 10 farmers who used 2,4-D on their crops suggests that 
there may be a risk for short-term immunosuppression (Faustini et al., 1996). Blood samples were analyzed 7 days pre-exposure, 1-12 days post-exposure, and 50-70 days post exposure (Faustini et al., 1996). $\mathrm{CD}^{+}, \mathrm{CD}^{+} \mathrm{T}$ cells, and NK cells were all reduced 1-12 days post exposure (Faustini et al., 1996). In addition, proliferative responses to ConA were decreased $50 \%$ from pre-exposure samples (Faustini et al., 1996). By 50-70 days post exposure, the lymphocyte numbers and proliferation were normal. This data indicates that occupational exposure to 2,4-D exerts immunotoxic effects seen in animal studies. Given the widespread use of 2,4-D and its potential to be immunotoxic in greater-than-additive fashion when combined with propanil, further studies evaluating mixture effects on adaptive immune responses is warranted.

\section{STREPTOCOCCUS PNEUMONIAE}

Streptococcus pneumoniae is a gram-positive coccus that kills approximately 1 million children worldwide each year (Kruetzmann et al., 2003). The antibody response to $S$. pneumoniae provides an excellent model for studying the humoral immune response to both TI-2 and TD antigens. The immunodominant antigen that elicits the TI-2 response is the cell wall polysaccharide phosphorylcholine (PC). One of the surface proteins that elicits a strong TD antibody response is pneumococcal surface protein A (PspA). Both of these antigens are important targets for vaccine development since robust antibody responses to these antigens are immunoprotective. In addition, these antigens serve as virulence factors for the bacteria. PC enables the bacterium to transport across endothelial and epithelial membranes (Cundell et al., 1995; Tuomanen et al., 1995). PspA inhibits the function of complement (Tu et al., 1999). 
This section is divided into five parts concentrating on literature relevant to regulation of the TI-2 antibody response. The first section will provide background information on the spleen, specific sites in the spleen involved in the response, and kinetics of the response. The second section will define the B cell subpopulations responsible for producing TI-2 antibodies. The third and fourth sections will describe mechanisms for enhancing or suppressing the TI- 2 antibody response by the innate immune system and $\mathrm{T}$ cells. The final section will briefly compare and contrast the PspA and PC response for the purpose of identifying possible mechanisms for later discussion.

\section{Site of humoral immune response}

The central location for PC-specific antibody production is the spleen. The necessity of the spleen is made apparent in individuals with asplenia. Splenectomized patients are afflicted with chronic respiratory infections primarily caused by $S$.

pneumoniae (Davidson and Wall, 2001). In addition, splenectomized individuals do not respond well to capsular polysaccharide vaccines (Davidson and Wall, 2001).

The marginal zone (MZ) in the spleen is the site primarily responsible for the TI-2 antibody responses (Guinamard et al., 2000). The MZ of the spleen is defined as the compartment consisting of a broad band of cells surrounding the periarteriolar lymphoid sheath (PALS) containing T cells and the B cell follicles (Vos et al., 2000). It has long been known that children under 2 years of age have poor responses to polysaccharide vaccines, which coincides with the maturation of MZ B cells (Timens et al., 1989). In addition, TI-2 antigens rapidly localize to the MZ within 15 minutes after an ip injection (Harms et al., 1996; van den Eertwegh et al., 1992). Studies in Pyk-2 deficient mice, animals lacking a tyrosine kinase involved in growth factor receptor and chemokine 
stimulation, showed that these mice do not develop MZ B cells (Guinamard et al., 2000). However, the B cell populations in the bone marrow, the B1 cells in the peritoneum, and the serum Ig levels were all identical to wild type mice (Guinamard et al., 2000). Subsequent immunization with TNP-Ficoll demonstrated that $\mathrm{Pyk}^{-1-}$ mice had dramatically reduced TNP-specific IgG2a ( $30 \%$ of control), IgG3 ( $2 \%$ of control), and $\operatorname{IgM}$ (30\% of control) serum titers (Guinamard et al., 2000). These observations strongly support the hypothesis that MZ B cells are responsible for producing the TI-2 specific antibodies.

As mentioned previously, TI-2 antigens are rapidly localized to the marginal zone. TI-2 antigen ligation of the $\mathrm{B}$ cell receptor (BCR) triggers $\mathrm{B}$ cell migration to the outer T cell borders in the spleen within the first 24 hours (Garcia et al., 1999b). By 48 hours, the number of TI-2 antigen specific B cells increases in the T cell zones, in the red pulp, and along the red pulp: T zone junction (Vinuesa et al., 2001). At 2-5 days, the antigen-specific B cells exponentially divide and differentiate into plasma cells primarily in extrafollicular foci in the red pulp of the spleen (Vinuesa et al., 2001). B cell proliferation is the most rapid between days 3 and 5 (Vinuesa et al., 2001). After day 7, the number of plasma cells decreases during the second week of the response. After day 14, the number of plasma cells remains static for at least 90 days (Garcia et al., 1999b).

\section{Responding B cell population}

TI-2 responses are distinguished by early isotype class switching that occur more rapidly than T-dependent responses to protein antigens (Wu et al., 1999). Isotype switching is observed as early as 3-4 days following immunization with polysaccharides (Leemans et al., 1999). Six days following heat-killed S. pneumoniae (HKSP) 
immunization, the $\operatorname{IgG}$ isotypes reach maximal levels (Wu et al., 2002). The predominant isotypes produced to PC following HKSP vaccination are $\operatorname{IgG} 3$ and $\operatorname{IgG} 2 \mathrm{~b}$ and to a lesser extent IgG1 and IgG2a (Wu et al., 1999).

The composition of responding B cells to a TI-2 response are predominantly high affinity B cells. Two days following antigen presentation, there are a 3-fold greater number of high affinity B cells entering cell cycle compared to low affinity B cells (Shih et al., 2002). The three major idiotypes specific for PC that dominate the early humoral response are T15, M167 or M511, and M603 (Perlmutter et al., 1984). T15 antibodies have the highest affinity of the three idiotypes. T15 is also the idiotype expressed by the majority of PC-specific antibody secreting cells (ASC) (Feeney et al., 1989; Martin et al., 2001). These idiotypes have also been shown to undergo very little somatic hypermutation and do not enter germinal centers (Feeney and Thuerauf, 1989; Wiens $e t$ al., 2003). T15 plasmablasts found in both the spleen and peritoneal cavity largely express the B1 B cell phenotype 3 days post immunization (Martin et al., 2001). The composition of MZ plasmablasts and B1 blasts is dependent on the route and dose of antigen administration (Martin et al., 2001). A high dose of HKSP (Sharer et al., 2003) given iv generates a larger T15 antibody response than a high dose given ip (Martin et al., 2001). Low doses (Van Ravenzwaay et al., 2003) given iv produce a reduced antibody response that is comparable to the high ip response. However, low ip doses initiate strong peritoneal B1 responses, which prevent sufficient amounts of antigen to reach the spleen thereby preventing a local splenic response (Martin et al., 2001). It is currently unknown what the peritoneal B1 cells, splenic B1 cells, and MZ B cells contribute to the PC-specific serum titers. 
Numerous studies reporting the importance of both MZ B cells and B1 cells in the TI-2 response have failed to reconcile the conflicting data demonstrating the contributions of these two B cell populations in TI-2 antibody responses. A recent report performed in transgenic mice (PV1TgL) containing B cells that are specific only for a synthetic TI-2 like Ag (PVP-360) suggests that B-1a cells are derived from MZ B cells (Whitmore et al., 2004). Naïve PV1TgL mice do not express B-1 B cells but contain splenic MZ B cells. Three days and 5 days after immunization, antigen-specific B-1a cells begin to appear in the spleen and peritoneal cavity, respectively (Whitmore et al., 2004). By days 5 and 8, the B-1a populations are the predominant B cell populations in the spleen and peritoneum, respectively. These data suggest that the MZ B cells may be the precursor population for B1a cells (Whitmore et al., 2004). Altogether, these studies demonstrated that $\mathrm{PC}$ responses require both $\mathrm{MZ} \mathrm{B}$ cells and $\mathrm{B} 1 \mathrm{~B}$ cells for TI-2 antibody production.

\section{Role of Innate Immunity}

The MZ B cells are characterized by their high expression of the CD21/CD35 molecules on their surface. The CD21/CD35/CD19 coreceptor complex is critical for recognizing and binding complement components on the B cell. CD35, complement receptor 1 (CR1), binds the $\mathrm{C} 3 \mathrm{~b}$ and the $\mathrm{C} 4 \mathrm{~b}$ degradation components of the complement cascade (Vos et al., 2000). CD21 (CR2) binds the complement component C3d. CD19 is a coactivator that is directly associated with CD21 and likely mediates the intracellular signaling of CD21 (Fearon et al., 2000). The high expression of these complement binding receptors suggests that complement activation has an important role in TI-2 responses. 
Components of the complement cascade are hypothesized to be one of the earliest signals necessary for TI-2 recognition. One of the roles of complement receptors in TI-2 responses is to lower the activation requirements necessary for antibody production. CD21/CD35 knockout mice vaccinated with $10^{5}$ CFU HKSP and challenged with 5000 CFU of live S. pneumoniae had a survival rate of $33 \%$ compared to $100 \%$ survival rate for wild type animals (Haas et al., 2002). However, increasing the immunization dose to $10^{7} \mathrm{CFU}$ HKSP for $\mathrm{CD} 21 / \mathrm{CD} 35^{-/-}$mice allowed all the mice to survive the live challenge (Haas et al., 2002). This study suggests that stimulation of the complement receptors lowers the threshold for B cell activation. Other reports have shown that both CD19 and CD21 lower the threshold for antigen stimulation in vitro. Mongini et al. demonstrated that $\mathrm{CD} 21$ and $\mathrm{IgM}$ receptor stimulation reduced the minimum concentration of antigen bound to $\mathrm{mIgM}$ required for entry into S phase by 100-fold (Mongini et al., 1997). Deletion of CD19 in mice reduced the number of high-affinity plasma cells in response to an NP-Ficoll vaccination by approximately 40\% (Shih et al., 2002). However, activation of low-affinity plasma cells was completely abrogated in $\mathrm{CD} 19^{-/-}$mice (Shih et al., 2002). These results indicate that the role of complement receptors in the TI-2 response is to lower the amount of antigen required for B cell activation.

Localization of antigen to the MZ is dependent on functional CR. Mice deficient in either the complement component $\mathrm{C} 3$ or the complement receptors $\mathrm{CR} 1 / 2$ are unable to localize TNP-Ficoll to the MZ (Guinamard et al., 2000; Shih et al., 2002). As expected, $\mathrm{C} 3^{-1-}$ mice and mice depleted of complement via cobra venom factor subsequently have reduced IgG and IgM serum titers to TI-2 antigens (Guinamard et al., 
2000; Harms et al., 1996). These data demonstrate that complement dependent localization of TI-2 antigens is crucial for normal antibody production.

The deposition of TI- 2 antigens on the spleen occurs in specific sites and cell types. For example, complement bound antigens accumulate on follicular dendritic cells (FDC). FDC have high expression of both CD21 and CD35 (Peset Llopis et al., 1996). Complement component $\mathrm{C} 3 \mathrm{~d}$ binds to $\mathrm{Ab} / \mathrm{Ag}$ complexes, which form immune complexes (IC) that are recognized by CD21 (Fearon and Carroll, 2000). The IC are then transported to FDC and presented on its surface. Once presented, the IC are easily recognized by MZ B cells thereby aiding their activation (Fearon and Carroll, 2000). Because FDC present complement components efficiently, they are able to amplify an antibody response. A series of studies demonstrated that FDC enhance the Ab response 10-1000 fold in a CR2 dependent manner to ovalbumin (Qin et al., 1998).

It is currently hypothesized that FDC have a role in the early isotype switching during the $\mathrm{Ab}$ response to TI-2 antigens. This hypothesis is supported by several findings. It has been observed that MZ B cells migrate to FDC within 24 hours following iv injection of $\mathrm{Ag}$ (Whipple et al., 2004). Another study demonstrated that TI-2 antigens do not require the presence of specific Ig to produce C3d binding and this allows for a rapid uptake and presentation of TI-2 antigens by FDC thereby enabling rapid recruitment and activation of B cells (Peset Llopis et al., 1996). When serum containing nonspecific antibody for pneumococcal polysaccharides (PPS) and complement were added to the spleens of vaccinated or naïve mice, no difference in PPS or C3d FDC localization was observed between the two groups (Peset Llopis et al., 1996). However, inactivation of complement in the serum reduces PPS and C3d localization to FDC (Peset 
et al., 1996). These studies suggest that a reduced requirement for specific Ig to initiate C3d binding enables a rapid uptake and presentation by FDC in the case of TI- 2 antigens, thereby enabling rapid recruitment and activation of B cells (Peset Llopis et al., 1996).

Other antigen presenting cells (APC) involved in early TI-2 antigens presentation and localization include MZ macrophages. MZ macrophages have been observed to rapidly take up TI-2 antigens shortly after injection (van den Eertwegh et al., 1992). Phagocytosis of TI-2 antigens by MZ macrophages occurs independent of complement (van den Eertwegh et al., 1992). Splenic deposition of TI-2 antigens is also dependent on the presence of MZ macrophages. Removal of MZ macrophages reduces the localization of TI- 2 antigens to both the red pulp of the spleen and the MZ, while increasing deposition of antigens in the follicles (van den Eertwegh et al., 1992). The increased localization of TI-2 antigens in the follicles corresponded with an increased humoral response to the antigen (van den Eertwegh et al., 1992). This demonstrates that MZ macrophages have an important role in regulation of the TI-2 response, which is largely suppressive.

In addition to complement, other innate immune factors that regulate early isotype switching to TI-2 antigens include pro-inflammatory and anti-inflammatory cytokines as well as toll-like receptors (TLR). Neutralizing the pro-inflammatory cytokine TNF- $\alpha$ via an injection with monoclonal antibody 1 day post-HKSP vaccination suppressed the $\operatorname{IgG}$ anti-PC response 2-3 fold (Khan et al., 2002). Other pro-inflammatory cytokines such as IL-6 and IFN- $\gamma$ have been shown to moderately influence early PC isotype switching. Mice deficient in IL-6 and IFN- $\gamma$ have significantly reduced IgG2a and IgG2b serum titers, respectively (Khan et al., 2002). The anti-inflammatory cytokines have the 
opposite effect on control of isotype switching. Mice deficient in IL-4 and IL-10

production have elevated IgG2a serum titers (2-fold) and increased IgG1 and IgG3 titers, respectively (Khan et al., 2002). The peak splenic mRNA production for both the proinflammatory and anti-inflammatory cytokines occurs between 2-6 hours postvaccination and returns to baseline within 24 hours. This indicates that these cytokines influence the beginning of the TI- 2 response.

Other innate signaling molecules such as, toll-like receptors (TLR), also play a role in antibody responses to polysaccharides. TLR $2^{-/}$mice have significantly reduced PC titers 7 days following vaccination with either purified polysaccharides or HKSP (Khan et al., 2005; Sen et al., 2005). Survival to a lethal challenge of S. pneumoniae is also mildly compromised in naive TLR2 ${ }^{-/}$mice (Khan et al., 2005). However, vaccinated TLR2 $2^{-/}$mice survive a lethal challenge similarly to normal mice (Khan et al., 2005). In addition, TLR stimulation enhances a polysaccharide response. Mice treated once with the TLR9 ligand unmethylated CpG-containing oligodeoxynucleotide (CpGODN) and alum and vaccinated twice with purified polysaccharide have enhanced primary and secondary antibody titers (Sen et al., 2006). CpG and alum treatment produced the greatest enhancement on day 21 (Sen et al., 2006). This data suggests that TLR are important for stimulating the TI-2 antibody response.

\section{Role of T cells}

The precise role of T cells in regulating the TI-2 humoral response is poorly understood. T cells are required for normal TI-2 responses. However, $\mathrm{T}$ cell deficient mice are able to produce antibody responses to polysaccharides, albeit, very poorly (Briles et al., 1982b). Mice deficient in $\alpha \beta$ T cells have a 6-10 fold reduction in IgG3, 
$\operatorname{IgG} 2 b$, IgG1, but not IgM PC specific serum antibody, indicating their importance for isotype switching (Wu et al., 1999). Removal of $\gamma \delta \mathrm{T}$ cells, however, does not significantly affect PC serum titers (Wu et al., 1999). The relative importance of CD4 ${ }^{+}$ and $\mathrm{CD}^{+} \mathrm{T}$ cells has produced conflicting results. $\mathrm{CD}^{+} \mathrm{T}$ cells are more effective at stimulating the anti-PC serum response than $\mathrm{CD} 8^{+} \mathrm{T}$ cells following HKSP vaccination (Wu et al., 2002). Injection of $2 \times 10^{6} \mathrm{CD}^{+} \mathrm{T}$ cells into athymic mice increased the $\mathrm{IgG}$ PC-specific serum response approximately 100-fold compared to a 5-fold increase in animals given $\mathrm{CD}^{+} \mathrm{T}$ cells (Wu et al., 2002). However, more recent findings suggest that $\mathrm{CD}^{+} \mathrm{T}$ cells have a greater impact on TI-2 antibody responses than $\mathrm{CD} 4^{+} \mathrm{T}$ cells (Kobrynski et al., 2005). CD8 ${ }^{-/-}$mice vaccinated with 23-valent pneumococcal polysaccharide vaccine Pneumovax failed to produce detectable polysaccharide antibody in the serum. In contrast, $\mathrm{CD}^{-/-}$mice did not have significantly different titers compared to wt mice in response to the Pneumovax vaccination (Kobrynski et al., 2005). A possible explanation for the discrepancy between these studies is that $\mathrm{CD} 8^{+}$cells are involved in responses to soluble polysaccharides and $\mathrm{CD} 4^{+}$cells are critical for whole bacterial responses (Kobrynski et al., 2005).

It has long been known that polysaccharide antigens cannot be presented on a MHC molecule. However, it is apparent that $\mathrm{T}$ cells contribute to PC antibody responses. Recent data suggests that $\mathrm{T}$ cells are activated in a noncognate fashion, which does not involve T cell receptor (TCR) antigen recognition in the context of MHC. Transgenic mice with $\mathrm{T}$ cells expressing only a TCR that is incapable of responding to a protein Ag did not affect PC-specific serum titers following HKSP vaccination (Wu et al., 2002). In addition, transgenic mice deficient in MHCII peptide loading have normal serum PC 
titers (Wu et al., 2002). These results indicate that specific recognition of antigen by the TCR is not required for normal TI-2 antibody responses.

Several studies have demonstrated that other $\mathrm{T}$ cell coactivating molecules are important for noncognate $\mathrm{T}$ cell polysaccharide responses. These coactivators have also been shown to be important for isotype switching. For example, studies have shown that B7:CD28 interactions are required for normal TI-2 responses. Blockade of B7 interactions with CD28 via in vivo administration of CTLA-4 Ig prior to HKSP vaccination suppresses PC-specific IgG sera titers but does not affect PC-specific IgM titers (Wu et al., 2002; Wu et al., 1999).

CD28 stimulation on T cells also upregulates the expression of CD137 (4-1BB) on T cells (Wu et al., 2003). Ligands for CD137 are found on APC such as dendritic cells and B cells. Several experiments have demonstrated the importance of CD137 in the TI-2 response. Mice deficient in CD137 expression have significantly reduced IgM and IgG anti-PC responses following HKSP vaccination (Wu et al., 2003). In addition, in vivo administration of anti-CD137 mAb to HKSP vaccinated mice increases proliferation in splenic $\mathrm{CD}^{+} \mathrm{T}$ cells in a B7 dependent manner 14 days post-immunization (Wu et al., 2003). Anti-CD137 administration also was found to increase B cell and $\mathrm{CD}^{+} \mathrm{T}$ cell proliferation (Wu et al., 2003). These data demonstrate that CD28 and CD137 cooperatively regulate splenic proliferation and isotype switching following HKSP vaccination.

A third coactivating molecule on the $\mathrm{T}$ cell that is also necessary for PC Ig production is $\mathrm{CD} 40 \mathrm{~L}$. CD40L-KO mice have a marked reduction in anti-PC IgM and a complete abrogation of anti-PC IgG responses following HKSP vaccination (Wu et al., 
1999). Antibodies specific for CD40 also act as an adjuvant for T-independent antibody responses. Anti-CD40 treatment increases the number of NP-specific ASC 25-fold following NP-Ficoll immunization (Garcia et al., 1999a). The increase in NP-specific ASC does not occur until 6 days post-immunization (Garcia et al., 1999a). The growth of plasmablasts is also sustained in the red pulp as demonstrated by immunohistochemistry (Garcia et al., 1999a). These data suggests that CD40 ligation increases the TI-2 response by extending proliferation rather than increasing the number of B cells recruited to the response.

Finally, CD1, the MHC class I-like molecule, presents several types of glycolipids and nonpeptide Ags (Kobrynski et al., 2005). Mice that do not express CD1 have undetectable polysaccharide serum titers following Pneumovax vaccination (Kobrynski et al., 2005). CD1 expressing APC are hypothesized to present polysaccharide antigens to $\mathrm{CD} 8^{+} \mathrm{T}$ cells, thereby contributing to their activation. $\beta_{2} \mathrm{~m}^{-/-}$mice, which lack functional CD1, MHC class I, and FcRn, have suppressed polysaccharide antibody responses following Pneumovax vaccination (Kobrynski et al., 2005). However, reconstitution of $\beta_{2} \mathrm{~m}^{-/-}$mice with normal CD $8^{+}, \mathrm{B}$ cells, and macrophage/monocytes restored the polysaccharide antibody response to those of normal mice (Kobrynski et al., 2005). Altogether, these data demonstrate the panoply of coactivators that affect PC responses.

\section{PspA response}

This section will briefly compare and contrast the major differences between the development of the antibody response to the TD protein antigen, PspA, with the PC antibody response. The differences between the PspA response and PC response are due primarily to the TD and TI-2 nature of the responses. T-dependent responses involve 
cognate $\mathrm{T}$ cell responses, affinity maturation of B cells in germinal centers, and high antibody output during the second week of the antibody response. Both TD and TI-2 responses require $\mathrm{CD} 21$ receptors, early cytokine production, and $\mathrm{T}$ cell-associated coreceptors.

TD antigens, such as PspA, are processed and presented by several types of APC such as dendritic cells, macrophages, and B cells. The antigen bound to APC then migrates to the PALS region of the spleen and present the antigen to T cells. B cells migrate through the high endothelial venules (HEV) into the T cell zone. B cells expressing a specific mIg for the immunizing antigen are upheld. Next, a primary focus of activated B cells and T cells localize at the T:B cell border as early as 2 days postimmunization (Jacob et al., 1991). B cells rapidly proliferate in the primary foci, which peaks by day 8 (Jacob et al., 1991). Between 4 and 12 days, some of these B cells in the primary foci will continue to differentiate into plasma cells and migrate to the red pulp where they will produce antibody of low affinity during the primary phase of the TD response (Liu et al., 1991).

The production of high affinity antibodies during TD responses depends on the formation of germinal centers. Germinal centers are characterized by three cellular components: FDC, B cells, and T cells (Han et al., 1995). Formation of germinal centers is observed by day 8 and persists until day 16 in the spleen (Jacob et al., 1991). Germinal center formation requires several costimulating molecules including those that are also required for $\mathrm{PC}$ responses.

CD21/CD35, CD40L, and B7 costimulation are all required for establishment and maintenance of germinal centers. B cells that do not express CD21 and CD35 fail to 
survive selection in germinal centers (Fischer et al., 1998). Deletion of both CD21 and CD35 on B cells also markedly reduces serum antibody titers to TD antigens (Croix et al., 1996). Administration of anti-CD40L antibody at the time of vaccination with a TD antigen severely reduces both germinal center formation and the sera antibody titers (Han et al., 1995). CD40L is also necessary for maintaining germinal centers as demonstrated when anti-CD40L is administered late in the response after germinal centers have already formed (Han et al., 1995). In addition to CD40L, B7-2 is necessary for normal germinal center formation. Administration of anti-B7-2 antibody at the time of vaccination decreases the number of germinal centers formed and serum titers by $50 \%$ (Han et al., 1995).

PspA-specific antibodies are measurable in the serum by day 6 and maximal by day 10 (Wu et al., 2000). The predominant isotypes produced are IgG2b, IgG1, and IgG2a (Wu et al., 1999). $\mathrm{CD}^{+} \mathrm{T}$ cell help is required for at least the first 6 days during the PspA response (Wu et al., 2000). However, $\mathrm{PC}$ responses only require $\mathrm{CD}^{+}{ }^{+} \mathrm{T}$ cell help for the first 2 days (Khan et al., 2004).

As mentioned previously, costimulatory molecules present on $\mathrm{T}$ cells are required for normal antibody responses and isotype switching for TD and TI-2 responses. B7-2 but not B7-1 stimulation is necessary for normal PspA responses (Wu et al., 2000). In addition, mice deficient in CD40L have nearly undetectable anti-PspA IgG responses (Wortham et al., 1998). As opposed to the PC response, deletion of CD137 does not affect the PspA response (Wu et al., 2003).

Studies suggest that early cytokine production has a greater impact on the PspA response compared to the PC response. TNF- $\alpha$ is required during the first 48 hours 
following vaccination for the PspA response (Khan et al., 2002). Other proinflammatory cytokines such as IFN- $\gamma$ and IL-6 are also required for IgG PspA switching (Khan et al., 2002). Lack of anti-inflammatory cytokines IL-4 and IL-10 were both found to increase IgG anti-PspA titers (Khan et al., 2002). The effect of IL-10 deletion produced a similar effect of general IgG increase to both PC and PspA antigens, however the increase was not consistently significant (Khan et al., 2002).

\section{ENDOCRINE REGULATION OF THE IMMUNE SYTEM}

Endocrine regulation of the immune system is a well-established phenomenon. The predominant classes of sex steroids produced by the gonads that regulate the immune response are estrogens, androgens, and progestins. The humoral immune response, in particular, is strongly influenced by sex hormones. This is evidenced by a number of observations. Autoantibody-mediated diseases afflict females at a much higher rate than males. For example, systemic lupus erythematosus (SLE) and Sjögrens' syndrome afflict women 9 times more frequently than men (Ansar et al., 1985). In addition, female mice have higher IgM and IgG serum titers than males (Eidinger et al., 1972).

This section will provide background information on previous hormone studies that identified immunomodulating effects leading to altered antibody responses. The three major classes of sex hormones are discussed. The effect of estrogen on the humoral response is given the greatest emphasis. The estrogen section will also present data demonstrating similar immunomodulating effects on the antibody response, thymus, and BM that is observed in both $17 \beta$-estradiol (E2) and propanil-treated animals.

\section{ESTROGEN}




\section{Autoimmune vs. nonautoimmune animals}

The sex hormone E2 is one of the first steroid hormones to be identified as an immunomodulator. Early studies were performed in the autoimmune mouse strain, NZB/W. This strain will spontaneously develop lupus-like symptoms that eventually are lethal.

Initial studies found that when male NZB/W mice were castrated and treated with E2, the mortality rate was greatly increased and resembled the mortality rate of female NZB/W mice (Roubinian et al., 1978). Subsequent studies found that E2 increased the antibody responses in autoimmune mice (Brick et al., 1985). Castrated male NZB/W mice treated with E2 for 10 weeks increased the number of IgM PFC to the TI-2 antigen TNP-Ficoll 3-4-fold (Brick et al., 1985). E2 also increased the number of IgG and IgM PFC 3-fold to the TI-1 antigen, TNP-LPS. The IgG and IgM PFC responses to the TD antigen SRBC was increased 2-fold following E2 treatment (Brick et al., 1985). In contrast, nonautoimmune DBA/2 mice did not have significantly changed PFC to TNPFicoll, TNP-LPS, or SRBC following identical E2 treatment (Brick et al., 1985). These early studies suggested that E2 stimulates the antibody response only in autoimmune mice.

Subsequent studies established that E2 exposure increases the antibody responses in nonautoimmune rats and mice, as well. Male Sprague Dawley rats treated with E2 3 days prior to SRBC immunization had a 4-fold increase in antibody titers 6 days postimmunization (Myers and Petersen, 1985). E2 treatment 3 days prior to the secondary immunization also yielded a similar increase in antibody titers (Myers and Petersen, 1985). However, in contrast to earlier findings demonstrating that $\mathrm{E} 2$ increases in the 
number of PFC, the number of PFC was not affected in the nonautoimmune mice suggesting that E2 treatment increased antibody synthesis in the plasma cells (Myers and Petersen, 1985).

A more prolonged exposure to E2 induced a greater enhancement of the humoral response. Castrated C57BL/6 mice were chronically exposed to E2 via pellet implantation for 4-6 months. The total number of IgG and IgM ASC in the spleen were increased 6-fold and 3-fold, respectively (Verthelyi and Ahmed, 1998). The chronic E2 exposure is characterized by a decrease in both the percent and number of B cells in the spleen, which suggests that more splenic B cells become activated (Verthelyi and Ahmed, 1998). The total number of IgG bone marrow ASC was also increased 12-fold in E2 exposed mice (Verthelyi and Ahmed, 1998). In addition to increasing the number of ASC in the spleen and BM, the amount of immunoglobulin produced by each plasma cell is also increased (Verthelyi and Ahmed, 1998). Morphometric analysis of the spots obtained from ELISPOT assays demonstrated that the density and area of the splenic and BM ASC were significantly increased in chronically E2 treated mice (Verthelyi and Ahmed, 1998). Finally, vaccination of the E2 exposed mice with a variety of autoantigens such as dsDNA and actin or killed whole bacteria such as Actinobacillus pleurpneumoniae or Brucella abortus yielded increased antibody serum titers to all tested antigens (Verthelyi, and Ahmed, 1998).

Altogether, these data established that E2 increases the antibody response in both nonautoimmune and autoimmune animals. The antibody response is increased both by increasing the number of plasma cells and increasing the immunoglobulin synthesis by each plasma cell. The data also suggest that the increased response is the result of 
polyclonal activation. However, the initial evidence presented conflicting data on the duration of an E2 exposure required for an increased antibody response.

A conclusive time course of E2 exposure necessary to enhance the humoral response is currently unknown. For example, peripheral blood mononuclear cells (PBMC) from rhesus macaque females treated for 18 hours with E2 increases the percent of IgG and IgA ASC (Lu et al., 2002). In contrast to the macaque studies, the lupus prone BWF1 mice require 2 months of chronic E2 pellet exposure until IgG and IgM anti-DNA serum titers are increased (Yurino et al., 2004). Variation in animal models and lack of antibody kinetic studies precludes a conclusion of the duration of E2 exposure required for an enhanced response.

\section{E2 sensitive B cell subpopulations}

It is hypothesized that the amplification of the ASC by E2 disproportionately affects certain B cell subpopulations. The B cell subpopulations, B1 B cells and MZ B cells, have both been shown to be targets for E2 induced proliferation and activation. B1 B cells from BWF1 mice cultured with E2 for 4 days had an approximate 2-fold increase in IgM production (Yurino et al., 2004). However, the classically defined B cell population, B2 B cells, cultured under identical conditions did not produce significantly different concentrations of IgM (Yurino et al., 2004). Another study found that B1 B cells from C57BL/6 mice exposed to E2 for 2-3 months and pretreated with bromelain had increased numbers of splenic bromelain-specific PFC. However, the number of B2 B cell PFC in the spleen was not affected (Ansar et al., 1989).

The MZ B cell population is also sensitive to the effects of E2. R4A-IgG2b

$\mathrm{BALB} / \mathrm{c}$ mice are a nonautoimmune strain of mouse that produce an easily detectable 
autoimmune B cell that is normally removed during the course of maturation (Grimaldi et al., 2006). When these mice are treated with E2 chronically, they develop a lupus-like phenotype (Grimaldi et al., 2001). Phenotypic analysis of the splenic anti-DNA ASC demonstrates that MZ B cells are increased 4-fold compared to control animals (Grimaldi et al., 2001). In contrast, follicular B cells are not significantly increased (Grimaldi and Diamond et al., 2001). Altogether, these studies suggest that the E2-induced increase in ASC is not the result of polyclonal activation, since particular subsets are affected. These data also suggests that the subpopulations of B cells affected by E2 exposure are also involved in the production of TI-2 antibodies.

\section{Mechanisms for E2-induced antibody enhancement}

The expression of ER $\alpha$ has been suggested to be the receptor regulating the increased antibody response. The ER $\alpha$ and ER $\beta$ are expressed on lymphocytes including B cells, suggesting a mechanism for a direct effect of E2 on B cells (Grimaldi et al., 2002). Analysis of ER mRNA expression in peritoneal B1 and splenic B2 B cells from 8-12 month old BWF1 mice treated chronically with E2 demonstrated that ER $\alpha$ is significantly increased in B1 B cells compared to control animals (Yurino et al., 2004). However, ER $\alpha$ expression in B2 B cells is unaffected (Yurino et al., 2004). ER $\alpha$ has been shown to regulate the increased humoral immune response following chronic E2 exposure. Nonautoimmune C57BL/6J/129 castrated male mice treated with E2 5 days/week for 2.5 weeks have significantly increased numbers of $\operatorname{IgA}, \operatorname{IgG}$, and $\operatorname{IgM}$ ASC in both the spleen and BM (Erlandsson et al., 2003). Deletion of ER $\alpha$ in mice abrogates the increased ASC in the spleen or BM (Erlandsson et al., 2003). However, ER $\beta$-/- mice had similar ASC responses as control mice (Erlandsson et al., 2003). 
Altogether, these data suggest that the E2-induced B cell activation is mediated through $\mathrm{ER} \alpha$.

E2 exposure elicits a number of changes in the genetic expression profile of B cells that decreases tolerance. BALB/c mice treated with E2 for 3-6 weeks have increased expression of the proteins VCAM-1 (40\%), CD22 (40\%), SHP-1 (20\%), and Bcl-2 (20\%) (Grimaldi et al., 2002). VCAM-1 functions as a ligand for VLA-4 and is hypothesized to protect B cells from apoptosis during early B cell development. CD22 and SHP-1 regulate the antigen threshold required for B cell activation. Bcl-2 increases survival of autoreactive B cells. The percent increase in these proteins induced by E2 is sufficient to alter B cell survival (Grimaldi et al., 2002).

It is hypothesized that increased expression of these proteins decreases the amount of stimulation required for activation and protects against apoptosis during B cell development. For example, Bcl-2 expression is also increased in the bone marrow of pro/pre B cells and immature B cells (Grimaldi et al., 2002). Supporting experiments show that E2 exposure decreases the percentages of BM B220 $0^{+}$cells, but transitional splenic type 2 B cells, which differentiate into mature splenic B cells, are increased (Grimaldi et al., 2001). In addition, transitional splenocytes from E2-treated mice demonstrated that these cells were resistant to apoptosis (Grimaldi et al., 2002). These data suggest that certain B cells during development in both the BM and spleen have antiapoptotic expression patterns that results in increased survival.

Other studies evaluating the effect of E2 on B cell maturation revealed that autoreactive B cells are eliminated from circulation, albeit less effectively than in normal mice (Grimaldi et al., 2006). R4A-IgG2b BALB/c mice treated with E2 for 5-6 weeks 
have a 4-fold increase in mature autoreactive B cells compared with control animals (Grimaldi et al., 2006). Autoreactive B cells survive in greater numbers throughout maturation in the BM and the spleen (Grimaldi et al., 2006). High affinity autoreactive B cells survived in slightly greater numbers than low affinity autoreactive B cells in E2 treated mice to enter into the splenic transitional pool from the BM, suggesting that some autoreactive B cells are eliminated in the BM similarly to normal animals (Grimaldi et al., 2006). However, E2 dramatically increased the number of high affinity autoreactive B cells that survived the splenic transitional stages to enter the mature B cell population (Grimaldi et al., 2006). Normal mice had a 3-fold reduction in high affinity autoreactive B cells during the transitional to mature stages, but the number of high affinity autoreactive B cells in E2 treated mice was not reduced (Grimaldi et al., 2006). Interestingly, E2 treatment did not affect the deletion of low affinity autoreactive B cells during the differentiation of transitional B cells into mature B cells (Grimaldi et al., 2006). These data indicate that E2 increases the number of autoreactive B cells by impairing the removal of high affinity autoreactive B cells during the immature and transitional phases of maturation.

\section{Effects of E2 on B cell maturation in the BM}

The effects of E2 on lymphopoiesis further upstream in the B cell maturation stages in the BM indicate a suppressive effect. The number of $\mathrm{B} 220^{+}$cells in the $\mathrm{BM}$ is decreased 5-fold following 2.5 weeks of treatment in C57BL/6J/129 castrated mice (Erlandsson et al., 2003). Furthermore, the E2 decreases the number of pro-B cells, preB cells, and immature $\operatorname{IgM}^{+}$B cells 70-80\% compared to control animals (Erlandsson et al., 2003). Selected deletion of the ER $\alpha$ and ER $\beta$ in mice demonstrated that both 
receptors are required for the E2-mediated decrease in the pro-B and IgM+ B cell populations (Erlandsson et al., 2003). ER $\alpha$ alone regulates the E2-mediated deletion of pre-B cells (Erlandsson et al., 2003).

\section{Effects of E2 on the thymus}

E2 also affects T cell development by inducing thymic atrophy and T cell apoptosis. E2 decreases the thymocyte population approximately $80 \%$ of controls (Screpanti et al., 1989). The decrease is primarily in the $\mathrm{CD} 4^{+} \mathrm{CD} 8^{+}$population (Screpanti et al., 1989). The mechanism regulating E2-mediated thymic atrophy is Fas/FasL dependent (Do et al., 2002). In contrast with antibody responses and lymphopoeisis, E2-mediated thymic atrophy requires both ERs for the maximal effect (Erlandsson et al., 2001). The increase in thymic atrophy is correlated with changes in the populations of $\mathrm{T}$ cells in the spleen of developing mice, however, no studies have been performed to determine if these changes affect adaptive immune responses (Erlandsson et al., 2001). Altogether, these data emphasize the diverse immunomodulating affects of estrogen.

\section{PROGESTERONE}

The other major immumodulatory female sex hormone is progesterone. Analysis of the effects of progesterone on immune function and antibody production suggest an inhibitory or an opposing effect to estradiol. In vitro progesterone treatment on PBMC from rhesus macaques inhibits the number of IgG and IgA ASC approximately $90 \%$ from controls (Lu et al., 2002). Progesterone has also been found to induce TH2 cytokine production. In vitro culture with progesterone of human cloned T cells from multiple sclerosis patients induced all of the clones to produce IL-4 and suppressed inflammatory 
cytokine production (Correale et al., 1998). The progesterone regulated protein, progesterone induced blocking factor (PIBF), regulates some of the immunomodulatory effects of progesterone. In vitro treatment with PIBF on ConA stimulated murine splenic $\mathrm{CD}^{+}$and $\mathrm{CD} 8{ }^{+} \mathrm{T}$ cells induced both cell populations to produce the TH2 cytokines IL-4, IL-10, and IL-3 (Szekeres-Bartho and Wegmann, 1996). However, the expression of the TH1 cytokine, IFN- $\gamma$, was not affected (Szekeres-Bartho and Wegmann, 1996). Progesterone may downregulate the antibody response by also affecting apoptosis and bcl-2 expression. Progesterone decreases the expression of bcl-2 in estrogen treated Jurkat $\mathrm{T}$ cells and increases apoptosis (McMurray et al., 2001). It is currently unknown if lymphocytes express progesterone receptors (Bouman et al., 2005). These data suggest that progesterone antagonizes the effects of estrogen.

Progesterone is hypothesized to have the greatest affect on mucosal immune responses. Subcutaneous progesterone exposure increased the number of antigen specific ASC in the vagina and the uterus following intranasal or vaginal immunization with cholera toxin B (Johansson et al., 1998). An opposing study demonstrated that progesterone exposure decreases resistance to a viral challenge (Gallichan and Rosenthal, 1996). Mice treated with progesterone prior to i.n. immunization with glycoprotein B from herpes simplex virus increased the ratio of IgG to IgA vaginal titers (Gallichan and Rosenthal, 1996). In addition, progesterone administration or elevated levels of progesterone associated with the diestrus stage of the estrus cycle increase viral load following vaginal HSV challenge (Gallichan and Rosenthal, 1996). Altogether, these data present a contrasting set of data concerning the effect of progesterone on mucosal challenges that differs according to antigen exposure. 


\section{ANDROGENS}

Androgens represent the third major sex hormone produced by the gonads. Numerous studies have demonstrated that testosterone suppresses the humoral response. The androgen receptor is expressed on B cells (Benten et al., 2002). NZB/W female mice chronically treated with testosterone had a 3-5 fold increase in survival time compared to controls (Roubinian et al., 1979). In addition, female OVX NZB/W mice treated with testosterone had a 2-fold reduction in the number of IgM PFC following TNP-Ficoll immunization (Brick et al., 1985). The numbers of IgG and IgM PFC were also reduced in the testosterone treated females 2-3 fold following TNP-LPS immunization (Brick et al., 1985). Androgen replacement therapy in patients with Klinefelter's syndrome demonstrated a significant reduction in serum $\operatorname{IgA}, \operatorname{IgG}$, and $\operatorname{IgM}$ serum titers (Kocar et al., 2000). Experiments suggest that compounds that are antiandrogenic do not have contrasting effects on the immune system. The antiandrogen, flutamide, does not significantly affect the anti-IgM response following SRBC immunization and chronic flutamide treatment (O'Connor et al., 2002; Ladics et al., 1998). These studies indicate that androgens are immunosuppressive with regards to humoral responses and antiandrogens are neither immunostimulatory nor immunosuppressive.

\section{SUMMARY}

These experiments employed the HKSP immunization model to study the effects of herbicide exposure on the humoral immune response. Previous reports demonstrated a number of immunotoxic effects induced by propanil and 2,4-D. These studies were 
conducted to determine if these previously observed immunotoxic effects affect an adaptive immune response to a common bacteria.

The experiments in Chapter 2 establish an environmentally relevant route of herbicide exposure to study these immunotoxic effects. Chapter 3 characterizes the effects of propanil, 2,4-D, and 1:1 mixture of the two herbicides on the PC and PspAspecific responses following HKSP immunization. Chapter 4 determines if propanil selectively enhances TI-2 antibody responses as well as determine the time of exposure and antigen concentration requirements for the enhanced antibody response. Chapter 5 examines the role of the endocrine system in the enhanced antibody response following propanil exposure. Finally, Chapter 6 explores the effect of the propanil-induced antibody enhancement on the survival to a virulent $S$. pneumoniae challenge. 


\section{CHAPTER 2: COMPARISON BETWEEN ASPIRATION AND IP ROUTES OF HERBICIDE EXPOSURE ON THE IMMUNE SYSTEM}




\section{INTRODUCTION}

Previous published data on the immunotoxic effects of propanil exposure have been performed using an ip exposure (de la Rosa et al., 2005). As mentioned in the General Introduction, human exposure to propanil occurs primarily via inhalational, dermal and oral routes. The goal of these experiments is to establish a model to study an environmentally relevant route of exposure for propanil. This new exposure model will be applied to contrast and compare the effects of propanil exposure on immune function that has previously been established to be susceptible following ip exposure. In addition, mixture interactions will be studied in the new exposure model.

An aspiration route of exposure was chosen based on the result of preliminary experiments performed in the laboratory. Dermal studies found that propanil was not readily transported across the skin (data not shown). As mentioned in the General Introduction, previous experiments have demonstrated that oral exposures to propanil require approximately twice the concentration to induce the same toxicity as ip exposures (Xie et al., 1997b). For these reasons, an inhalational model was studied.

Propanil has previously been shown to induce thymic atrophy that is easily measured by decreases in thymic weight and in the number of thymocyte subpopulations (de la Rosa et al., 2005). In addition, 2,4-D induces a greater-than-additive effect on the thymus when administered with propanil (de la Rosa et al., 2005). One of the common routes of occupational exposure to 2,4-D includes inhalation (Garabrant and Philbert, 2002). For these reasons, thymic atrophy was chosen as the endpoint for evaluating the efficacy of herbicide exposure by aspiration. Long-term goals for this research include 
evaluating the effects on a humoral response following vaccination. Therefore, the effects of an aspiration exposure were also studied in HKSP immunized animals.

\section{METHODS}

\section{Animals}

Six to eight week old C57B1/6 female mice were purchased from Hill Top Lab Animals (Scottdale, PA). Mice were housed in microisolator cages in pathogen free conditions at West Virginia University's animal facility. Mice were kept on a $12 \mathrm{hr}$ lightdark cycle and allowed to acclimate to the facility for 1 week. These studies were conducted in accordance with all federal and institutional guidelines for animal use and were approved by the West Virginia University Institutional Animal Care and Use Committee.

\section{Pesticides}

Propanil, 3,4-dichloropropionanilide, 99\% pure was purchased from Chem Service. 2,4-D, Dimethylamine salt of 2,4-dichlorophenoxyacetic acid was purchased from Universal Cooperatives. 2,4-dichlorophenoxyacetic acid, 99.5\% pure was purchased from Chem Service.

\section{Herbicide exposures}

For aspiration, pesticides were diluted in $12 \mu \mathrm{l}$ of olive oil and $8 \mu \mathrm{l}$ DMSO. Three or $4 \mathrm{mg}$ of purified pesticide was dissolved in DMSO/olive oil for a $150-\mathrm{mg} / \mathrm{kg}$ or $200 \mathrm{mg} / \mathrm{kg}$ treatment, respectively. Mixture exposures were prepared by dissolving both herbicides in the $20 \mu \mathrm{l}$ olive oil and DMSO solution. Animals were lightly anesthesized with $150 \mu \mathrm{l}$ of a $5 \mathrm{mg} / \mathrm{ml}$ solution of Nembutal prior to pesticide exposure. Mice were 
suspended vertically and the tongue was extended with forceps to prevent swallowing of the herbicides. Herbicides were pipetted at the base of the tongue and subsequently inhaled.

For ip exposures, propanil was dissolved in peanut oil at a concentration of 15 $\mathrm{mg} / \mathrm{ml}$ or $20 \mathrm{mg} / \mathrm{ml}$ for $150 \mathrm{mg} / \mathrm{kg}$ or $200 \mathrm{mg} / \mathrm{kg}$ exposures. Commercial formulation of 2,4-D was diluted in sterile PBS at the appropriate concentration for a $150 \mathrm{mg} / \mathrm{kg}$ or 200 $\mathrm{mg} / \mathrm{kg}$ injection. Herbicides were injected ip in $200 \mu \mathrm{l}$ volumes.

\section{Bacterial preparation and immunization with $\mathbf{R} 36 \mathrm{~A}$}

S. pneumoniae strain R36A, an avirulent, nonencapsulated strain, was grown to mid-log phase in Todd-Hewitt broth (Becton Dickinson, Sparks, MD) $+.05 \%$ yeast extract (Becton Dickinson) and stored at $-80^{\circ} \mathrm{C}$. For immunization, stock was cultured in a candle jar for $18 \mathrm{hrs}$ at $37^{\circ} \mathrm{C}$ on blood agar plates (Becton Dickinson). A few characteristic colonies were selected and suspended in $200 \mathrm{ml}$ Todd-Hewitt broth $+.05 \%$ yeast extract. Bacteria were grown at $37^{\circ} \mathrm{C}$ to an absorbance reading at $650 \mathrm{~nm}$ of 0.4 and heat killed for 4 hours in a $60^{\circ} \mathrm{C}$ water bath. A final concentration of $10^{9} \mathrm{CFU} / \mathrm{ml}$ was established in PBS based on colony counts. Sterility was confirmed by culture. Heatkilled stock was stored at $-20^{\circ} \mathrm{C}$ in $1 \mathrm{ml}$ aliquots. Mice were immunized ip with $2 \times 10^{8}$ CFU on the same day as herbicide exposure.

\section{Organ preparation}

Mice were euthanized with $100 \mu \mathrm{l}$ Nembutal Sodium Solution $(50 \mathrm{mg} / \mathrm{ml}$, Abbott Laboratories, North Chicago, IL). Spleen and thymus wet weights were recorded. Spleens were mechanically dissociated through Spectra nylon mesh (Spectrum Labs, Rancho Dominguez, CA) in complete cell media containing RPMI-1640 (BioWhitaker, 
Walkersville, MD), 10\% heat inactivated fetal bovine serum (FBS, Hyclone Laboratories, Inc, Logan, UT), 10 mM HEPES (Sigma), 1 mM L- glutamine (Gibco, Rockville, MD), $5 \times 10^{-5} \mathrm{M} 2$-mercaptoethanol (Sigma), $100 \mathrm{U} / \mathrm{ml}$ penicillin (Gibco), and $100 \mu \mathrm{g} / \mathrm{ml}$ streptomycin (Gibco). Thymuses were mechanically dissociated between microscope slides in complete cell media. Red blood cells in the spleen and thymus were lysed with Tris-buffered ammonium chloride. Cell suspensions were washed twice and counted using a hemacytometer. Viability was determined using Trypan blue dye exclusion.

\section{Measurement of antibody secreting B cells (ASC) in the spleen}

Acrowell ${ }^{\mathrm{TM}} 96$ well filter plates (Pall Life Sciences, Ann Arbor, MI) were coated with $50 \mu \mathrm{l}$ PC-BSA (Biosearch Technologies, Novato, CA) $(10 \mu \mathrm{g} / \mathrm{ml})$ overnight at $4^{\circ} \mathrm{C}$. In all subsequent steps, plates were washed with PBS $+.01 \%$ Tween-20. Plates were blocked with $200 \mu \mathrm{l} /$ well complete medium $+25 \%$ FBS for 2 hours at $37^{\circ} \mathrm{C}$. Plates were washed and cells $(100 \mu \mathrm{l} /$ well $)$ were then added at a concentration of $5 \times 10^{6}$ cells $/ \mathrm{ml}$ or $1 \times 10^{6}$ cells $/ \mathrm{ml}$. All samples were plated in triplicate. Plates were incubated for 4-6 hours at $37^{\circ} \mathrm{C}$ in a $5 \% \mathrm{CO}_{2}$ incubator. After washing, goat anti-mouse alkaline phosphatase (AP) conjugated IgG or IgM antibodies (Southern Biotechnology Associates, Birmingham, AL), diluted $1 / 250$ in PBS $+1 \% \mathrm{BSA}+.05 \%$ Tween-20, were added to the appropriate wells $\left(100 \mu \mathrm{l} /\right.$ well). Plates were incubated overnight at $4{ }^{\circ} \mathrm{C}$ and washed. SIGMAFAST 5-bromo-4-chloro-3-indolyl phosphate/nitro blue tetrazolium tablets (Sigma-Aldrich, St. Louis, MO) were dissolved in distilled water and added at $100 \mu \mathrm{l} /$ well. Color development was stopped by washing with distilled water. The number of spots/well was counted using a dissection microscope (Olympus Optical Co., Melville, 
NY). The number of ASC was calculated by using the mean number of spots from triplicate wells. The number of ASC was normalized to $1 \times 10^{6} \mathrm{~B}$ cells.

\section{Flow cytometric analysis}

Splenic cells were stained with the appropriate combinations of rat anti-mouse B220-APC (RA3-6B2), rat anti-mouse CD4-FITC (GK1.5), or rat anti-mouse CD8 $\alpha$-PE (53-6.7) (BD PharMingen, San Diego, CA). All steps were performed in PBS

supplemented with $1 \%$ FBS and $0.04 \%$ sodium azide (Sigma). Briefly, $1 \times 10^{6}$ cells were stained in a total volume of $25 \mu \mathrm{l}$ of antibodies at the appropriate concentrations for 25 minutes on ice in the dark. After incubation, cells were washed twice and fixed in $0.04 \%$ paraformaldehyde overnight at $4{ }^{\circ} \mathrm{C}$ (Fisher Scientific, Pittsburgh, PA). The following day cells were washed twice to remove the paraformaldehyde and resuspended in $1 \mathrm{ml}$ of staining media. For each sample, 10,000 cells were collected for analysis on a BectonDickinson FACScan (Becton Dickinson Immunocytometry Systems, Mansfield, MA). Analysis was performed using WinMDI software (Joseph Trotter, Scripps Institute, San Diego, CA). Population percentages, obtained from flow cytometric analysis, were used to calculate the absolute cell number by multiplying the percentage of cells in a population by the total number of cells harvested per organ.

\section{Statistics}

One-way analysis of variance (ANOVA) was performed for all statistical analyses using a Tukey-Kramer t-test to perform multiple comparisons between all treatment groups. A significance level of $\mathrm{p} \leq 0.05$ was used for all tests. Statistical analysis was performed using JMP software (SAS Institute Inc., Cary, NC). All experiments were 
performed 3 or more times with similar results. The figures are representative data from one experiment.

\section{RESULTS}

\section{Aspirated herbicides decrease thymic weight similarly to an ip injection.}

Mice were treated with either a $150 \mathrm{mg} / \mathrm{kg}$ or $200 \mathrm{mg} / \mathrm{kg}$ concentration of herbicides. Animals were exposed to either individual propanil or 2,4-D treatments or a 1:1 mixture of the two herbicides. Mice were exposed to the herbicides via either an ip or aspiration route of exposure. Animals that received the herbicides via the aspiration route did not remain unconscious as long as animals receiving herbicides via the ip route.

Propanil-treated mice exposed via the aspiration route were unconscious for approximately 45 min compared to $30 \mathrm{~min}$ in animals receiving Nembutal alone.

However, ip injected mice receiving propanil were unconscious for 6-8 hours. A 150/150 $\mathrm{mg} / \mathrm{kg}$ ip mixture herbicide exposure to the mixture of herbicides significantly decreased the thymic weights in a greater-than-additive fashion compared to the single herbicide exposures (Figure 1). Aspiration exposure to the mixture of herbicides was not significantly different from the ip mixture exposure (Figure 1). In addition, $150 \mathrm{mg} / \mathrm{kg}$ single herbicide exposures were not significantly different between both aspiration and ip routes of exposure (Figure 1). Aspirated or ip injected $200 \mathrm{mg} / \mathrm{kg}$ single propanil and aspirated or ip injected mixture herbicide exposures produced statistically similar thymic atrophy (Figure 1). However, single 2,4-D exposure was an approximate $\mathrm{LD}_{50}$ when the herbicide was aspirated (data not shown). Surviving mice exposed to 2,4-D by aspiration induced similar decreases in thymus size compared to ip injected animals (Figure 1). 


\section{Aspirated herbicides decrease the number of thymocytes similar to ip injected herbicides.}

Thymocyte populations were analyzed from the thymuses of herbicide-treated animals. The total number of thymocytes from $150 \mathrm{mg} / \mathrm{kg}$ and $200 \mathrm{mg} / \mathrm{kg}$ in mixture treated animals were decreased similarly in both aspirated or ip injected groups (Figure

2). Aspirated $200 \mathrm{mg} / \mathrm{kg}$ propanil and 2,4-D significantly decreased the number of thymocytes compared to aspirated controls (Figure 2). In contrast, ip injected $200 \mathrm{mg} / \mathrm{kg}$ propanil and 2,4-D were not significantly decreased from ip vehicle controls (Figure 2).

Analysis of the $\mathrm{CD} 4^{+} \mathrm{CD} 8^{+}, \mathrm{CD}^{+} \mathrm{CD}^{-}$, and $\mathrm{CD} 4^{-} \mathrm{CD} 8^{+}$subpopulations demonstrate a similar magnitude of reduction in mixture treated animals via either the aspiration or ip route of exposure (Figures 3A, 3B, 3C). Single exposures produced similar decreases in thymocyte subpopulations regardless of aspiration or ip injection (Figures 3A, 3B, 3C). The statistical significance of single exposures varied with concentration and route of exposure, however, the general effect of the herbicides on the thymocyte subpopulations is similar regardless of the route of exposure (Figures 3A, 3B, 3C).

\section{Aspirated herbicides do not affect the number of ASC.}

Since herbicide exposure induced thymic atrophy similarly in aspirated and ip injected animals, the effect of aspirated herbicides on the antibody response to an ip HKSP immunization was examined. Previous experiments demonstrated that propanil and 2,4-D mixture exposure increases the number of PC-specific ASC following HKSP immunization (de la Rosa dissertation). Mice were immunized with HKSP and treated with herbicides via either aspiration or ip injection. Mixture herbicide exposure 
increased the number of IgG and IgM PC-specific ASC when animals were ip injected with a 150/150 mg/kg herbicide mixture (Figure 4). However, aspirated herbicides did not significantly increase the number of PC-specific ASC compared to aspirated vehicle mice (Figure 4).

\section{DISCUSSION}

These experiments begin to explore how the toxic effects of the herbicides 2,4-D and propanil differ when animals are exposed via different routes. These experiments use established immunotoxic effects induced by ip exposure to evaluate the efficacy of an environmental route of exposure on immune function. Propanil and mixture treatments produced similar immunotoxic effects on the thymus when animals were aspirated or ip injected. 2,4-D treatments were more lethal when animals were aspirated instead of ip injected. The cause of increased mortality for aspirated 2,4-D compared to ip or dermal exposures is not currently known. However, the thymic atrophy induced in the surviving animals was similar in both exposure models. Animals exposed to herbicides via aspiration did not have significantly different antibody responses. Altogether, these data demonstrate the importance of considering exposure routes when evaluating the toxicity of chemical exposures.

Propanil induces thymic atrophy by increasing glucocorticoids in ip injected mice. Although aspirated propanil treatment induces similar thymic atrophy as ip injection, the mechanism has not been studied. However, given the similarity of the response in ip vs. aspiration, it is plausible that the mechanisms are the same. Aspirated herbicides did not exhibit the overt neurotoxicity that is observed in ip injected animals. This result 
suggests that the hind leg paralysis and the period of unconsciousness induced by the toxicity from ip injected herbicides is not involved in thymic atrophy.

The route of immunization and the site of the antibody response might be responsible for the inability of aspirated herbicides to enhance the antibody response. IP immunizations typically pass through the subdiaphragmatic lymphatics (Smith et al., 1996). Since the mechanism that is responsible for enhancing the antibody response following herbicide exposure is probably different from the one regulating thymic atrophy, it is unknown what is required for splenic effects. Respiratory exposure to herbicides may induce a more localized effect. Since ip immunization does not produce strong antibody responses in the lung, a different route of immunization may be necessary. Follow-up studies may utilize an antigen that elicits a strong local antibody response via respiratory challenge. Preliminary experiments with live aspirated $S$. pneumoniae were unsuccessful due to a high mortality associated with herbicide and bacterial challenge. Death was observed within hours of exposure, suggesting acute respiratory distress. Future experiments may attempt an immunization several days prior to herbicide exposure to allow for complete clearance of the antigen and a reduction in inflammation.

Altogether, these data demonstrate the importance of route of administration when analyzing toxicity of chemical exposure. Thymic atrophy is readily induced by herbicide exposure and the sensitivity of the assay may serve as an endpoint for determining pesticide exposure. However, effects on humoral responses are dependent on the primary site of antibody production. 


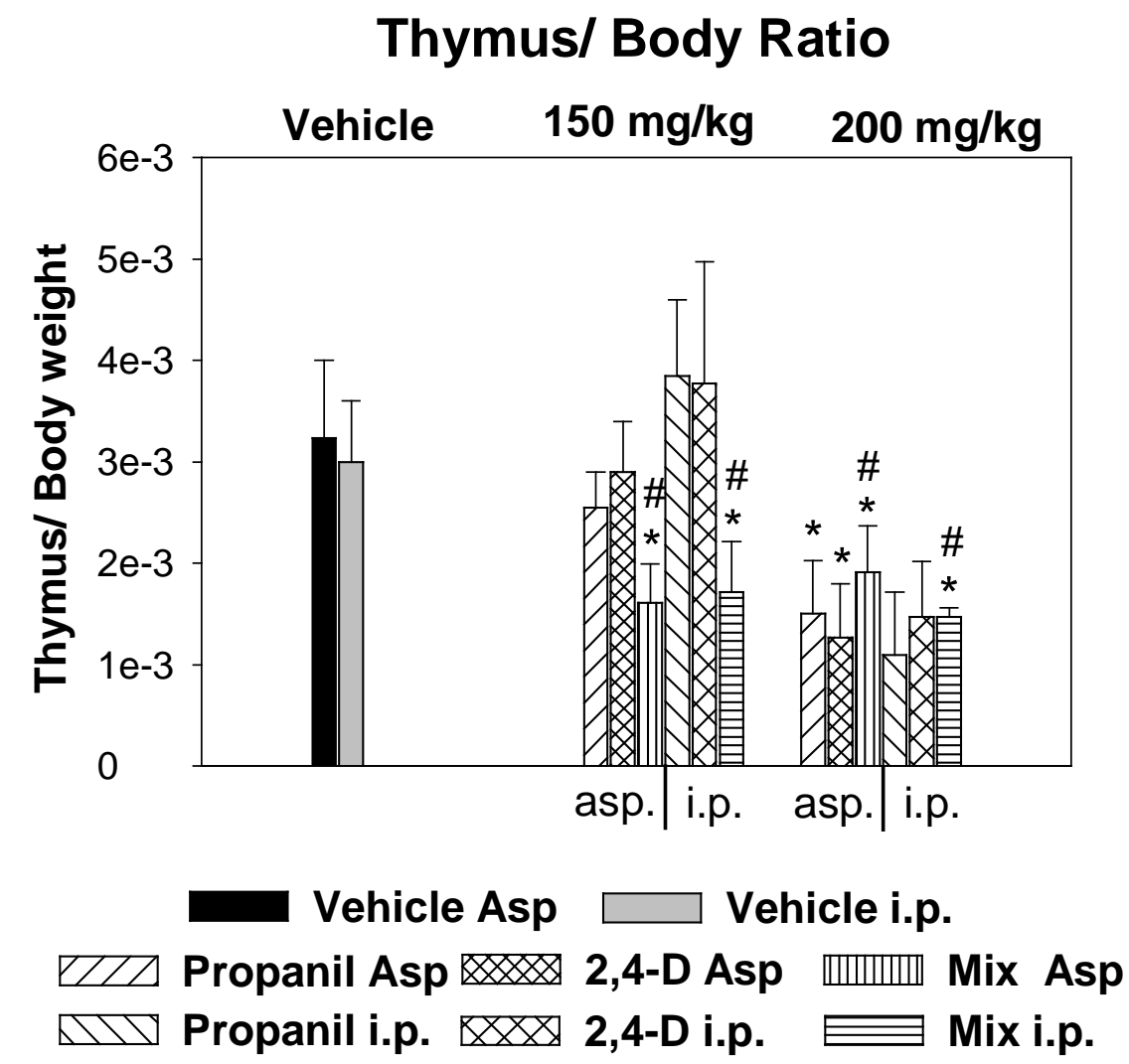

Figure 1. Aspirated herbicides decrease thymic weight similarly to ip injection.

C57BL/6 female mice (5/group) were treated with vehicle control, 150 or $200 \mathrm{mg} / \mathrm{kg}$ propanil, 150 or $200 \mathrm{mg} / \mathrm{kg}$ 2,4-D, or a $150 / 150$ or 200/200 mixture. Mice were exposed via aspiration or ip injection and thymic weights were recorded on day 2. Values represent the mean $\pm \mathrm{SD}$. $*$ Significantly different from vehicle, $\mathrm{p} \leq .05$. \# indicates a mixture interaction. 


\section{Total Number of Thymocytes}

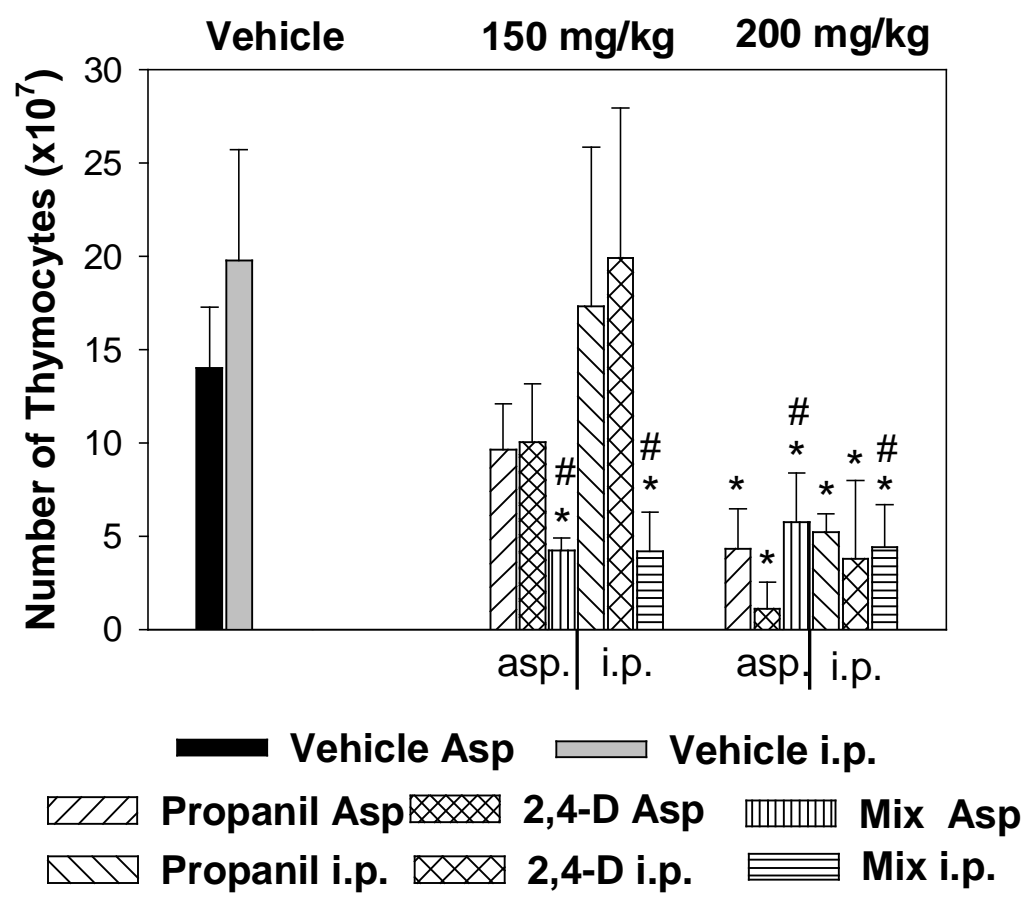

Figure 2. Aspirated herbicides decrease the number of thymocytes similarly to ip injection.

C57BL/6 female mice (5/group) were treated with vehicle control, 150 or $200 \mathrm{mg} / \mathrm{kg}$ propanil, 150 or $200 \mathrm{mg} / \mathrm{kg}$ 2,4-D, or a 150/150 or 200/200 mixture. Mice were exposed via aspiration or ip injection and thymocyte numbers were counted on day 2. Values represent the mean number of thymocytes $\pm \mathrm{SD} . *$ Significantly different from vehicle, $\mathrm{p}$ $\leq .05$. \# indicates a mixture interaction. 
A.

\section{CD4 ${ }^{+}$CD8 ${ }^{-}$Thymocytes}

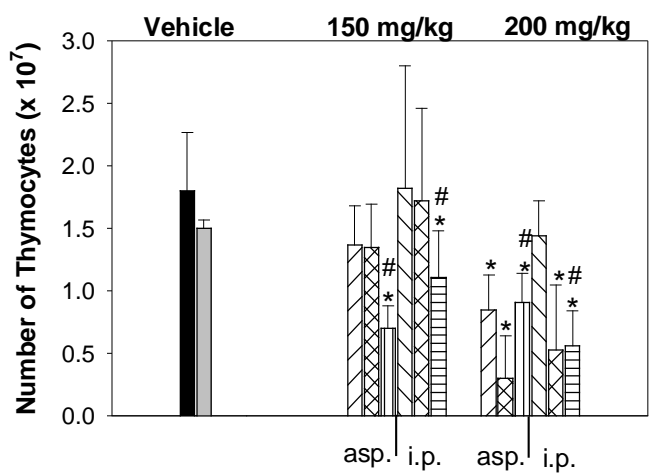

C.

CD4 ${ }^{+}$CD8 ${ }^{+}$Thymocytes

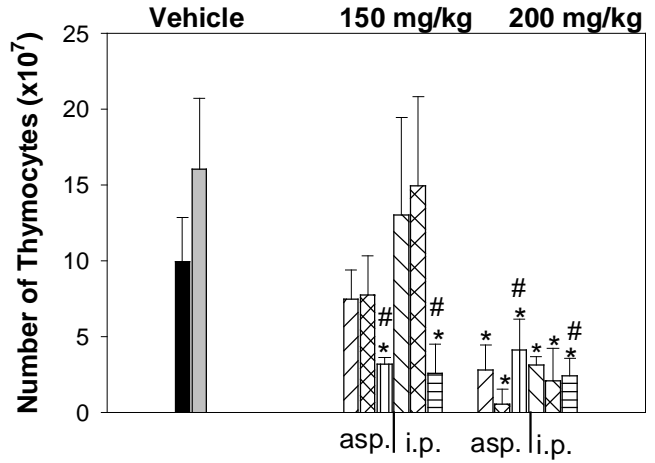

B. CD4CD8+ Thymocytes

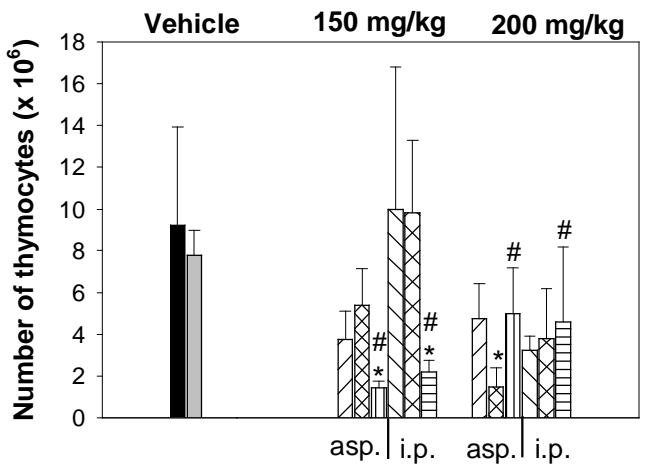

Figure 3. Aspirated herbicides decrease thymocyte subpopulations similar to ip injection.

C57BL/6 female mice (5/group) were treated with vehicle control, 150 or $200 \mathrm{mg} / \mathrm{kg}$ propanil, 150 or $200 \mathrm{mg} / \mathrm{kg}$ 2,4-D, or a $150 / 150$ or 200/200 mixture. Mice were exposed via aspiration or ip injection. The thymocyte subpopulations (A) $\mathrm{CD}^{+} \mathrm{CD} 8^{-}$, (B) $\mathrm{CD}^{-}$ $\mathrm{CD} 8^{+}$, and $(\mathrm{C}) \mathrm{CD} 4^{+} \mathrm{CD} 8^{+}$were enumerated by flow cytometry on day 2 . Values represent the mean number of thymocytes $\pm \mathrm{SD}$. * Significantly different from vehicle, $\mathrm{p}$ $\leq .05$. \# indicates a mixture interaction. 


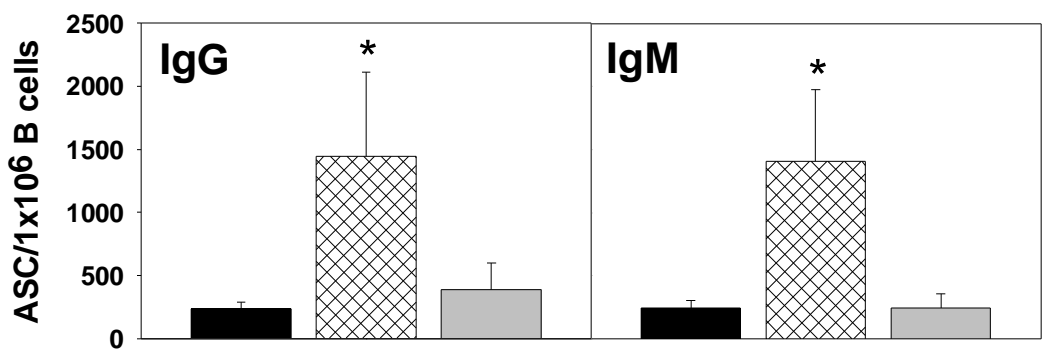

\section{Vehicle 150/150 ip $150 / 150$ asp}

Figure 4. Aspirated herbicides do not affect the number of PC-specific ASC.

C57BL/6 female mice (5/group) were treated via aspiration or ip injection with vehicle control or a $150 / 150$ mixture and vaccinated ip with $2 \times 10^{8}$ CFU HKSP. Numbers of PCspecific IgG and IgM ASC were determined by ELISPOT assay on day 7. Values represent the mean $\pm \mathrm{SD}$ of ASC $/ 1 \times 10^{6}$ B cells. * Significantly different from vehicle, $\mathrm{p}$ $\leq .05$. 
CHAPTER 3: THE POLYSACCHARIDE ANTIBODY RESPONSE AFTER STREPTOCOCCUS PNEUMONIAE VACCINATION IS DIFFERENTIALLY ENHANCED OR SUPPRESSED BY 3,4-DICHLOROPROPIONANILIDE AND 2,4-DICHLOROPHENOXYACETIC ACID 
The polysaccharide antibody response after Streptococcus pneumoniae vaccination is differentially enhanced or suppressed by 3,4-dichloropropionanilide and 2,4dichlorophenoxyacetic acid

Keith D. Salazar" (ksalazar@hsc.wvu.edu)

Patricia de la Rosa ${ }^{+}$(pdelarosa@cdc.gov)

John B. Barnett ${ }^{*}$ (jbarnett@ hsc.wvu.edu)

Rosana Schafer*(rschafer@hsc.wvu.edu)

"Department of Microbiology, Immunology and Cell Biology, Robert C. Byrd Health

Sciences Center, West Virginia University, Morgantown, West Virginia, 26506-9177.

+NIOSH-HELD-ASB, 1095 Willowdale Rd., MS L-4218, Morgantown, WV 26505.

Running title: Propanil and 2,4-D alter TI-2 antibody levels

Corresponding author. Rosana Schafer, Ph.D. Department of Microbiology,

Immunology and Cell Biology, Health Sciences Center North, P.O. Box 9177, West

Virginia University, Morgantown, WV 26506-9177

E-mail: rschafer@hsc.wvu.edu. Telephone: 304-293-3104. Fax: 304-293-7823. 


\begin{abstract}
Propanil (3,4-dichloropropionanilide) and 2,4-D (2,4-dichlorophenoxyacetic acid) are commonly used herbicides that have toxic effects on the immune system. The present study determined the effect of exposure to these chemicals on the immune response to a bacterial vaccine. The antibody responses to the T-independent type 2 antigen, phosphorylcholine (PC) and the T-dependent antigen, pneumococcal surface protein A (PspA) were characterized in C57BL/6 mice following heat-killed Streptococcus pneumoniae (HKSP) immunization and single or mixture herbicide exposure. Propanil exposure significantly increased the number of PC-specific IgM, IgG2b, and IgG3 antibody secreting B cells (ASC) in the spleen 4-6 fold over control animals in a dose dependent manner. However, the number of ASC in the bone marrow and serum titers were comparable in control and propanil-treated mice. In contrast, 2,4-D exposure decreased the number of PC-specific IgM and IgG bone marrow ASC 2-3 fold from control animals. The decrease in bone marrow ASC in 2,4-D-treated mice corresponded to a 3-4 fold decrease in PC-specific IgM, IgG2b, and IgG3 serum titers compared to control mice. The number of ASC in the spleens of 2,4-D-treated mice was, however, comparable to control mice. The antibody response to PspA was not affected by any of the treatments. There were no mixture interactions between the two herbicides in any of the responses measured. These results characterize the primary PC-specific antibody response in the bone marrow, spleen, and serum following HKSP vaccination and herbicide exposure. The differential effects of propanil and 2,4-D on the antibody response to a bacterial vaccine demonstrate the potential of chemical exposure to augment or suppress immune responses to vaccines and infectious diseases.
\end{abstract}




\section{INTRODUCTION}

The class of pesticides, commonly referred to as herbicides, is extensively used both commercially and by individuals making them ubiquitous in the environment. The immune system, in particular, is reported to be sensitive to the toxic effects of herbicides (Faustini et al., 1996; Short and Colborn, 1999). Since infectious diseases are a major cause of morbidity and mortality worldwide, it is important to determine if exposure to these compounds compromises the immune response to an infection. 2,4dichlorophenoxyacetic acid (2,4-D) and 3,4-dichloropropionanalide (propanil) are commonly used herbicides marketed as a chemical mixture under the product names of NOX-D and Herbanil 368 (Crop Protection Handbook, 2003). Previous research has demonstrated that 2,4-D and propanil are immunotoxic to the primary immune organs and to specific immune cell functions, however, the effects of an exposure to a mixture of these herbicides on an in vivo immune response has not been studied (de la Rosa et al., 2003; de la Rosa et al., 2005; Barnett and Gandy, 1989; Blakley, 1997). This study was performed to determine if exposure to these herbicides, either alone or as a mixture, altered the primary humoral immune response to the model bacterial vaccine, heat-killed Streptococcus pneumoniae (HKSP).

Propanil is an amide class herbicide that induces thymic atrophy and splenomegaly. Numerous studies have established that exposure to propanil can inhibit the function of a variety of immune cell populations including macrophages, $\mathrm{T}$ cells, and natural killer cells (Barnett and Gandy, 1989; Barnett et al., 1992; Xie et al., 1997; Zhao et al., 1998). Murine studies have demonstrated that propanil inhibits the antibody response in the spleen to the model T cell-independent-type 2 (TI-2) antigen DNP-Ficoll 
and the T-dependent (TD) antigen sheep red blood cells (SRBC) (Barnett and Gandy, 1989; Barnett et al., 1992). 2,4-D is a chlorinated phenoxy compound designed as a synthetic form of the plant hormone auxin (Munro et al., 2002). Reports on the immunotoxic effects of 2,4-D are inconclusive. Studies using a mouse model demonstrated that oral exposure to 2,4-D at the time of vaccination with SRBC increased the number of antibody producing cells (ASC) in the spleen (Blakley, 1986). Conversely, another report found that exposure to a mixture of 2,4-D and the herbicide picloram decreased the number of plaque-forming cells in the spleen following SRBC vaccination (Blakley, 1997). Thus, additional studies are needed to determine the effects of 2,4-D on the humoral immune response.

S. pneumoniae kills approximately 1 million children aged 5 years or younger annually and remains one of the most common causes of pneumococcal death worldwide. Due to its prevalence, it is a well-characterized model for studying the humoral immune response. Vaccination with HKSP elicits a TD antibody response and a TI-2 antibody response (Wu et al., 1999). Pneumococcal surface protein A (PspA) is a TD antigen on S. pneumoniae that acts as a virulence factor by inhibiting the functions of complement (Tu et al., 1999). Phosphorylcholine (PC) is a cell wall polysaccharide and the immunodominant antigen that elicits the TI-2 antibody response. PC is a virulence factor that functions by transporting the bacterium across the epithelial and endothelial membranes (Cundell et al., 1995; Tuomanen et al., 1995). Current vaccine strategies use a 23-valent polysaccharide vaccine or a 7-valent conjugate vaccine, both of which produce a robust anti-polysaccharide response (Bogaert et al., 2004). The kinetics of the 
serum antibody response and the predominant isotypes produced to PspA and PC are well characterized (Wu et al., 2000; Wu et al., 1999).

Our laboratory focuses on studying potential synergistic effects on the immune system following exposure to a mixture of propanil and 2,4-D. Previous studies show that exposure to either propanil or 2,4-D alone induced thymic atrophy and reduced the number of double positive $\left(\mathrm{CD} 4^{+} \mathrm{CD} 8^{+}\right)$thymocytes (de la Rosa et al., 2005). In the bone marrow, exposure to either herbicide alone decreased the number of pre-B $\left(\mathrm{B} 220^{+} \mathrm{CD} 3^{+} \operatorname{IgM}^{\mathrm{lo}}\right)$ cells and $\operatorname{IgM}^{+}$B $\left(\mathrm{B} 220^{+} \mathrm{CD} 43^{-} \operatorname{IgM}^{\mathrm{hi}}\right)$ cells (de la Rosa et al., 2003). However, exposure to the mixture of propanil and 2,4-D caused greater-than-additive decreases in the same cell populations in the thymus and bone marrow suggesting that interactions of the mixture increased the toxicity of the individual chemicals (de la Rosa et al., 2003; de la Rosa et al., 2005).

Based on the previous reports on the immunotoxic effects of propanil and 2,4-D, it was originally hypothesized that exposure to the herbicides would inhibit the humoral immune response after vaccination with HKSP and that exposure to the mixture would be more immunotoxic than the individual compounds. However, in contrast to the hypothesis, the results demonstrated that propanil and 2,4-D differentially affected the immune response to HKSP and there were no apparent interactions between the two herbicides. Exposure to propanil significantly increased the number of PC-specific ASC in the spleen. 2,4-D had no effect on the PC response in the spleen but significantly decreased the number of PC-specific ASC in the bone marrow. The decrease in ASC in the bone marrow after exposure to 2,4-D correlated with a significant decrease in the PCspecific serum antibody titers. There was no effect on the response to PspA by any of the 
treatments. In addition, these results extend our knowledge of the humoral immune response to vaccination with HKSP by characterizing the primary antibody response to $\mathrm{PC}$ in the bone marrow and the spleen in conjunction with the serum antibody response. 


\section{MATERIALS AND METHODS}

Mice.

Six to eight week old C57B1/6 female mice were purchased from Charles River Farms (Wilmington, DE). Mice were housed in microisolator cages in pathogen free conditions at West Virginia University's animal facility. Mice were kept on a $12 \mathrm{hr}$ lightdark cycle and allowed to acclimate to the facility for 1 week. Food and water was provided ad libidum. These studies were conducted in accordance with all federal and institutional guidelines for animal use and were approved by the West Virginia University Institutional Animal Care and Use Committee.

\section{Chemicals.}

Propanil (3,4-dichloropropionanilide, 99\% pure) was purchased from Chem Service (West Chester, PA). Commercial-grade 2,4-D amine (47.2\% dimethylamine salt of 2,4-dichlorophenoxyacetic acid, 52.8\% inert ingredients, Universal Cooperatives, Inc., Minneapolis, MN) was purchased from Southern States Cooperative (Morgantown, WV).

\section{Bacterial preparation and immunization.}

S. pneumoniae strain R36A (a gift from Meenal Elliott, West Virginia University) an avirulent, nonencapsulated strain, was used for all experiments. Strain R36A was chosen because it is a commonly used strain of $S$. pneumoniae and the kinetics of the serum antibody response and the predominant isotypes to PC and PspA have been well established (Wu et al., 1999; Wu et al., 2000). Strain R36A was grown to mid-log phase in Todd-Hewitt broth (Becton Dickinson, Sparks, MD) $+.05 \%$ yeast extract (Becton Dickinson) and stored at $-70^{\circ} \mathrm{C}$. For immunization, stock was cultured in a candle jar for $18 \mathrm{hrs}$ at $37^{\circ} \mathrm{C}$ on blood agar plates (Becton Dickinson). A few characteristic colonies 
were selected and suspended in $200 \mathrm{ml}$ Todd-Hewitt broth $+.05 \%$ yeast extract. Bacteria were grown at $37^{\circ} \mathrm{C}$ to an absorbance reading at $650 \mathrm{~nm}$ of 0.4 . Bacteria were heat killed for 4 hours at $60^{\circ} \mathrm{C}$. A final concentration of $10^{9} \mathrm{CFU} / \mathrm{ml}$ was established in PBS based on colony counts. Sterility was confirmed by culture. Heat-killed stock was stored at $20^{\circ} \mathrm{C}$ in $1 \mathrm{ml}$ aliquots. Mice were immunized intraperitoneally (i.p.) with $2 \times 10^{8} \mathrm{CFU}$.

\section{Exposure of mice to herbicides.}

Mice (5-6/ group) were treated with either single doses of herbicides (propanil or 2,4-D) or a 1:1 mixture of both herbicides by i.p. injection within one hour of HKSP vaccination. Mice were treated with a range of concentrations of herbicide based on milligrams of herbicide/ kilogram of body weight $(\mathrm{mg} / \mathrm{kg})$. Propanil was dissolved in peanut oil and animals were treated with $25,50,100$, or $150 \mathrm{mg} / \mathrm{kg}$. 2,4-D was diluted in sterile PBS and mice were treated with $150 \mathrm{mg} / \mathrm{kg}$. 2,4-D concentration was based on the amount of active 2,4-D in the commercial preparation. The route of exposure and the doses used were based on previous studies that demonstrated a mixture interaction at 150 $\mathrm{mg} / \mathrm{kg}$ propanil and $150 \mathrm{mg} / \mathrm{kg}$ 2,4-D on thymocyte populations (de la Rosa et al., 2005). Control animals were treated with the vehicle peanut oil only as previous studies determined that there was no difference between animals treated with the peanut oil vehicle compared to the PBS vehicle.

\section{Preparation of spleen and bone marrow cell suspensions.}

Mice were euthanized with $100 \mu \mathrm{l}$ Nembutal Sodium Solution $(50$ mg/ml, Abbott Laboratories, North Chicago, IL) on days 3, 5, 7, 10, and 14 following herbicide exposure and vaccination. Spleen wet weights were recorded. Spleens were mechanically dissociated through Spectra nylon mesh (Spectrum ${ }^{\circledR}$ Labs, Rancho Dominguez, CA) in 
complete cell media containing RPMI-1640 (BioWhitaker, Walkersville, MD), 10\% heat inactivated fetal bovine serum (FBS, Hyclone Laboratories, Inc, Logan, UT), 10 mM HEPES (Sigma, St. Louis, MO), $1 \mathrm{mM}$ L- glutamine (Gibco, Rockville, MD), 5x10-5 M 2-mercaptoethanol (Sigma), $100 \mathrm{U} / \mathrm{ml}$ penicillin (Gibco), and $100 \mu \mathrm{g} / \mathrm{ml}$ streptomycin (Gibco). To collect bone marrow cells, one hind leg was removed from each animal. Femur and tibia were flushed with complete media for single cell suspensions. Red blood cells in the spleen and bone marrow populations were lysed with Tris-buffered ammonium chloride. Cell suspensions were washed twice and counted by hemacytometer in Trypan blue.

\section{Flow cytometric analysis.}

Cells were stained with the appropriate combinations of rat anti-mouse B220APC (RA3-6B2), rat anti-mouse CD23-PE (B3B4), rat anti-mouse CD21-FITC (7G6), rat anti-mouse CD4-FITC (GK1.5), or rat anti-mouse CD8 $\alpha$-PE (53-6.7) (all from BD PharMingen, San Diego, CA). All steps were performed in PBS supplemented with 1\% FBS and $0.04 \%$ sodium azide (Sigma). Briefly, $1 \times 10^{6}$ cells were stained in a total volume of $25 \mu \mathrm{l}$ of antibodies at the appropriate concentrations for 25 minutes on ice in the dark. After incubation, cells were washed twice and fixed in $0.04 \%$ paraformaldehyde overnight at $4^{0} \mathrm{C}$ (Fisher Scientific, Pittsburgh, PA). The following day cells were washed twice to remove the paraformaldehyde and resuspended in $1 \mathrm{ml}$ of staining media. For each sample, 10,000 cells were collected for analysis on a BectonDickinson FACScan (Becton Dickinson Immunocytometry Systems, Mansfield, MA). Analysis was performed using WinMDI software (Joseph Trotter, Scripps Institute, San Diego, CA). Population percentages, obtained from flow cytometric analysis, were used 
to calculate the absolute cell number by multiplying the percentage of cells in a population by the total number of cells harvested per organ. Marginal zone B cells are defined as $\mathrm{B} 220^{+} \mathrm{CD} 21 / 35^{\text {hi }} \mathrm{CD} 23^{\text {neg/low }}$, follicular B cells are defined as $\mathrm{B} 220^{+} \mathrm{CD} 21 / 35^{\text {int }}$ CD23 ${ }^{\text {hi }}$ (Oliver et al., 1997). B cells are defined as all cells that are B220 ${ }^{+}$and include marginal zone B cells and follicular B cells.

\section{Measurement of antibody secreting $B$ cells $(A S C)$ in the bone marrow and spleen.}

Acrowell $^{\text {TM }} 96$ well filter plates (Pall Life Sciences, Ann Arbor, MI) were coated with $50 \mu \mathrm{l}$ PC-BSA (Biosearch Technologies, Novato, CA) $(10 \mu \mathrm{g} / \mathrm{ml})$ or $50 \mu \mathrm{l} \mathrm{PspA} \mathrm{(10}$ $\mu \mathrm{g} / \mathrm{ml}$ ) (PspA was a generous gift from Clifford Snapper, USUHS) overnight at $4{ }^{\circ} \mathrm{C}$. In all subsequent steps, plates were washed with PBS $+.01 \%$ Tween-20. Plates were blocked with $200 \mu \mathrm{l} /$ well complete media $+25 \%$ FBS for 2 hours at $37^{\circ} \mathrm{C}$. Plates were washed and cells $\left(100 \mu \mathrm{l} /\right.$ well) were then added at a concentration of $5 \times 10^{6}$ cells $/ \mathrm{ml}$ or $1 \times 10^{6}$ cells $/ \mathrm{ml}$. All samples were plated in triplicate. Plates were incubated for 4-6 hours at $37^{\circ} \mathrm{C}$ in a $5 \% \mathrm{CO}_{2}$ incubator. Plates were washed and goat anti-mouse alkaline phosphatase (AP) conjugated IgG, IgG1, IgG2a, IgG2b, IgG3, or IgM antibodies (Southern Biotechnology Associates, Birmingham, AL), diluted 1/250 in PBS + 1\%BSA $+.05 \%$ Tween-20, were added to the appropriate wells $(100 \mu 1 /$ well $)$. Plates were incubated overnight at $4^{\circ} \mathrm{C}$ and washed. SIGMAFAST 5-bromo-4-chloro-3-indolyl phosphate/nitro blue tetrazolium tablets (Sigma-Aldrich, St. Louis, MO) were dissolved in distilled water and added at $100 \mu \mathrm{l} /$ well. Color development was stopped by washing with distilled water. The number of spots/well was counted using a dissection microscope (Olympus Optical Co., Melville, NY). The number of ASC was calculated 
by using the mean number of spots from triplicate wells. Data are expressed as the number of ASC per $1 \times 10^{6} \mathrm{~B}$ cells or as the number of ASC per spleen or bone marrow. Measurement of PC- and PspA-specific titers.

Serum samples were prepared via blood collected from the heart. Immulon 2 plates (for PC) or Immulon 4 plates (for PspA) (ThermoLabsystems, Franklin, MA) were coated overnight at $4^{\circ} \mathrm{C}$ with $5 \mu \mathrm{g} / \mathrm{ml}$ PC-BSA or $10 \mu \mathrm{g} / \mathrm{ml}$ PspA $(50 \mu \mathrm{l} /$ well $)$. Plates were washed, blocked with $3 \% \mathrm{BSA}+\mathrm{PBS}$ at $37^{\circ} \mathrm{C}$ for 2 hours. Plates were washed and $100 \mu \mathrm{l} /$ well of twofold dilutions of sera in PBS $+1 \%$ BSA were added starting at 1/400 for the IgG and IgM ELISAs and 1/250 for the IgG subclasses. Plates were then incubated for 1 hour at $37^{\circ} \mathrm{C}$ and washed. AP conjugated antibodies (100 $\mu \mathrm{l} /$ well $)$ were added for 1 hour at $37^{\circ} \mathrm{C}$. Plates were washed and phosphatase substrate tablets (SigmaAldrich) were dissolved in PNPP (p-Nitrophenyl Phosphate, Disodium Salt) substrate buffer. Plates were developed and absorbance read at $405 \mathrm{~nm}$ on a $\mu$ Quant spectrophotometer (Bio-Tek instruments, Winooski, VT) using KCJunior software (BioTek instruments). To determine the titer a standard pooled sera was diluted and plated on each ELISA plate. The titer for each sample was determined by comparison to the standard sera when the OD $405 \mathrm{~nm}$ for the standard was 0.200 at a 1:3200 dilution for IgM and $\operatorname{IgG}$ or at $1: 2000$ for $\operatorname{IgG} 2 \mathrm{~b}$ and $\mathrm{IgG}$. These dilutions were chosen because they are in the linear part of the curve for the respective isotypes.

\section{Measurement of ex vivo PC-specific antibody production.}

Spleen cells were cultured in vitro with no additional stimulation for 5 days at $37^{\circ} \mathrm{C}$ and $5 \% \mathrm{CO}_{2}$ at a concentration of $5 \times 10^{5}$ cells $/ \mathrm{ml}$ in $500 \mu \mathrm{l}$ complete media in 48 well tissue culture plates (Costar, Corning Inc., Acton, MA). All cultures were 
performed in duplicate. The protein synthesis inhibitor cycloheximide was added to replicate samples at a concentration of $75 \mu \mathrm{g} / \mathrm{ml}(50 \mu \mathrm{l} /$ well $)$ to distinguish the amount of antibody produced de novo in culture from preformed antibody secreted during the culture period (Dhanjal et al., 1992). Supernatants were collected and antibody ELISAs were performed as described above. De novo antibody synthesis was determined by subtracting the absorbance readings from cycloheximide treated cells from absorbance readings from non-cycloheximide treated cells.

\section{Statistics.}

One-way analysis of variance (ANOVA) was performed for all statistical analyses using a Dunnett's t-test to compare herbicide treated animals with control animals. A significance level of $\mathrm{p} \leq 0.05$ was used for all tests. Identification of possible mixture interactions was determined using a partial factorial design. A mixture interaction was defined as the sum of the responses of the individual components of the mixture is significantly different from the response of the mixture treatment. Statistical analysis was performed using JMP software (SAS Institute Inc., Cary, NC). All experiments were performed 3 or more times with similar results. The figures are representative data from one experiment. 


\section{RESULTS}

\section{Propanil exposure increased the number of PC-specific antibody secreting $B$ cells in}

\section{the spleen.}

To determine if propanil and 2,4-D had either individual effects or cooperative effects on the humoral response in the spleen, mice were vaccinated with HKSP and treated with either a single dose of propanil $(150 \mathrm{mg} / \mathrm{kg}), 2,4-\mathrm{D}(150 \mathrm{mg} / \mathrm{kg})$, or a mixture $(150 / 150 \mathrm{mg} / \mathrm{kg})$. Serum titers to the PC antigen are detectable by day 4 and peak at day 6-7 following HKSP vaccination (Wu et al., 2000; Wu et al., 1999). Splenic ASC have been reported to peak 2-3 days prior to serum titers (Verheul et al., 1990). Based on these reports, days $3,5,7$, and 10 post-exposure were chosen to analyze the in vivo time course of the PC-specific antibody response.

Initial experiments in vehicle control animals immunized with HKSP demonstrated that IgM ASC were detectable at day $3\left(30 \pm 10 \mathrm{ASC} / 1 \times 10^{6} \mathrm{~B}\right.$ cells, Figure 1A) and peak 5 to 7 days post-exposure $(144 \pm 73$ ASC and $252 \pm 42$ ASC, respectively, Figure 1A). There was no statistical difference between day 5 and day 7 . By day 10 , the number of splenic ASC in control animals had decreased 2 -fold $(83 \pm 35$ ASC). The predominant isotypes produced were IgM, IgG2b, and IgG3 and all had similar kinetics (Figure 1A, 1B, and 1C, respectively). Comparable results were obtained when the number of ASC per spleen were determined (Figure 1D, 1E, and 1F). IgG1 and IgG2a were below the limit of detection by ELISPOT at all time points.

Following exposure to propanil or the mixture of propanil and 2,4-D, the number of PC-specific IgM (Figure 1A, 1D), IgG2b (Figure 1B, 1E), and IgG3 (Figure 1C, 1F) ASC were significantly increased 5 days after immunization (3-4 fold over vehicle 
control). Similar fold increases were determined for the number of ASC per whole organ (Figure 1D, 1E, 1F) and for the number of ASC normalized to one million B cells (Figure 1A, 1B, 1C) in all experiments. There was a statistically significant 4-6-fold increase in the number of $\operatorname{IgM}, \operatorname{IgG} 2 b$, and $\operatorname{IgG} 3$ ASC in the animals treated with propanil alone or the mixture at day 7 post-exposure (Figure 1A - 1F). By day 10, the number of ASC was declining in all groups, but was still significantly increased 3.5 fold in propanil and mixture-treated animals over control animals (Figure 1A - 1F). 2,4-D exposure alone did not alter the splenic ASC response compared to the control at any of the days measured (Figure 1A - 1F). Propanil and mixture-treated animals produced statistically similar ASC responses in the spleen, which suggests that the propanil component of the mixture is responsible for the increase in ASC in the spleen.

Previous studies had demonstrated that propanil treatment induces splenomegaly (Barnett and Gandy, 1989). The spleen weights were determined after herbicide exposure and HKSP vaccination. Propanil and the mixture of propanil and 2,4-D, but not 2,4-D alone, caused an increase in spleen weight at 7 and 10 days post-exposure (Figure 2). However, flow cytometric analysis of the major cell populations in the spleen at all time points determined that there were no significant changes in any of the treatment groups in the number of total $\mathrm{B} 220^{+} \mathrm{B}$ cells, $\mathrm{CD} 21 / 35^{\text {hi }} \mathrm{CD} 23^{\text {neg/low }}$ marginal zone $\mathrm{B}$ cells, CD21/35 ${ }^{\text {int }} \mathrm{CD} 23^{\text {hi }}$ follicular B cells, $\mathrm{CD} 4^{+} \mathrm{T}$ cells, and $\mathrm{CD} 8^{+} \mathrm{T}$ cells (Table 1 , representative data from day 7 post-exposure and vaccination). The total number of bone marrow cells was also comparable for the vehicle $\left(28.5 \pm 1.8 \times 10^{6}\right)$, propanil (27.6 $\left.\pm 3.5 \times 10^{6}\right), 2,4-\mathrm{D}\left(25.4 \pm 3.8 \times 10^{6}\right)$, and mixture treated groups $\left(27.4 \pm 3.2 \times 10^{6}\right)$. 
Additional experiments were performed to determine the dose response to propanil that enhanced the ASC response in the spleen. The lowest observed adverse effect level (LOAEL) dose of propanil that induced an increase in PC-specific ASC over control animals was $50 \mathrm{mg} / \mathrm{kg}$ (Figure $3 \mathrm{~A}-3 \mathrm{~F}$ ). A $25 \mathrm{mg} / \mathrm{kg}$ dose of propanil failed to increase the number of splenic ASC over control animals (Figure 3A-3F). A higher dose of propanil of $200 \mathrm{mg} / \mathrm{kg}$ increased the ASC response 4-6 fold, similar to the 150 $\mathrm{mg} / \mathrm{kg}$ dose (data not shown).

\section{Ex vivo splenic antibody production is increased in propanil-treated mice.}

To determine if there was a concomitant increase in antibody production from the spleens of animals that had an increase in ASC, spleens were harvested 7 days postexposure and immunization and cultured in vitro for 5 days. The supernatants were harvested and IgM and total IgG determined by ELISA. Spleen cells from propanil and mixture-treated animals produced antibody at concentrations 3-4 fold higher than spleen cells from the vehicle control or 2,4-D- treated animals (Figures 4A and 4B). Analyses performed from day 5 and day 10 post-exposure and immunization had similar results (data not shown).

\section{2,4-D decreased the number of PC-specific ASC in the bone marrow.}

The number of PC-specific ASC in the bone marrow was also measured on days

$3,5,7$, and 10 post-exposure and vaccination. Individual isotypes were not detectable in the bone marrow at days 3 and 5 after immunization. However, IgM and total IgG were detectable at the early time points (Figure 5A - 5D). 2,4-D and mixture herbicide exposure decreased the number of PC-specific IgM and IgG ASC in the bone marrow approximately 2 -fold by day 5 compared to the vehicle controls (Figure 5A - 5D). There 
was a significant decrease at days 7 and 10 (2-3 fold) in ASC in the bone marrow (Figures 5A - 5D). Propanil-treated animals had responses comparable to the vehicle controls at all time points (Figure 5A-5D). These results suggest that the 2,4-D component of the mixture is responsible for the reduction in ASC in the bone marrow. Propanil exposure did not increase the PC-specific titers, however 2,4-D exposure decreased the PC-specific titers.

PC-specific titers were measured to determine if the increase in ASC in the spleens of propanil-treated mice, or the decrease in bone marrow ASC in 2,4-D-treated mice, altered serum titers. Individual isotypes were not detectable at day 3. Propanil and vehicle control animals had comparable titers of $\operatorname{IgM}$, IgG2b, and $\operatorname{IgG} 3$ at 5, 7, and 10 days post-exposure and immunization (Figure 6A, 6B, and 6C). These results demonstrate that the increased splenic ASC in propanil-treated mice do not affect the serum antibody titers. However, 2,4-D and mixture treatments significantly reduced the PC-specific IgM, IgG2b, and IgG3 isotypes 3-4 fold from vehicle control and propaniltreated animals by day 10 (Figure 6A, 6B, and 6C). The serum titers of mixture and 2,4D-treated groups were not significantly different, indicating that 2,4-D is the chemical component of the mixture responsible for the decrease in titers. The results also indicate a correlation between the reduced bone marrow ASC response and the decrease in serum antibody levels.

\section{Herbicide exposure does not affect the antibody response to PspA.}

To determine if exposure to propanil, 2,4-D, or the mixture would affect the response to a TD antigen, mice were treated with the herbicides and vaccinated with HKSP. The peak serum antibody response to PspA has been demonstrated to be at 14 
days post-vaccination (Wu et al., 1999). The results demonstrate that the number of splenic IgM and total IgG PspA-specific ASC was comparable to the vehicle control in the propanil, 2,4-D and mixture-treated animals 14 days after herbicide exposure and vaccination with HKSP (Figure 7A - 7D). The PspA-specific serum antibody titers were also not affected by herbicide exposure and were comparable for all of the treatment groups (data not shown). The PspA-specific ASC in the bone marrow were below the limit of detection at day 14. 


\section{DISCUSSION}

Propanil and 2,4-D are immunotoxic herbicides commonly applied together as a mixture (Crop Protection Handbook, 2003; Farenhorst and Prokopowich, 2003). Previous findings have demonstrated that the two herbicides exert greater-than-additive immunotoxic effects on the primary immune organs, the thymus and bone marrow (de la Rosa et al., 2003; de la Rosa et al., 2005). However, the present study demonstrated that there was no subsequent effect on the mature lymphocyte populations in the spleen. The increase in total spleen cell number in the mixture-treated group is probably due to the presence of immature precursor cell populations as determined by differential analysis (not shown). Furthermore, increased immunotoxicity due to mixture exposure did not occur in the humoral response to HKSP examined in the present study. At the $150 \mathrm{mg} / \mathrm{kg}$ 1:1 mixture tested, the mixture combination failed to produce a greater-than-additive effect on ASC or the serum antibody levels. Splenic PC-specific ASC were increased to the same extent in both propanil and mixture-treated mice, suggesting that propanil was responsible for the increase in splenic ASC. Reduction in the number of bone marrow PC-specific ASC and serum antibody titers was dependent on 2,4-D treatment. These experiments indicate that propanil and 2,4-D modulate the immune response to vaccination with HKSP independently.

Propanil magnified the splenic PC-specific ASC response without altering the kinetics of the response or shifting the isotype composition. The earliest observed increase due to propanil exposure was 5 days post-exposure. Maximal effects were observed at day 7 and ASC decreased by day 10. Both T helper 1 (Th1) and Th2 cytokines alter the antibody response. IFN- $\gamma$, a Th1 cytokine, promotes IgG3 production 
and TGF- $\beta$, a Th2 cytokine, promotes a shift to IgG2b production (Stavnezer, 1996). The retention of the predominant PC-specific isotypes $\mathrm{IgG} 3$ and $\mathrm{IgG} 2 \mathrm{~b}$ suggests that propanil does not skew the cytokine profile of the immune response. The kinetics of the splenic antibody response in propanil and vehicle-treated animals were similar, suggesting that proliferation and activation is not unregulated as would be indicated by a continued increase in ASC at day 10.

Despite a several fold increase in the number of PC-specific ASC in the spleen, and an increased ex vivo production of PC-specific antibody by splenocytes from propanil-treated animals in comparison to the control, the serum antibody titers were comparable for the two groups. There are several possible explanations for this result. First, it is possible that the increased amount of antibody produced in propanil-treated animals remains localized to the spleen. Second, the antibodies produced in the spleen in propanil-treated mice may be rapidly catabolized if serum antibodies levels are at a saturated concentration, therefore no increase in serum titers would be detected. However, the second possibility is unlikely since mixture-treated animals also had increased splenic ASC but reduced serum titers. Several earlier reports established the bone marrow as the primary source of serum antibodies (reviewed in Benner et al., 1981). Exposure to propanil had no effect on the number of bone marrow PC-specific ASC. In contrast to propanil, 2,4-D decreased PC-specific ASC in the bone marrow and the decrease correlated with a decrease in PC-specific titers. Splenic ASC were comparable to control animals after 2,4-D exposure. Taken together, the results suggest that 2,4-D decreased serum PC-specific titers by decreasing bone marrow ASC and demonstrates the importance of bone marrow ASC for PC-specific titers during the 
primary response to HKSP. The ability of a chemical to decrease the number of plasma cells in the bone marrow could have long-term implications for maintaining circulating levels of protective antibody after immunizations.

In contrast to the results presented here, propanil exposure has previously been reported to suppress the number of plaque-forming cells after immunization with the TI-2 antigen DNP-Ficoll, and the TD antigen, SRBC (Barnett and Gandy, 1989; Barnett et al., 1992). The nature of the antigen may be important for the immunomodulation of the immune response by propanil. DNP-Ficoll and PC are both model TI-2 antigens. However, in the present study, PC is presented in the context of whole HKSP, a complex particulate immunogen. It was previously demonstrated that the requirements for the humoral response to PC, after immunization with HKSP, is substantially different than after immunization with purified polysaccharide preparations (Wu et al., 1999). Although the PC antibody response is classically considered to be T-independent, Wu et $a l$, (1999) demonstrated that the IgG isotype responses to PC after immunization with HKSP was decreased in T cell receptor $\beta$ knock-out mice. In addition, they demonstrated that $\mathrm{CD}^{+} \mathrm{T}$ cells and $\mathrm{CD}^{+} \mathrm{T}$ cells contributed to an optimal antibody response, and the PC response was significantly decreased in CD40L knockout mice (Wu et al., 1999). Further studies demonstrated that noncognate $\mathrm{T}$ cell help was required for an optimal PC response after HKSP immunization (Wu et al., 2002). Therefore, propanil could affect one of the components necessary for the response to PC after immunization with HKSP that is not required after immunization with soluble DNP-Ficoll.

The time of exposure to the herbicide may also be important to the subsequent effects on the immune response. In the previous studies that demonstrated propanil 
suppressed the plaque-forming cell response to SRBC and DNP-Ficoll, the antigens were administered 3 days after propanil exposure (Barnett and Gandy, 1989; Barnett et al., 1992). In the present study, propanil was administered at the time of HKSP vaccination. This may suggest that propanil is acting as an adjuvant to affect innate immune mechanisms and enhance the immune response to PC.

The antibody response to vaccination with HKSP is influenced by the early innate immune response. S. pneumoniae has pathogen associated molecular patterns on its surface that can stimulate signaling pathways through pattern recognition receptors such as toll-like receptor-2 (TLR2) (Yoshimura et al., 1999). It was recently demonstrated that the IgG2b and IgG3 antibody response to PC after immunization with heat-killed $S$. pneumoniae type 14 is decreased in TLR-2 knockout mice (Khan et al., 2005). The complement pathways are also important for the innate immune response to $S$. pneumoniae that can influence the subsequent adaptive immune response (Brown et al., 2002). Conjugation of the complement component, C3d, to pneumococcal capsular polysaccharide, has been demonstrated to enhance the antibody response to the polysaccharide dependent on the dose of antigen (Test et al., 2001). Similarly, preliminary studies in our laboratory suggest that the dose of HKSP is important, as mice vaccinated with suboptimal doses of HKSP did not have an increase in ASC. The effect of propanil on specific components of the innate immune response has not been investigated.

Propanil may alter the immune response through interactions with the endocrine system. Propanil induces thymic atrophy primarily through the induction of glucocorticoids, however, inhibition of glucocorticoid production does not completely 
abrogate thymic atrophy (Cuff et al., 1996; de la Rosa et al., 2005). In addition, glucocorticoids are reported to inhibit Th1 responses and enhance Th2 responses (Ashwell et al., 2000; Miyaura and Iwata, 2002). Propanil did not alter the major isotype response to $\mathrm{PC}$, which suggests that the $\mathrm{T}$ cell response and subsequent production of cytokines driving B cell switching was not affected. This suggests that additional mediators may play a role in the immunotoxic effects of propanil. Propanil also decreases the pre- $\mathrm{B}$ cell and $\operatorname{IgM}^{+} \mathrm{B}$ cell populations in the bone marrow via an unknown mechanism (de la Rosa et al., 2003). Similar to propanil, 17ß-estradiol exposure has been shown to induce thymic atrophy and decrease immature B cell populations in the bone marrow (Erlandsson et al., 2003). Chronic exposure to $17 \beta$-estradiol has been reported to increase ASC to bacterial and autoantigens in C57BL/6 mice (Verthelyi and Ahmed, 1998). In addition, exposure to $17 \beta$-estradiol was demonstrated to increase activation of the marginal zone B cell population and lead to the production of autoantibodies by the marginal zone B cells (Grimaldi et al., 2001). Marginal zone B cells are crucial in the generation of the immune response to TI- 2 antigens (reviewed in Zandvoort and Timens, 2002). Mice deficient in marginal zone B cells have a deficient antibody response to TI-2 antigens (Guainamard et al., 2000). If propanil induced the production of $17-\beta$ estradiol it could enhance the antibody response to $\mathrm{PC}$ through the effects of $17-\beta$ estradiol on the marginal zone B cell population. Preliminary studies in our laboratory have demonstrated that propanil does not increase the number of PCspecific splenic ASC in ovariectomized mice suggesting an important potential role for 17ß-estradiol. 
The mechanism by which 2,4-D decreased the bone marrow PC-specific ASC is unknown. However, there are several possibilities. Homing of plasma cells from the spleen to the bone marrow is dependent on the expression of the chemokine receptor, CXCR4, on splenic plasma cells and its ligand, CXCL12, in the bone marrow (Erickson et al., 2003). The splenic ASC in 2,4-D-treated mice could be defective in the expression of CXCR4. It is also possible that production of CXCL12 in the bone marrow could be defective. Finally, support of plasma cells in the bone marrow could be affected due to damage to the bone marrow microenvironment.

In contrast to the effect on the TI-2 antigen, PC, exposure to propanil, 2,4-D or the mixture had no effect on the response to the TD antigen, PspA. The number of PspAspecific ASC in the spleen and the serum titers to PspA were comparable to the controls for all of the treatment groups. This could suggest that the effects of both propanil and 2,4-D occur early after vaccination when the TI-2 antigen response is being generated. If propanil has effects on the innate immune system or on marginal zone B cells which are critical to the response to TI-2 antigens, as discussed above, the effects may not impact the subsequent response to the TD antigen, PspA. A second possibility is that the time of exposure to the herbicides during the immune response to each antigen is critical. In the experiments presented here, herbicide exposure was on the day of HKSP vaccination. The peak response to $\mathrm{PC}$ was determined 7 days post-exposure while the peak response to PspA is at day 14. If the herbicides mediate their effect during the time antigenspecific B cells are undergoing activation or expansion, and the effect is short-term, then the later response to PspA may not be affected. Similar to PspA, propanil exposure does 
not increase the number of splenic IgM ASC to SRBC, another TD antigen, when administered at the time of SRBC immunization (de la Rosa, unpublished results).

As the use of herbicides escalates, it is necessary to have an accurate understanding of the risks associated with their use. This report illustrates the importance of studying immunotoxic effects using naturally occurring microbial pathogens and the diverse effects that different compounds can have. The enhanced antibody response after exposure to propanil has implications for the potential of this class of compounds to be environmental factors in autoimmune disease. In contrast, other compounds, such as 2,4$\mathrm{D}$, may impair the ability of the host to mount an appropriate protective immune response after vaccination. 


\section{ACKNOWLEDGEMENTS}

This work was supported by the National Institutes of Health grants ES07460 and ES010953. The Flow Cytometric Core Facility is supported by the National Institutes of Health grant RR16440.

We thank Clifford M. Snapper, M.D. (Department of Pathology, Uniformed Services University of the Health Sciences, Bethesda, MD) for the generous gift of recombinant PspA. We thank Meenal Elliott, Ph.D. for the S. pneumoniae strain R36A, Cheryl L. Walton for excellent technical assistance, and Kathleen Brundage, Ph.D. for helpful discussion and reading of the manuscript (all from the Department of Microbiology, Immunology and Cell Biology, Robert C. Byrd Health Sciences Center, West Virginia University). 


\section{REFERENCES}

1. Ashwell, J. D., Lu, F. W., and Vacchio, M. S. (2000). Glucocorticoids in T cell development and function. Ann. Rev. Immunol. 18, 309-345.

2. Barnett, J. B. and Gandy, J. (1989). Effect of acute propanil exposure on the immune response of C57B1/6 mice. Fundam. Appl. Toxicol. 12, 757-764.

3. Barnett, J. B., Gandy, J., Wilbourn, D., and Theus, S. A. (1992). Comparison of the immunotoxicity of propanil and its metabolite, 3,4-dichloroaniline, in C57B1/6 mice. Fundam. Appl. Toxicol. 18, 628-631.

4. Benner, R., Hijmans, W., and Haaijman, J. J. (1981). The bone marrow: the major source of serum immunoglobulins, but still a neglected site of antibody formation. Clin. Exp. Immunol. 46, 1-8.

5. Blakley, B. R. (1986). The effect of oral exposure to the n-butylester of 2,4dichlorophenoxyacetic acid on the immune response in mice. Int. J. Immunopharmacol. 8, 93-99.

6. Blakley, B. R. (1997). Effect of roundup and tordon 202C herbicides on antibody production in mice. Vet. Hum. Toxicol. 39, 204-206.

7. Bogaert, D., Hermans, P. W., Adrian, P. V., Rumke, H. C., and De Groot, R. (2004). Pneumococcal vaccines: an update on current strategies. Vaccine 22, 2209-2220.

8. Brown, J. S., Hussell, T., Gilliland, S. M., Holden, D. W., Paton, J. C., Ehrenstein, M. R., Walport, M. J., and Botto, M. (2002). The classical pathway is the dominant 
complement pathway required for innate immunity to Streptococcus pneumoniae infection in mice. Proc. Natl. Acad. Sci. U.S.A 99, 16969-16974.

9. Crop Protection Handbook, Meister, Willoughby, OH. (2003)

10. Cuff, C. F., Zhao, W., Nukui, T., Schafer, R., and Barnett, J. B. (1996). 3,4Dichloropropionanilide-induced atrophy of the thymus: mechanisms of toxicity and recovery. Fundam. Appl. Toxicol. 33, 83-90.

11. Cundell, D. R., Gerard, N. P., Gerard, C., Idanpaan-Heikkila, I., and Tuomanen, E. I. (1995). Streptococcus pneumoniae anchor to activated human cells by the receptor for platelet-activating factor. Nature $\mathbf{3 7 7}, 435-438$.

12. de la Rosa, P., Barnett, J., and Schafer, R. (2003). Loss of pre-B and $\operatorname{IgM(+)~B~cells~}$ in the bone marrow after exposure to a mixture of herbicides. J. Toxicol. Environ. Health A 66, 2299-2313.

13. de la Rosa, P., Barnett, J. B., and Schafer, R. (2005). Characterization of thymic atrophy and the mechanism of thymocyte depletion after in vivo exposure to a mixture of herbicides. J. Toxicol. Environ. Health A 68, 81-98.

14. Dhanjal, M. K., Towler, A. E., Tuft, S., Hetzel, C., Richards, D., and Kemeny, D. M. (1992). The detection of IgE-secreting cells in the peripheral blood of patients with atopic dermatitis. J. Allergy Clin. Immunol. 89, 895-904. 
15. Erickson, L. D., Lin, L. L., Duan, B., Morel, L., and Noelle, R. J. (2003). A genetic lesion that arrests plasma cell homing to the bone marrow. Proc. Natl. Acad. Sci. U.S.A 100, 12905-12910.

16. Erlandsson, M. C., Jonsson, C. A., Islander, U., Ohlsson, C., and Carlsten, H. (2003). Oestrogen receptor specificity in oestradiol-mediated effects on B lymphopoiesis and immunoglobulin production in male mice. Immunology $\mathbf{1 0 8 ,}$ 346-351.

17. Farenhorst, A. and Prokopowich, B. (2003). The effect of propanil co-application on 2,4-D sorption by soil. J. Environ. Sci. Health B 38, 713-721.

18. Faustini, A., Settimi, L., Pacifici, R., Fano, V., Zuccaro, P., and Forastiere, F. (1996). Immunological changes among farmers exposed to phenoxy herbicides: preliminary observations. Occup. Environ. Med. 53, 583-585.

19. Grimaldi, C. M., Michael, D. J., and Diamond, B. (2001). Cutting edge: expansion and activation of a population of autoreactive marginal zone B cells in a model of estrogen-induced lupus. J. Immunol. 167, 1886-1890.

20. Guinamard, R., Okigaki, M., Schlessinger, J., and Ravetch, J. V. (2000). Absence of marginal zone B cells in Pyk-2-deficient mice defines their role in the humoral response. Nat Immunol. 1, 31-6.

21. Khan, A. Q., Chen, Q., Wu, Z. Q., Paton, J. C., and Snapper, C. M. (2005). Both innate immunity and type 1 humoral immunity to Streptococcus pneumoniae are 
mediated by MyD88 but differ in their relative levels of dependence on toll-like receptor 2. Infect. Immun. 73, 298-307.

22. Miyaura, H. and Iwata, M. (2002). Direct and indirect inhibition of Th1 development by progesterone and glucocorticoids. J. Immunol. 168, 1087-1094.

23. Munro, I. C., Carlo, G. L., Orr, J. C., Sund, K. G., Wilson, R. M., Kennepohl, E., Lynch, B. $\quad$ S., Jablinske, M., and Lee, N. L. (2002). A comprehensive, integrated review and evaluation of the scientific evidence relating to the safety of the herbicide 2,4-D. J. Am. Coll. Toxicol. 11, 559-663.

24. Oliver, A. M., Martin, F., Gartland, G. L., Carter, R.H., Kearney, J.F. (1997). Marginal zone B cells exhibit unique activation, proliferative and immunoglobulin secretory responses. Eur. J. Immunol. 27, 2366-2374.

25. Short, P. and Colborn, T. (1999). Pesticide use in the U.S. and policy implications: a focus on herbicides. Toxicol. Ind. Health 15, 240-275.

26. Stavnezer, J. (1996). Immunoglobulin class switching. Curr. Opin. Immunol. 8, 199-205.

27. Test, S. T., Mitsuyoshi, J., Connolly, C. C., and Lucas, A. H. (2001). Increased immunogenicity and induction of class switching by conjugation of complement C3d to pneumococcal serotype 14 capsular polysaccharide. Infect. Immun. 69, 3031-3040. 
28. Tu, A. H., Fulgham, R. L., McCrory, M. A., Briles, D. E., and Szalai, A. (1999). Pneumococcal surface protein A inhibits complement activation by Streptococcus pneumoniae. J. Infect. Immun. 67, 4720-4.

29. Tuomanen, E. I., Austrian, R., and Masure, H. R. (1995). Pathogenesis of pneumococcal infection. N. Engl. J. Med. 332, 1280-1284.

30. Verheul, A. F., Versteeg, A. A., Westerdaal, N. A., Van Dam, G. J., Jansze, M., and Snippe, H. (1990). Measurement of the humoral immune response against Streptococcus pneumoniae type 14-derived antigens by an ELISA and ELISPOT assay based on biotin-avidin technology. J. Immunol. Methods 126, 79-87.

31. Verthelyi, D. I. and Ahmed, S. A. (1998). Estrogen increases the number of plasma cells and enhances their autoantibody production in nonautoimmune C57BL/6 mice. Cell Immunol. 189, 125-134.

32. Wu, Z. Q., Khan, A. Q., Shen, Y., Schartman, J., Peach, R., Lees, A., Mond, J. J., Gause, W. C., and Snapper, C. M. (2000). B7 requirements for primary and secondary protein- and polysaccharide-specific Ig isotype responses to Streptococcus pneumoniae. J. Immunol. 165, 6840-6848.

33. Wu, Z. Q., Shen, Y., Khan, A. Q., Chu, C. L., Riese, R., Chapman, H. A., Kanagawa, O., and Snapper, C. M. (2002). The mechanism underlying T cell help for induction of an antigen-specific in vivo humoral immune response to intact Streptococcus pneumoniae is dependent on the type of antigen. J. Immunol. 168, $5551-5557$ 
34. Wu, Z. Q., Vos, Q., Shen, Y., Lees, A., Wilson, S. R., Briles, D. E., Gause, W. C., Mond, J. J., and Snapper, C. M. (1999). In vivo polysaccharide-specific IgG isotype responses to intact Streptococcus pneumoniae are T cell dependent and require. $J$. Immunol. 163, 659-667.

35. Xie, Y. C., Schafer, R., and Barnett, J. B. (1997). The immunomodulatory effects of the herbicide propanil on murine macrophage interleukin- 6 and tumor necrosis factor-alpha production. Toxicol. Appl. Pharmacol. 145, 184-191.

36. Yoshimura, A., Lien, E., Ingalls, R. R., Tuomanen, E., Dziarski, R., and Golenbock, D. (1999). Cutting edge: recognition of Gram-positive bacterial cell wall components by the innate immune system occurs via Toll-like receptor 2 . J. Immunol. 163, 1-5.

37. Zandvoort, A. and Timens, W. (2002). The dual function of the splenic marginal zone: essential for initiation of anti-TI-2 responses but also vital in the general firstline defense against blood-borne antigens. Clin. Exp. Immunol. 130, 4-11.

38. Zhao, W., Schafer, R., and Barnett, J. B. (1998). Cytokine production by C57BL/6 mouse spleen cells is selectively reduced by exposure to propanil. J. Toxicol. Environ. Health A 55, 107-120. 


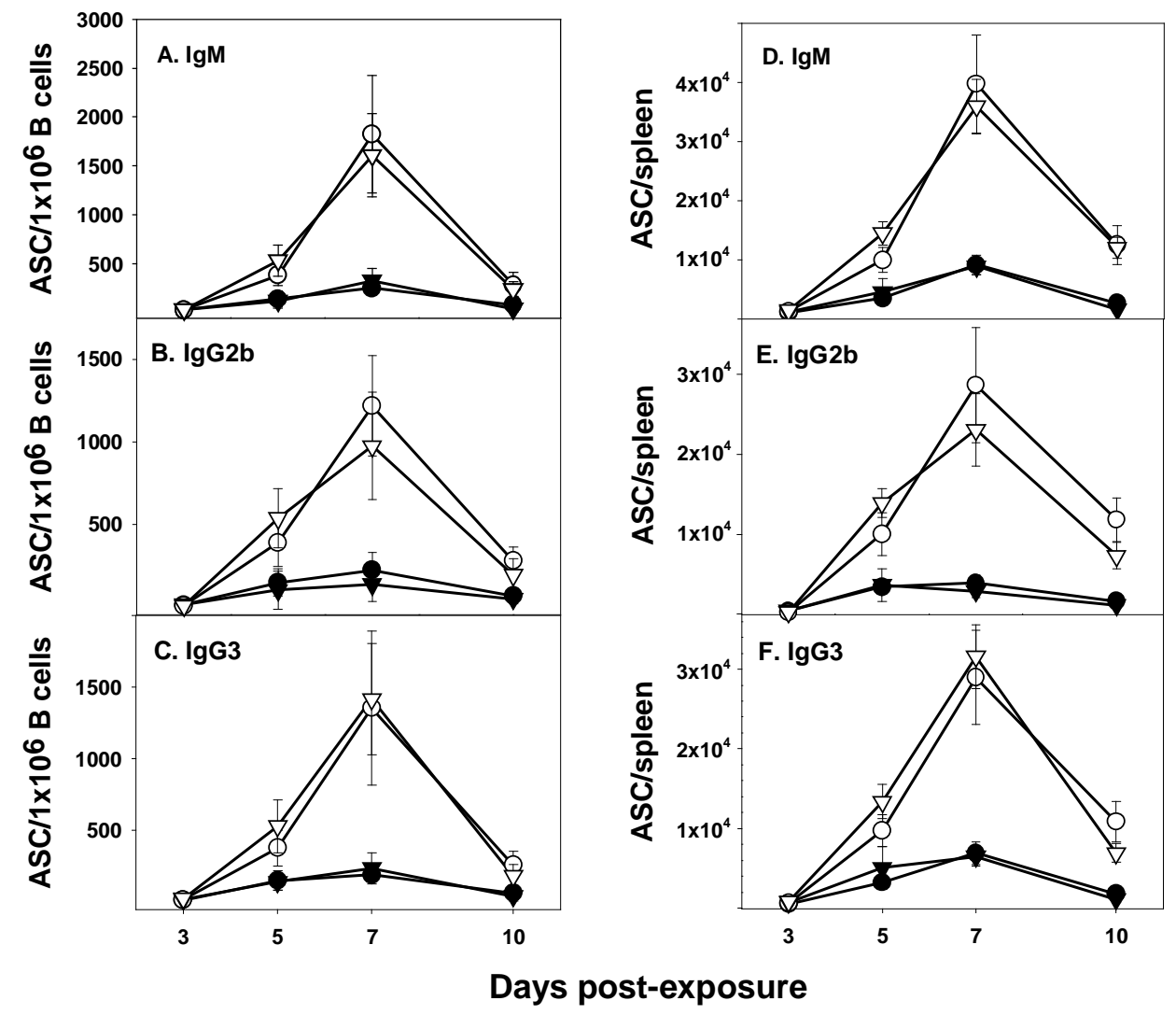

$$
\begin{aligned}
& \text { - Vehicle } \\
& - \text { - Propanil } \\
& - \text { 2,4-D } \\
& -\nabla-\text { Propanil/ 2,4-D }
\end{aligned}
$$

Figure 1. Propanil and mixture exposure increases the number of PC-specific ASC in the spleen.

C57BL/6 mice (5/group) were vaccinated with HKSP $\left(2 \times 10^{8} \mathrm{CFU} /\right.$ mouse $)$ and treated with vehicle control, $150 \mathrm{mg} / \mathrm{kg}$ propanil, $150 \mathrm{mg} / \mathrm{kg}$ 2,4-D, or a 150/150 mixture. Spleens were removed at days 3, 5, 7, and 10. Numbers of PC-specific IgM (A, D), $\operatorname{IgG} 2 \mathrm{~b}(\mathrm{~B}, \mathrm{E})$, and $\operatorname{IgG} 3(\mathrm{C}, \mathrm{F})$ ASC were determined by ELISPOT assay. All values represent the mean \pm SD of ASC per $1 \times 10^{6} \mathrm{~B}$ cells $(\mathrm{A}, \mathrm{B}$, and C) or per spleen (D, E, F). Propanil and mixture treatments are significantly different from vehicle control on days $5,7,10$ for $\operatorname{IgM}$, IgG2b, and $\operatorname{IgG} 3, \mathrm{p} \leq .05$. 


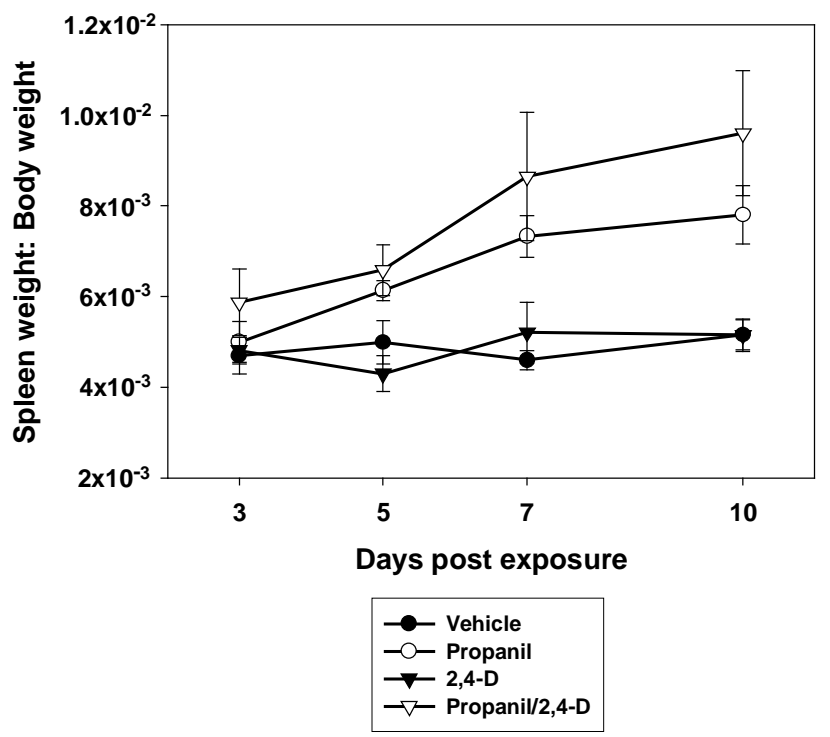

Figure 2. Propanil and mixture exposure increase spleen weight.

C57BL/6 mice (5/group) were vaccinated with $\mathrm{HKSP}\left(2 \times 10^{8} \mathrm{CFU} /\right.$ mouse $)$ and treated with vehicle control, $150 \mathrm{mg} / \mathrm{kg}$ propanil, $150 \mathrm{mg} / \mathrm{kg}$ 2,4-D, or a 150/150 mixture.

Spleens were removed at days 3, 5, 7, and 10 and the wet weights determined. Results are expressed as the ratio of spleen weight to body weight. Propanil and mixture treatments are significantly different from vehicle control on days $5,7,10, \mathrm{p} \leq .05$. 
Table 1. Spleen cell populations 7 days after herbicide exposure and HKSP vaccination.

\begin{tabular}{|c|c|c|c|c|c|c|}
\hline Treatment $^{\mathrm{a}}$ & Total cells $^{b}$ & $\begin{array}{l}\text { B220 } \\
\text { B cells }\end{array}$ & $\begin{array}{l}\text { Marginal zone } \\
\text { B cells }\end{array}$ & $\begin{array}{l}\text { Follicular } \\
\text { B cells }\end{array}$ & $\mathrm{CD}^{+} \mathrm{T}$ cells & $\mathrm{CD}^{+} \mathrm{T}$ cells \\
\hline Vehicle & $80 \pm 13.6$ & $30 \pm 3.6^{\mathrm{d}}$ & $1.9 \pm 0.25$ & $20 \pm 3.8$ & $18 \pm 5.1$ & $11 \pm 3.7$ \\
\hline Propanil & $108 \pm 31.8$ & $34 \pm 6.4$ & $2.1 \pm 0.31$ & $23 \pm 4.2$ & $22 \pm 5.9$ & $15 \pm 3.5$ \\
\hline $2,4-\mathrm{D}$ & $76 \pm 17.6$ & $33 \pm 7.7$ & $1.8 \pm 0.42$ & $22 \pm 4.9$ & $18 \pm 5.0$ & $12 \pm 3.5$ \\
\hline Propanil/2,4-D & $143 \pm 35.7^{\mathrm{e}}$ & $40 \pm 5.4$ & $2.1 \pm 0.43$ & $26 \pm 2.4$ & $27 \pm 3.1$ & $17 \pm 0.9$ \\
\hline
\end{tabular}

${ }^{\mathrm{a}}$ C57BL/6 mice (5/group) were vaccinated with HKSP and treated with vehicle, 150 $\mathrm{mg} / \mathrm{kg}$ propanil, $150 \mathrm{mg} / \mathrm{kg} \mathrm{2,4-D}$, or a $150 / 150 \mathrm{mg} / \mathrm{kg}$ mixture of propanil and 2,4-D. Spleens were harvested on day 7.

${ }^{\mathrm{b}}$ Total number of spleen cells $\left(\mathrm{x} 10^{6}\right) \pm \mathrm{SD}$.

${ }^{c}$ Individual cell populations were determined by flow cytometric analysis as described in the Methods.

${ }^{d}$ Data represents the total number of cells $\left(\times 10^{6}\right) \pm$ SD.

${ }^{\mathrm{e}} \mathrm{p} \leq 0.05$ versus vehicle control. 

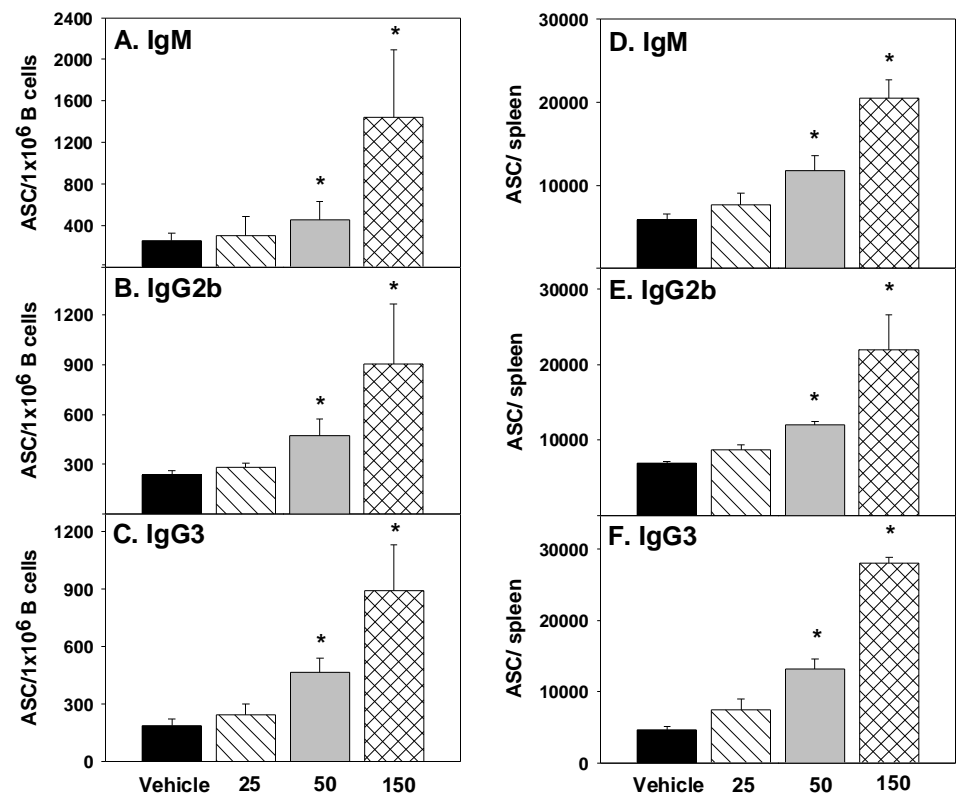

Figure 3. Propanil increases the number of splenic ASC in a dose dependent manner.

C57BL/6 mice (5/group) were vaccinated with HKSP $\left(2 \times 10^{8} \mathrm{CFU} /\right.$ mouse $)$ and treated with vehicle control (0), $25 \mathrm{mg} / \mathrm{kg}, 50 \mathrm{mg} / \mathrm{kg}$, and $150 \mathrm{mg} / \mathrm{kg}$ propanil. Spleens were removed at day 7. Numbers of PC-specific $\operatorname{IgM}(\mathrm{A}, \mathrm{D}), \operatorname{IgG} 2 \mathrm{~b}(\mathrm{~B}, \mathrm{E})$, and $\operatorname{IgG} 3(\mathrm{C}, \mathrm{F})$ ASC were determined by ELISPOT assay. All values represent the mean \pm SD of ASC per $1 \times 10^{6} \mathrm{~B}$ cells $(\mathrm{A}, \mathrm{B}$, and $\mathrm{C})$ or per spleen $(\mathrm{D}, \mathrm{E}, \mathrm{F})$. The asterisk $\left(^{*}\right)$ represents a significant difference $(\mathrm{p} \leq .05)$ from vehicle control. 


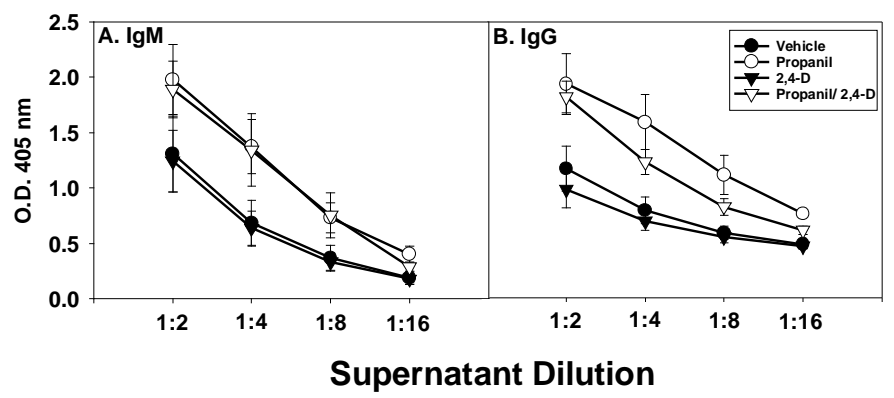

Figure 4. Propanil and mixture exposure increases ex vivo antibody production by splenocytes following HKSP vaccination.

C57BL/6 mice (5/group) were vaccinated with HKSP $\left(2 \times 10^{8} \mathrm{CFU} / \mathrm{mouse}\right)$ and treated with vehicle control, $150 \mathrm{mg} / \mathrm{kg}$ propanil, $150 \mathrm{mg} / \mathrm{kg}$ 2,4-D, or a 150/150 mixture.

Spleens were harvested on day 7 and cultured in vitro for 5 days. Antibody supernatants were collected and analyzed by ELISA. De novo PC-specific $\operatorname{IgM}(\mathrm{A})$ and $\operatorname{IgG}(\mathrm{B})$ production was determined by subtracting cycloheximide treated samples from the total antibody produced. Values represent the mean de novo antibody produced $\pm \mathrm{SD}$. Propanil and mixture treatments are significantly different from vehicle control at dilutions $1: 2,1: 4$, and 1:8 for $\operatorname{IgM}$ and $\operatorname{IgG}, \mathrm{p} \leq .05$. 


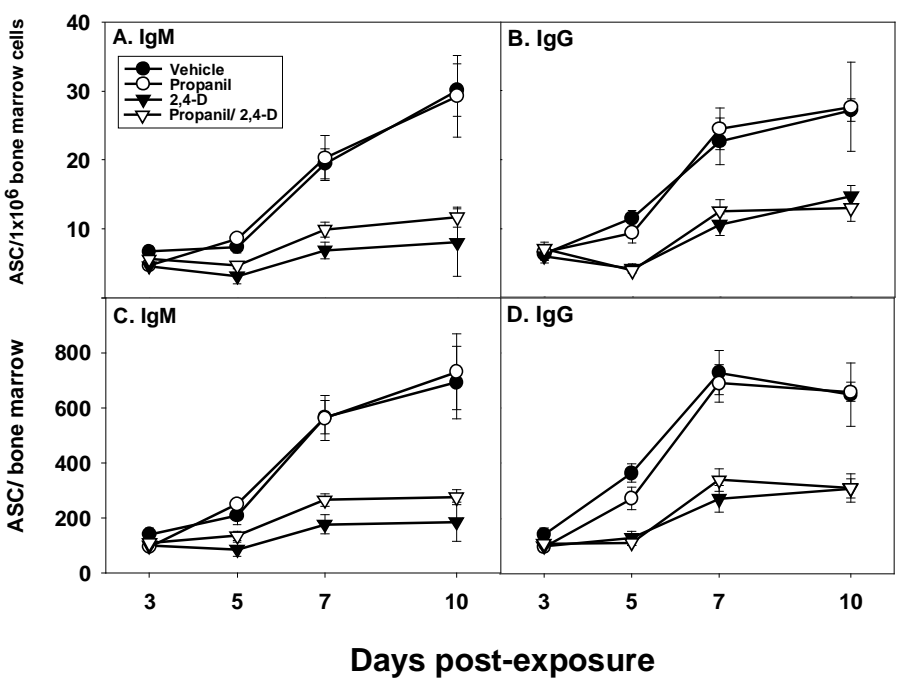

Figure 5. 2,4-D and mixture exposure decreases the number of PC-specific bone marrow ASC.

C57BL/6 mice (5/group) were vaccinated with HKSP $\left(2 \times 10^{8} \mathrm{CFU} /\right.$ mouse $)$ and treated with vehicle control, $150 \mathrm{mg} / \mathrm{kg}$ propanil, $150 \mathrm{mg} / \mathrm{kg}$ 2,4-D, or a 150/150 mixture. Bone marrow was harvested on days $3,5,7,10$. Numbers of PC-specific $\operatorname{IgM}(\mathrm{A}, \mathrm{C})$ and $\operatorname{IgG}$ (B, D) ASC were determined by ELISPOT assay. Values represent the mean $\pm \mathrm{SD}$ of ASC per $1 \times 10^{6}$ bone marrow cells (A, B) or per total bone marrow (D, E). 2,4-D and mixture treatments are significantly different from vehicle control on days 5,7 , and 10 for $\operatorname{IgM}$ and $\operatorname{IgG}, \mathrm{p} \leq .05$. 

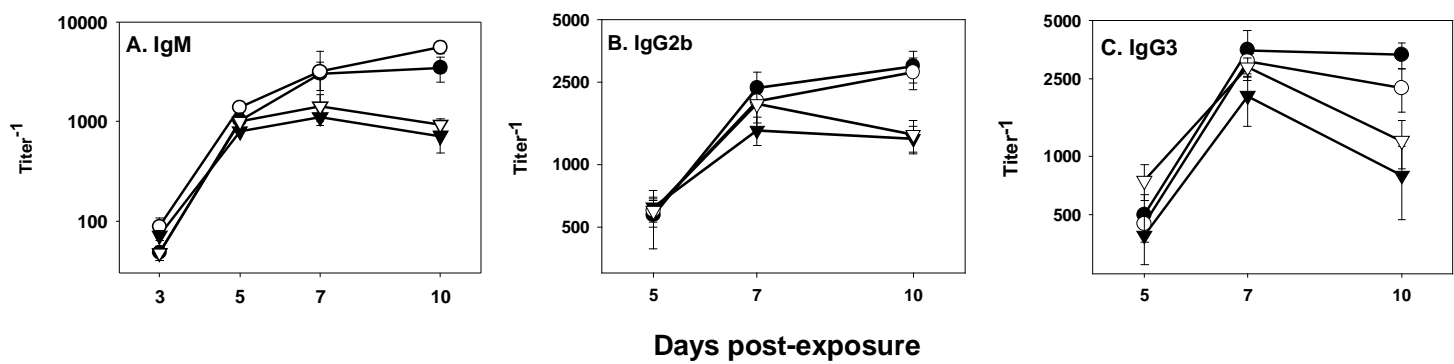

Figure 6. 2,4-D and mixture exposure decreases PC-specific titers.

C57BL/6 mice (5/group) were vaccinated with $\mathrm{HKSP}\left(2 \times 10^{8} \mathrm{CFU} /\right.$ mouse $)$ and treated with vehicle control, $150 \mathrm{mg} / \mathrm{kg}$ propanil, $150 \mathrm{mg} / \mathrm{kg}$ 2,4-D, or a 150/150 mixture. Serum was collected on days $3,5,7,10$. The titers of PC-specific IgM (A), IgG2b (B), and $\mathrm{IgG} 3(\mathrm{C})$ were determined by ELISA. Values represent the mean \pm SEM. 2,4-D and mixture treatments are significantly different from vehicle control at day 10 for IgM and $\operatorname{IgG}, \mathrm{p} \leq .05$. 


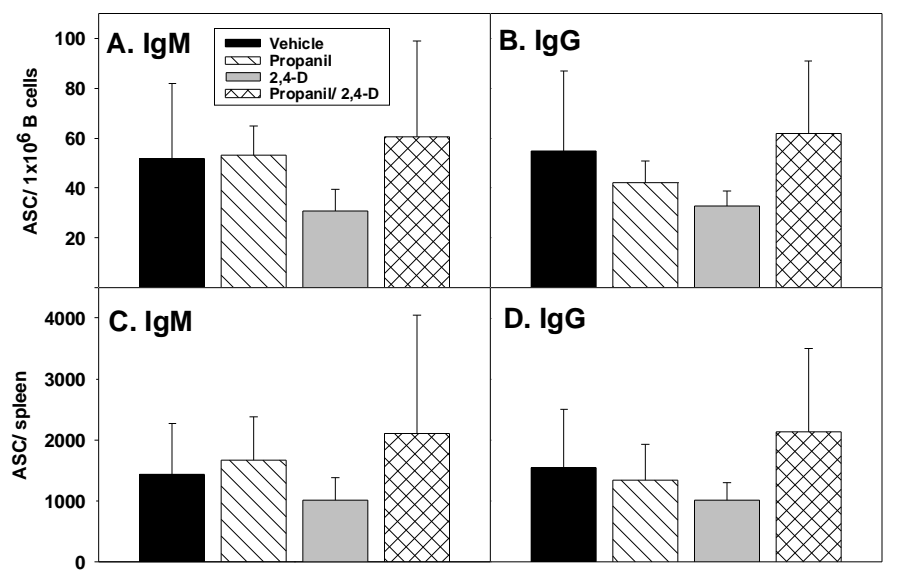

Figure 7. Herbicide exposure has no effect on the number of splenic PspA-specific ASC.

C57BL/6 mice (5/group) were vaccinated with HKSP $\left(2 \times 10^{8} \mathrm{CFU} / \mathrm{mouse}\right)$ and treated with vehicle control, $150 \mathrm{mg} / \mathrm{kg}$ propanil, $150 \mathrm{mg} / \mathrm{kg}$ 2,4-D, or a 150/150 mixture.

Spleens were harvested on day 14. Numbers of PspA-specific $\operatorname{IgM}(A, C)$ and $\operatorname{IgG}(B$, D) ASC were determined by ELISPOT assay. Values represent the mean $\pm \mathrm{SD}$ of ASC per $1 \times 10^{6}$ B cells $(A, B)$ or per spleen $(C, D)$. 


\section{CHAPTER 4: FURTHER CHARACTERIZATION OF THE EFFECT OF PROPANIL EXPOSURE ON THE HUMORAL IMMUNE RESPONSE}




\section{INTRODUCTION}

Previous studies demonstrated that propanil enhances the antibody response to the TI-2 antigen PC when presented on the surface of killed whole bacteria (de la Rosa, 2005). However, propanil did not increase the number of ASC to the TD antigen PspA on day 14 in mice that were vaccinated and treated with herbicides on day 0 (de la Rosa, 2005). In addition, the increased number of PC-specific ASC in propanil-treated animals did not cause an elevated response in PC-specific serum titers. The following experiments were performed to answer a number of questions raised from these findings that are important in determining the immune-based mechanisms involved in enhancing the humoral response.

The context in which the antigen is presented to the immune system can alter the response in a number of ways. For example, S. pneumoniae contains a number of pathogen associated molecular patterns (PAMPS) that are recognized by Toll-like receptors (Sen et al., 2005). TLR have been shown to be important for enhanced antibody responses (Sen et al., 2006). Processing and presentation by the APCs differs in mice immunized with particulate or soluble antigens (Ramachandra et al., 1999). An example of a soluble antigen that induces a TI-2 PC-specific response independent of TLR activation is PC-Ficoll. The following experiments utilized PC-Ficoll to evaluate the importance of soluble versus particulate antigens in the ability of propanil to enhance the immune response.

The inability of propanil to increase the number of PspA-specific ASC suggests that propanil may induce changes on a specific subset of B cells responsible for TI-2 responses and the effect is independent of T-cell help. Alternatively, propanil may 
enhance the antibody response only within a limited timeframe following herbicide exposure. For example, immunization of mice with DNP-Ficoll 3 days following propanil exposure suppresses the antibody response on day 7 (Barnett et al., 1992). Given that the PspA response is not measurable until day 6 and peaks around 10-14 days, it is possible that propanil, which is eliminated from the body within 2 days, may not remain in the animal long enough to enhance the PspA response (Izmerov, 1984). Experiments were also performed to determine the effect of exposure to herbicides at different time points following HKSP immunization on the PspA response.

The inability of propanil to increase serum titers despite a robust enhancement of the splenic response and increased ex vivo antibody production suggest a number of explanations. Antibody catabolism has been discussed in Chapter 3. Alternatively, the increased antibodies may not exit the spleen into the serum due to binding of the antibodies to HKSP in the spleen. Finally, the serum antibody titers may be increased at a later time point. Experiments were performed to examine these possibilities.

\section{METHODS}

\section{Animals}

Six to eight week old C57B1/6 female mice were purchased from Hill Top Lab Animals (Scottdale, PA). Mice were housed in microisolator cages in pathogen free conditions at West Virginia University’s animal facility. Mice were kept on a $12 \mathrm{hr}$ lightdark cycle and allowed to acclimate to the facility for 1 week. These studies were conducted in accordance with all federal and institutional guidelines for animal use and 
were approved by the West Virginia University Institutional Animal Care and Use Committee.

\section{Reagents}

Propanil (3,4-dichloropropionanilide, 99\% pure) was purchased from Chem Service (West Chester, PA). PC-Ficoll containing 6 PC molecules per molecule of Ficoll was purchased from Biosearch Technologies (Novato, CA). PC-KLH containing 15 PC molecules per molecule of Ficoll was purchased from Biosearch Technologies.

\section{Bacterial preparation and immunization with $\mathbf{R} 36 \mathrm{~A}$}

S. pneumoniae strain R36A, an avirulent, nonencapsulated strain, was grown to mid-log phase in Todd-Hewitt broth (Becton Dickinson, Sparks, MD) $+.05 \%$ yeast extract (Becton Dickinson) and stored at $-80^{\circ} \mathrm{C}$. For immunization, stock was cultured in a candle jar for $18 \mathrm{hrs}$ at $37^{\circ} \mathrm{C}$ on blood agar plates (Becton Dickinson). A few characteristic colonies were selected and suspended in $200 \mathrm{ml}$ Todd-Hewitt broth $+.05 \%$ yeast extract. Bacteria were grown at $37^{\circ} \mathrm{C}$ to an absorbance reading at $650 \mathrm{~nm}$ of 0.4 and heat killed for 4 hours in a $60^{\circ} \mathrm{C}$ water bath. A final concentration of $10^{9} \mathrm{CFU} / \mathrm{ml}$ was established in PBS based on colony counts. Sterility was confirmed by culture. Heatkilled stock was stored at $-20^{\circ} \mathrm{C}$ in $1 \mathrm{ml}$ aliquots. Mice were immunized ip with either $5 \times 10^{6}$ or $2 \times 10^{8}$ CFU.

\section{Animal exposures}

Propanil was dissolved in peanut oil for a final concentration of $15 \mathrm{mg} / \mathrm{ml}$ for all experiments. Mice (5/group) were treated ip with either $150 \mathrm{mg}$ of propanil/kg of body weight $(\mathrm{mg} / \mathrm{kg})$ or vehicle on the same day as immunization. For PC-Ficoll, mice were

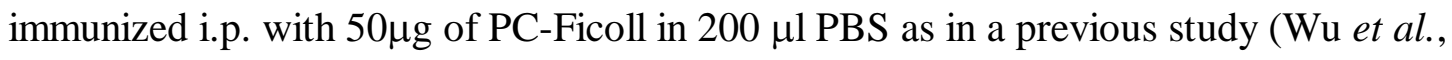


1999). For PC-KLH immunizations, mice were immunized i.p. with $100 \mu \mathrm{g}$ of PC-KLH in $200 \mu \mathrm{lPBS}$.

\section{Preparation of splenocytes}

Mice were euthanized with $100 \mu \mathrm{l}$ Nembutal Sodium Solution $(50$ mg/ml, Abbott Laboratories, North Chicago, IL) vaccination. Spleen wet weights were recorded. Spleens were mechanically dissociated through Spectra nylon mesh (Spectrum Labs, Rancho Dominguez, CA) in complete cell media containing RPMI-1640 (BioWhitaker, Walkersville, MD), $10 \%$ heat inactivated fetal bovine serum (FBS, Hyclone Laboratories, Inc, Logan, UT), 10 mM HEPES (Sigma), 1 mM L- glutamine (Gibco, Rockville, MD), $5 \times 10^{-5}$ M 2-mercaptoethanol (Sigma), $100 \mathrm{U} / \mathrm{ml}$ penicillin (Gibco), and $100 \mu \mathrm{g} / \mathrm{ml}$ streptomycin (Gibco). Red blood cells in the spleen were lysed with Tris-buffered ammonium chloride. Cell suspensions were washed twice and counted using a hemacytometer. Viability was determined using Trypan blue dye exclusion.

\section{Measurement of antibody secreting $B$ cells $(A S C)$ in the spleen}

Acrowell $^{\mathrm{TM}} 96$ well filter plates (Pall Life Sciences, Ann Arbor, MI) were coated with $50 \mu$ PC-BSA (Biosearch Technologies, Novato, CA) $(10 \mu \mathrm{g} / \mathrm{ml})$ or $50 \mu \mathrm{l}$ PspA (10 $\mu \mathrm{g} / \mathrm{ml}$ ) (PspA was a generous gift from Clifford Snapper, USUHS) overnight at $4^{\circ} \mathrm{C}$. In all subsequent steps, plates were washed with PBS $+.01 \%$ Tween-20. Plates were blocked with $200 \mu \mathrm{l} /$ well complete medium $+25 \%$ FBS for 2 hours at $37^{\circ} \mathrm{C}$. Plates were washed and cells $(100 \mu \mathrm{l} /$ well $)$ were then added at a concentration of $5 \times 10^{6}$ cells $/ \mathrm{ml}$ or $1 \times 10^{6}$ cells $/ \mathrm{ml}$. All samples were plated in triplicate. Plates were incubated for 4-6 hours at $37^{\circ} \mathrm{C}$ in a $5 \% \mathrm{CO}_{2}$ incubator. After washing, goat anti-mouse alkaline phosphatase (AP) conjugated IgG, IgG1, IgG2a, IgG2b, IgG3, or IgM antibodies (Southern 
Biotechnology Associates, Birmingham, AL), diluted 1/250 in PBS $+1 \% \mathrm{BSA}+.05 \%$

Tween-20, were added to the appropriate wells (100 $\mu 1 /$ well). Plates were incubated overnight at $4{ }^{\circ} \mathrm{C}$ and washed. SIGMAFAST 5-bromo-4-chloro-3-indolyl phosphate/nitro blue tetrazolium tablets (Sigma-Aldrich, St. Louis, MO) were dissolved in distilled water and added at $100 \mu \mathrm{l} /$ well. Color development was stopped by washing with distilled water. The number of spots/well was counted using a dissection microscope (Olympus Optical Co., Melville, NY). The number of ASC was calculated by using the mean number of spots from triplicate wells. The number of ASC was normalized to $1 \times 10^{6} \mathrm{~B}$ cells. Comparable fold increases were noted when normalized to whole spleen.

\section{Flow cytometric analysis}

Splenic cells were stained with the appropriate combinations of rat anti-mouse B220-APC (RA3-6B2). All steps were performed in PBS supplemented with 1\% FBS and $0.04 \%$ sodium azide (Sigma). Briefly, $1 \times 10^{6}$ cells were stained in a total volume of $25 \mu \mathrm{l}$ of antibodies at the appropriate concentrations for 25 minutes on ice in the dark. After incubation, cells were washed twice and fixed in $0.04 \%$ paraformaldehyde overnight at $4^{\circ} \mathrm{C}$ (Fisher Scientific, Pittsburgh, PA). The following day cells were washed twice to remove the paraformaldehyde and resuspended in $1 \mathrm{ml}$ of staining media. For each sample, 10,000 cells were collected for analysis on a Becton-Dickinson FACScan (Becton Dickinson Immunocytometry Systems, Mansfield, MA). Analysis was performed using WinMDI software (Joseph Trotter, Scripps Institute, San Diego, CA). Population percentages, obtained from flow cytometric analysis, were used to calculate the absolute cell number by multiplying the percentage of cells in a population by the total number of cells harvested per organ. 


\section{Measurement of PC- and PspA-specific titers}

Serum samples were prepared via blood collected from the heart. Immulon 2 plates (for PC) or Immulon 4 plates (for PspA) (ThermoLabsystems, Franklin, MA) were coated overnight at $4^{\circ} \mathrm{C}$ with $5 \mu \mathrm{g} / \mathrm{ml}$ PC-BSA or $5 \mu \mathrm{g} / \mathrm{ml} \mathrm{PspA}$ ( $50 \mu \mathrm{l} /$ well). Plates were washed, blocked with $3 \% \mathrm{BSA}+\mathrm{PBS}$ at $37^{\circ} \mathrm{C}$ for 2 hours. Plates were washed and 100 $\mu 1 /$ well of twofold dilutions of sera in PBS $+1 \%$ BSA were added starting at $1 / 400$ for the IgG and IgM ELISAs and 1/250 for the IgG subclasses. Plates were then incubated for 1 hour at $37^{\circ} \mathrm{C}$ and washed. AP conjugated antibodies $(100 \mu 1 /$ well $)$ were added for 1 hour at $37^{\circ} \mathrm{C}$. Plates were washed and phosphatase substrate tablets (Sigma-Aldrich) were dissolved in PNPP (p-Nitrophenyl Phosphate, Disodium Salt) substrate buffer. Plates were developed and absorbance read at $405 \mathrm{~nm}$ on a $\mu$ Quant spectrophotometer (Bio-Tek instruments, Winooski, VT) using KCJunior software (Bio-Tek instruments).

\section{Statistics}

ANOVA was performed for all statistical analyses using a Tukey-Kramer t-test to perform multiple comparisons between all treatment groups. A significance level of $\mathrm{p} \leq$ 0.05 was used for all tests. Statistical analysis was performed using JMP software (SAS Institute Inc., Cary, NC). All experiments were performed 3 or more times with similar results. The figures are representative data from one experiment.

\section{RESULTS}

Propanil increases the number of PC-specific ASC following PC-Ficoll immunization. 
Previous studies have demonstrated that propanil increases the antibody response to PC following immunization with the particulate antigen HKSP. To determine if the propanil-induced antibody enhancement requires immunization with whole bacteria, mice were vaccinated with the soluble TI-2 antigen PC-Ficoll and treated on the same day with propanil or vehicle. The number of splenic PC-specific ASC and the PC-specific serum titers were determined 7 days later by ELISPOT and ELISA, respectively. Propanil increased the number of PC-specific IgG2b, IgG3 and IgM ASC 3-4 fold in PC-Ficoll immunized animals (Figure 1). The fold increase in ASC in propanil-treated and PCFicoll immunized mice was similar to propanil-treated HKSP immunized mice. However, the baseline PC response to PC-Ficoll was 6-10 fold lower than after vaccination with HKSP (Figure 1). However, PC-specific serum titers in propanil-treated mice were not significantly increased following either PC-Ficoll or HKSP immunization compared to the controls (Figure 2). This data suggests that propanil induces a similar effect on the immune response to a soluble TI- 2 antigen.

\section{Propanil does not enhance the antibody response to a suboptimal HKSP immunization.}

These experiments were performed to determine if the propanil-induced enhancement of the antibody response has a minimum threshold for antigen stimulation. To determine if propanil exposure can increase the antibody response to a suboptimal immunization to the same level as an optimal immunization, mice were immunized with $5 \times 10^{6}$ or $2 \times 10^{8}$ CFU of HKSP and treated on the same day with propanil or vehicle. The number of PC-specific ASC was determined at day 7. The number of PC-specific ASC in vehicle-treated mice immunized with $5 \times 10^{6}$ CFU HKSP is decreased 4-5-fold from 
mice immunized with $2 \times 10^{8} \mathrm{CFU}$ HKSP (Figure 3). In addition, propanil does not significantly affect the number of PC-specific ASC in mice immunized with $5 \times 10^{6} \mathrm{CFU}$ HKSP. This data suggests that propanil enhancement of the antibody response has a minimum threshold of antigen stimulation to induce the effect.

\section{Propanil increases secondary antibody responses to PC and PspA.}

Previous data demonstrated that propanil enhances a primary TI-2 antibody response but not a primary TD response. These experiments were performed to determine if propanil enhances a TI-2 or TD secondary antibody response and if multiple exposures to propanil can produce either greater enhancement or prolonged enhancement of the antibody response. Mice were immunized with $2 \times 10^{8}$ HKSP on day 0 and day 14 . Mice were exposed to propanil on either day 0 , day 14, or days 0 and 14. PC and PspAspecific antibody responses were measured on day 21. The number of PC-specific ASC from mice treated with propanil once on day 0 and mice treated with propanil twice on days 0 and 14 were not significantly different from vehicle controls (Figure 4A). However, PC-specific ASC from mice exposed to propanil once on day 14 were increased 2-3 fold compared to controls (Figure 4A). None of the propanil exposure treatments significantly affected PC-specific serum titers (Figure 5A).

The effect of propanil on the PspA-specific response was similar to the PCspecific response. The number of PspA-specific ASC from mice exposed to propanil once on day 14 was increased 2-fold compared to vehicle-treated mice (Figure 4B). Propanil exposure on day 0 or days 0 and 14 did not significantly affect the number of PspA-specific ASC (Figure 4B). None of the propanil exposure treatments significantly affected PspA-specific serum titers (Figure 5B). Altogether, these data suggest that 
propanil enhances the antibody response to both protein and polysaccharides. However, enhanced splenic ASC did not increase serum titers on day 21.

\section{Delayed propanil exposure enhances a primary antibody response to PspA.}

The previous findings demonstrating that propanil enhances the secondary antibody response to PspA when mice are exposed on day 14 suggest that the enhancement of the antibody response is dependent on the time of propanil exposure relative to the developing antibody response. To determine if propanil can increase the number of PspA-specific ASC during a primary response, mice were immunized with HKSP on day 0 and treated with propanil on day 9. The PspA and PC antibody responses were measured on day 14. The number of PspA-specific ASC was increased approximately 2-fold compared to vehicle-treated mice (Figure 6A). In addition, the number of PC-specific ASC was also increased 4-6-fold in propanil-treated mice compared to vehicle controls (Figure 6B). This data demonstrates that the enhancement of the antibody response is dependent on the condition of the antibody response when mice are exposed to propanil.

\section{Propanil does not enhance the antibody response following PC-KLH immunization.}

To determine if propanil requires the TD antigen to be presented in a particulate form such as HKSP to enhance the antibody response, mice were immunized with PCKLH or HKSP and treated with propanil or vehicle on day 0. The number of PC-specific ASC was determined on day 7. Both high affinity and low affinity PC-specific ASC were also determined by using a high and low conjugation ratio of PC-BSA. To detect high affinity ASC, ELISPOT plates were coated with 2PC-BSA. Low affinity ASC were detected by $15 \mathrm{PC}-\mathrm{BSA}$ coated plates. PC-KLH immunization produced a 2-fold greater 
number of ASC in vehicle-treated animals compared to vehicle-treated animals immunized with HKSP (Figure 7A). Interestingly, propanil did not enhance the PCspecific response following PC-KLH immunization (Figure 7A). Analysis of the affinity of PC-specific antibodies demonstrates that the number of low affinity ASC is $20 \%, 65 \%$, and $220 \%$ greater than high affinity IgM, IgG3, and IgG2b ASC, respectively (Figure 7A vs. Figure 7B). This data indicates that high and low affinity ASC are detectable with this assay. The number of low affinity PC-specific ASC in propanil-treated animals was increased approximately 4-fold for IgG2b and 5-fold for IgG3 and IgM (Figure 7A). The number of high affinity PC-specific ASC in propanil-treated animals were increased approximately 6-fold, 5-fold, and 4-fold for $\operatorname{IgG} 2$ b, IgG3, and $\operatorname{IgM}$, respectively (Figure 7B). Altogether, this data suggests that propanil does not preferentially increase either high or low affinity ASC.

\section{DISCUSSION}

This set of experiments addressed a number of questions concerning the effect of propanil on the antibody response. Effects of propanil on humoral responses to particulate and soluble antigens also provide important information on any putative effects on antigen processing. As mentioned previously, the role of $\mathrm{T}$ cells in the amplification of the antibody response can be assessed through TI-2 and TD comparison studies. Finally, determining when during the time of the response the immune system is susceptible to the effects of propanil exposure was also addressed. The results from these initial experiments may help to focus experiments studying the immunological mechanisms regulating the enhanced antibody response. 
These data suggest that the increased antibody response is not due to a nonspecific polyclonal increase in ASC. Propanil increased the PC-specific response following HKSP and PC-Ficoll immunization. However, propanil does not increase the PC-specific response following PC-KLH immunization, despite a robust antibody response at day 7. In addition, propanil induction of nonspecific polyclonal activation would predict a greater increase in low affinity PC-specific B cells. However, the data indicates that both high and low affinity PC-specific ASC are increased equally. Previous reports demonstrated that the low affinity PC-specific serum titers are increased $120 \%$ compared to high affinity PC-specific serum titers in samples collected on days 6 or 9 (Wu and Ward, 1993). However, the affinity of individual isotypes was not determined (Wu and Ward, 1993). Our study supports the previous affinity analysis however precise comparisons are difficult due to the different time points and antigen employed. Altogether, these data suggest an antigen-specific increase in antibody production.

Another unresolved finding in the previous chapter was the discrepancy between increased ASC and increased ex vivo antibody production in propanil-treated animals, but unchanged serum antibody titers. The results from Chapter 3 indicate that antibody serum titers are more sensitive to changes in the number of BM ASC. Since the number of BM ASC are not increased in propanil-treated animals despite an increase in splenic ASC, propanil treatment may not increase the antibody serum titers since the increased number of plasma cells do not survive in the BM.

Propanil failed to amplify the antibody response exposure following a suboptimal HKSP immunization. This data provided an interesting finding that propanil exposure 
increased the antibody response to a weak PC-Ficoll response but not to a weak HKSP immunization. The low conjugation ratio of the PC-Ficoll used in this experiment (6 PCFicoll) was lower than that used in previous experiments (25 PC-Ficoll) which generated serum titers comparable to optimal HKSP immunization (Wu et al., 1999). A possible explanation for the discrepancy between responses is that the low PC-concentration on PC-Ficoll activates high affinity B cells. Propanil is able to amplify the PC response to low PC-Ficoll immunization because the concentration of PC-Ficoll molecules is in excess, allowing for receptor engagement by the increased number of responding PCspecific B cells. In contrast the low dose of HKSP would limit the number of individual PC expressing bacterium thus fewer BCR are able to bind to HKSP. This hypothesis would suggest that propanil cannot increase the number of PC-specific ASC in suboptimally vaccinated mice because the increased number of responding B cells require antigen stimulation to differentiate to plasma cells. Altogether, these data suggest that propanil enhancement of the antibody response is not dependent on particulate or soluble antigen presentation by the APC.

A second question addressed by these set of experiments was whether the enhancement of the antibody response by propanil was specific for TI-2 responses. Given the major differences in the processes leading to B cell activation in TD and TI-2 responses as noted in the General Introduction, addressing this issue is important for determining the mechanisms responsible for the increased numbers of ASC. These data demonstrate that enhancement of the antibody response is dependent on when the animal is exposed to propanil during the antibody response. Propanil increased the antibody response to a TD antigen when it is given 5 days prior the peak antibody response in 
HKSP immunized mice. Although PC-KLH elicits a robust TD PC-specific response at day 7, previous reports have demonstrated that the $\mathrm{T}^{+} 5^{+}$antibody response following PCKLH immunization is maximal on day 13 in Balb/c mice (Wiens et al., 2003). The data suggests that propanil exposure to PC-KLH on day 8 would amplify the anti-PC response.

These data indicate that the amplification of the antibody response by propanil is not a direct effect on the B cells and may require $\mathrm{T}$ cell involvement. This hypothesis is supported by the observation that enhancement of the PC-specific response is not observed in HKSP immunized animals until day 5, despite actively differentiating and proliferating B cells by day 3. Similarly, PC-KLH immunization produces a greater number of PC-specific ASC on day 7 than a HKSP immunization. This also indicates robust B cell differentiation and proliferation. One of the differences between TD and TI-2 responses is the nature of T cell help and other costimulation molecules early on during B cell activation. For instance, $\mathrm{T}$ cell help is required for the first 3-4 days of the PC response and the first 5-6 days for the PspA response (Wu et al., 2002). B7dependent costimulation is required for the first 1-2 days during the $\mathrm{PC}$ response in contrast to the first 5-6 days for the PspA response (Wu et al., 2000). It is possible that propanil may affect $\mathrm{T}$ cell dependent costimulation, which could explain the delayed enhancement of the PC response until day 5 and the requirement of delayed propanil exposure to enhance TD responses.

Altogether these data eliminate a number of possible immunological mechanisms by which propanil amplifies the TI- 2 and TD humoral responses. Antibody enhancement does not require a particulate antigen on a whole killed bacterium. Increased antibody 
responses are antigen specific and not polyclonal. However, more experimentation is required to resolve the discrepancy between ASC and serum titers and to determine the importance of $\mathrm{T}$ cell help in the amplified response. 

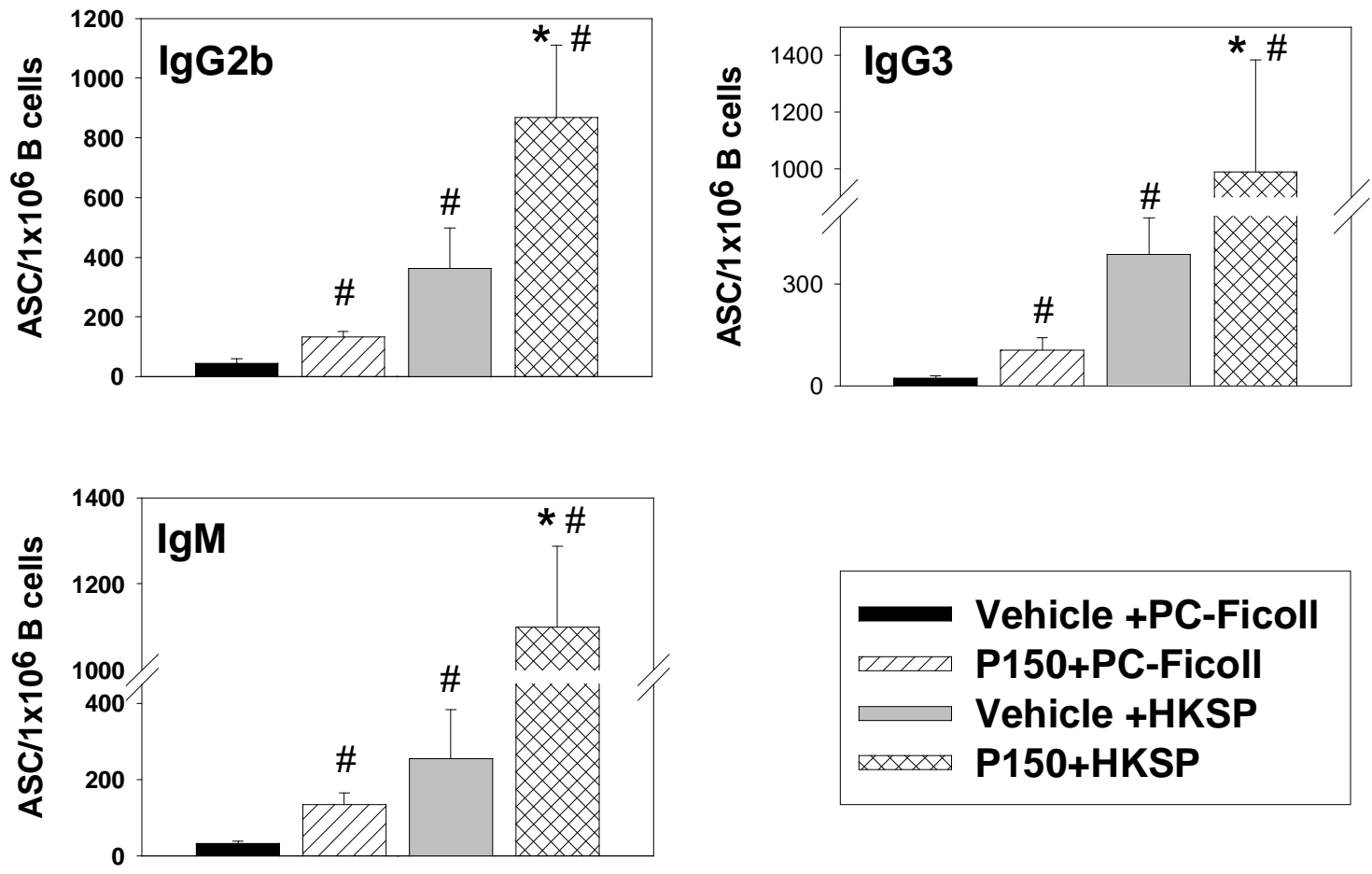

\section{Vehicle +PC-Ficoll \\ P150+PC-Ficoll Vehicle +HKSP \\ P150+HKSP}

Figure 1. Propanil exposure increases the number of PC-specific ASC following PC-Ficoll immunization.

Female C57BL/6 mice (5/group) were treated with $150 \mathrm{mg} / \mathrm{kg}$ propanil or vehicle control and vaccinated with $2 \times 10^{8} \mathrm{CFU}$ HKSP or PC(6)-Ficoll. Numbers of PC-specific IgG2b, IgG3, and IgM ASC were determined by ELISPOT assay on day 7. Values represent the mean \pm SD of ASC $/ 1 \times 10^{6}$ B cells. \# Significantly different from Vehicle + PC-Ficoll, $p$ $\leq .05 . *$ significantly different from Vehicle + HKSP, $\mathrm{p} \leq .05$. 


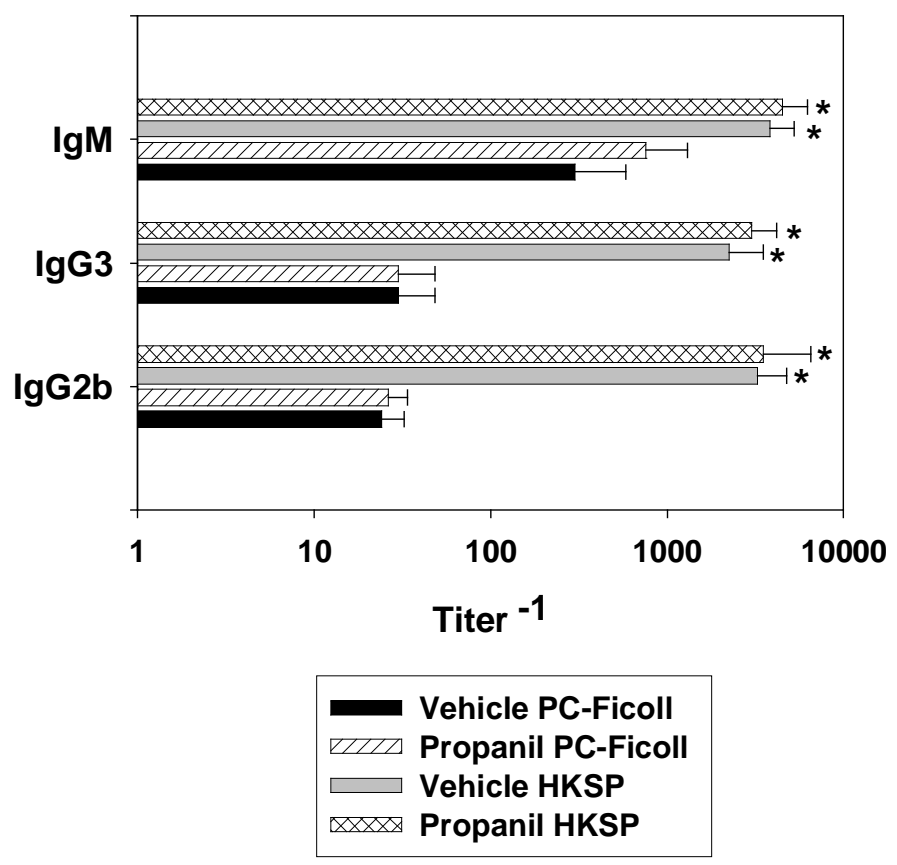

Figure 2. Propanil does not affect PC-specific serum titers following PC-Ficoll immunization.

Female C57BL/6 mice (5/group) were treated with $150 \mathrm{mg} / \mathrm{kg}$ propanil or vehicle control and vaccinated with $2 \times 10^{8} \mathrm{CFU}$ HKSP or PC(6)-Ficoll. IgG2b, IgG3, and IgM PCspecific serum titers were determined by ELISA on day 7. Values represent the mean titer \pm SD. * significantly different from Vehicle + Ficoll , $\mathrm{p} \leq .05$. 

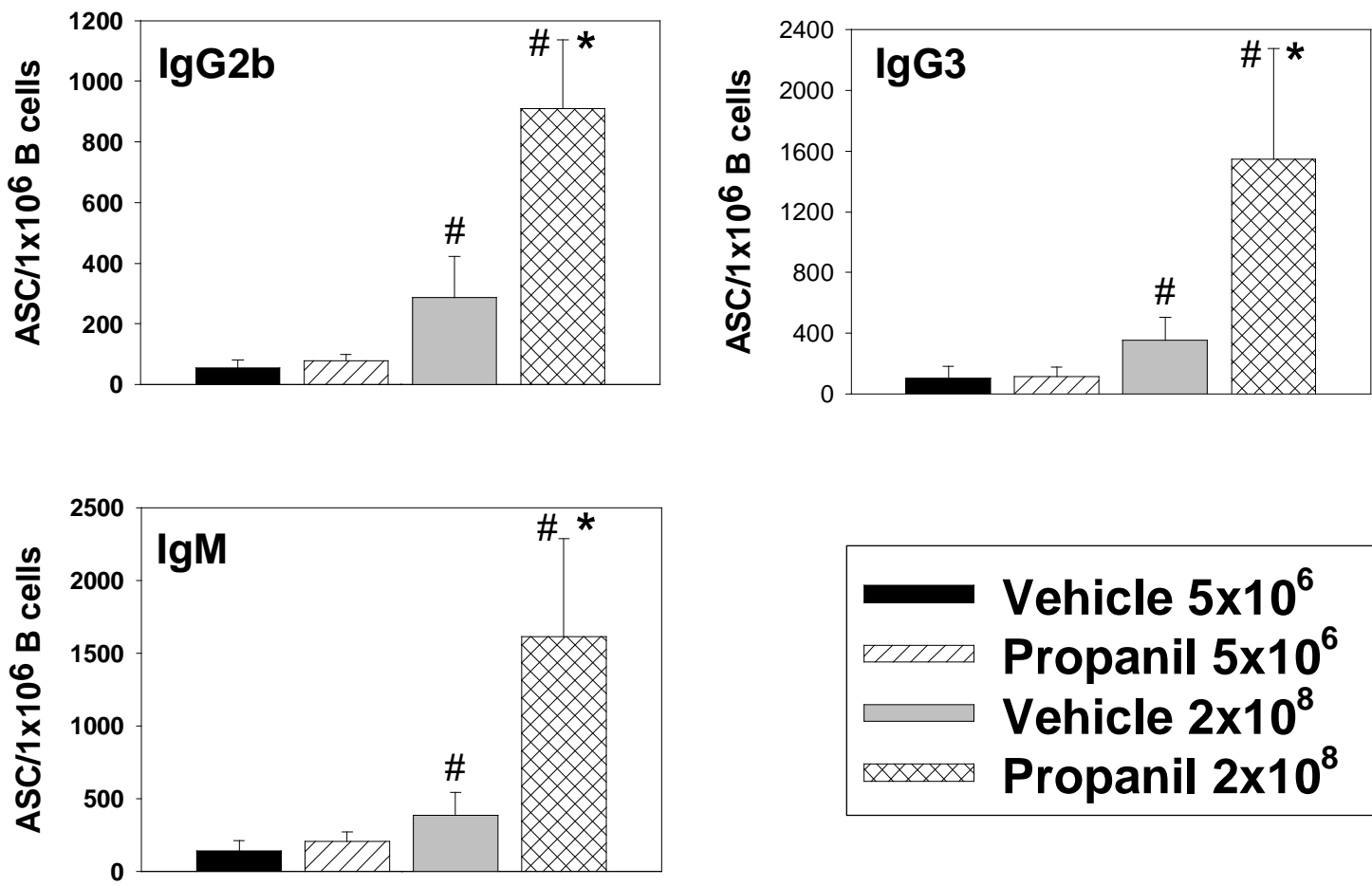

Figure 3. Propanil exposure does not affect PC-specific ASC in suboptimally HKSP immunized mice.

Female C57BL/6 mice (5/group) were treated with $150 \mathrm{mg} / \mathrm{kg}$ propanil or vehicle control and vaccinated with $2 \times 10^{8}$ or $5 \times 10^{6}$ CFU HKSP. Numbers of PC-specific IgG2b, IgG3, and IgM ASC were determined by ELISPOT assay on day 7. Values represent the mean $\pm \mathrm{SD}$ of ASC $/ 1 \times 10^{6}$ B cells. \# Significantly different from Vehicle $5 \times 10^{6}, \mathrm{p} \leq .05$. * Significantly different from Vehicle $2 \times 10^{8}, \mathrm{p} \leq .05$ 
A. $\mathrm{PC}$
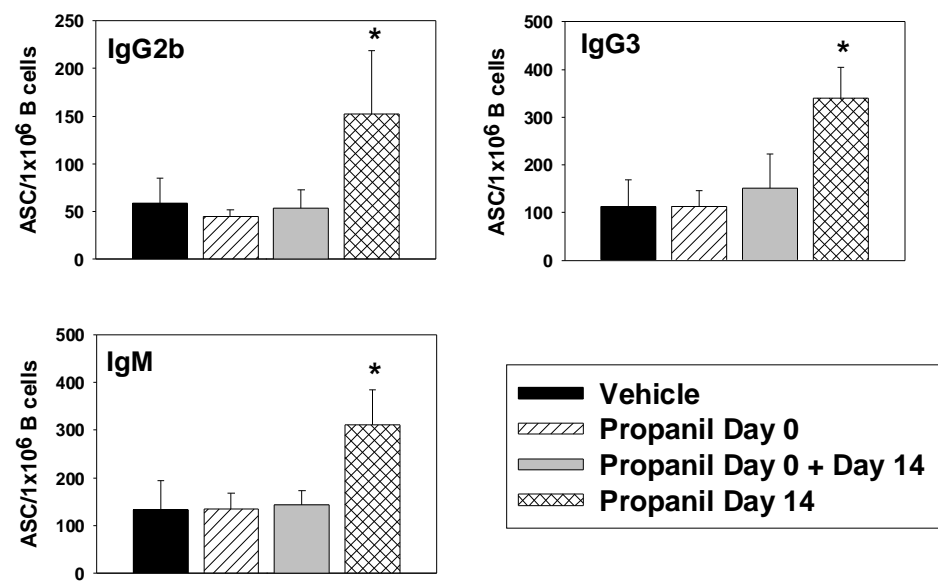

B. PspA
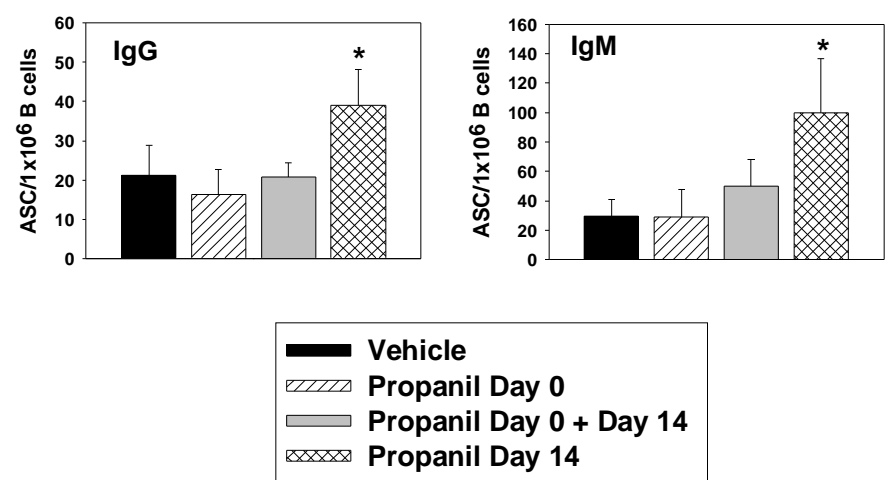

Figure 4. Day 14 propanil exposure increases the number of PC-specific and PspAspecific ASC following a HKSP boost on day 14.

Female C57BL/6 mice (5/group) were treated with vehicle control or $150 \mathrm{mg} / \mathrm{kg}$ propanil on day 0 , day 14 or day 0 and day 14 and vaccinated on day 0 and day 14 with $2 \times 10^{8}$ CFU HKSP. (A) Numbers of PC-specific IgG2b, IgG3, and IgM ASC were determined by ELISPOT assay on day 21. (B) Numbers of PspA-specific IgG and IgM ASC were determined by ELISPOT assay on day 21. Values represent the mean \pm SD of ASC $/ 1 \times 10^{6}$ B cells. * Significantly different from vehicle control, $\mathrm{p} \leq .05$. 

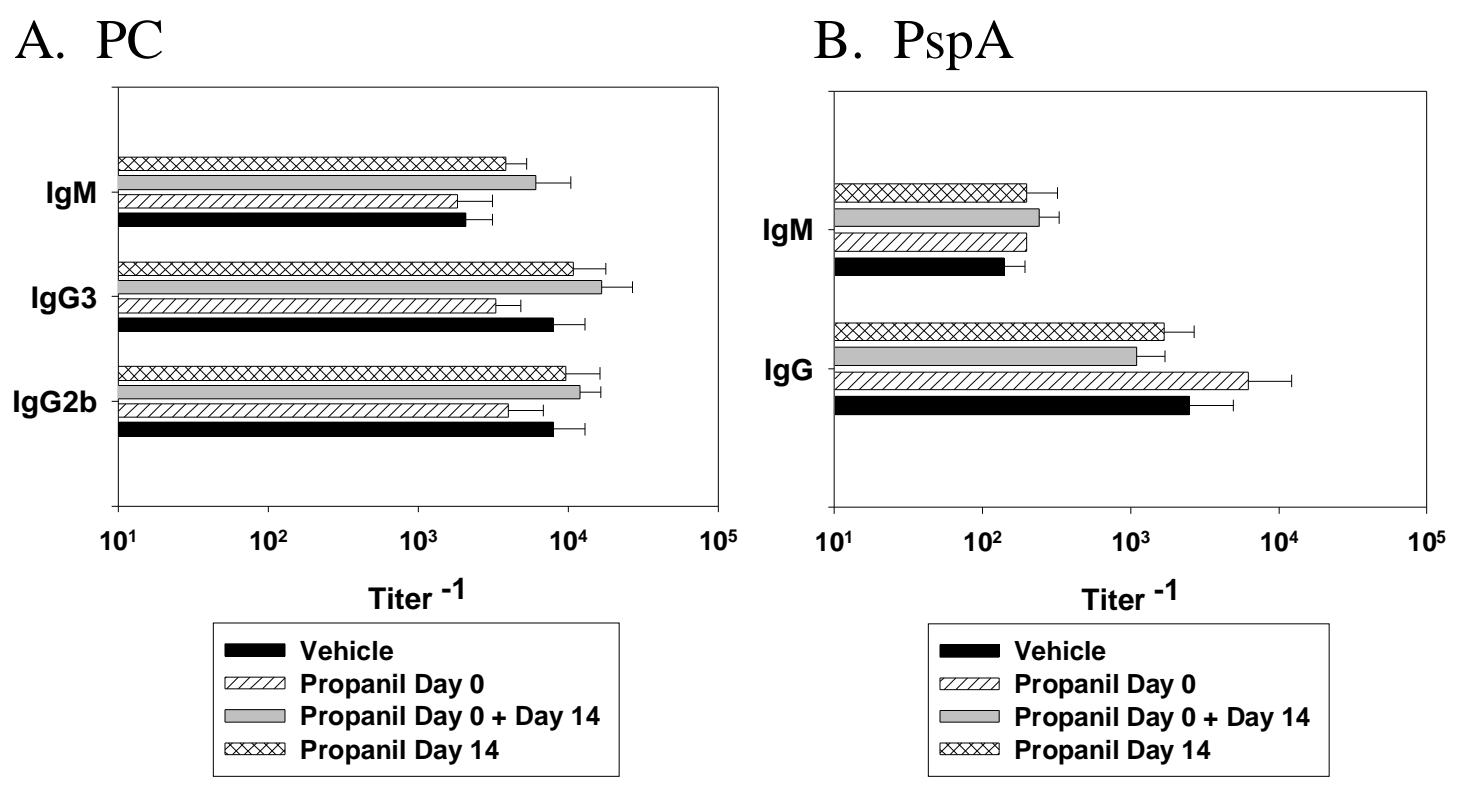

Figure 5. Propanil exposure does not affect serum titers following secondary HKSP immunization.

Female C57BL/6 mice (5/group) were treated with vehicle control or $150 \mathrm{mg} / \mathrm{kg}$ propanil on day 0 , day 14 or day 0 and day 14 and vaccinated on day 0 and day 14 with $2 \times 10^{8}$ CFU HKSP. (A) IgG2b, IgG3, and IgM PC-specific serum titers were determined by ELISA on day 21. (B) IgG and IgM PspA-specific ASC were determined by ELISA on day 21. Values represent the mean titer $\pm \mathrm{SD}$. 


\section{A. PspA}
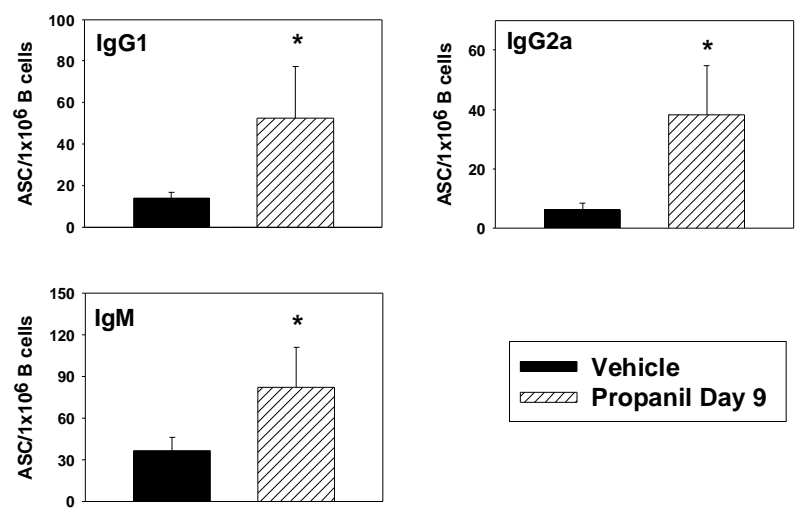

$$
\begin{array}{ll} 
& \text { Vehicle } \\
\text { एयाग Propanil Day } 9
\end{array}
$$

\section{B. PC}
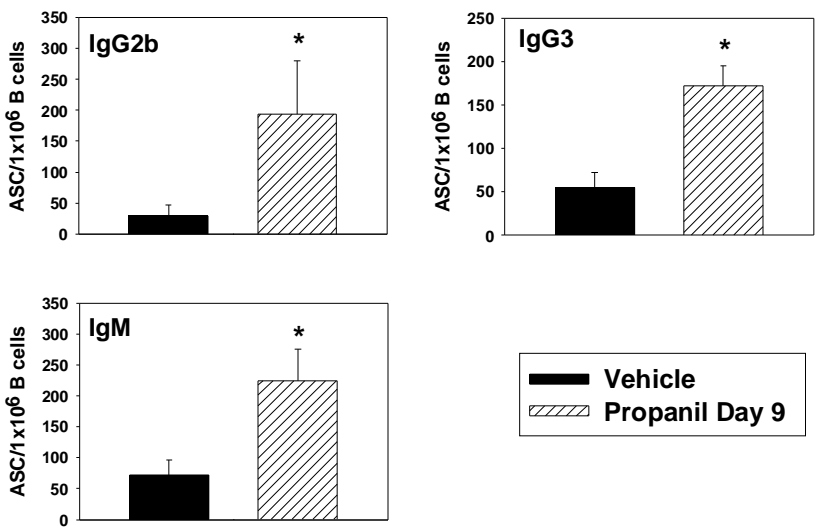

Vehicle שz/D Propanil Day 9

\section{Figure 6. Day 9 propanil exposure increases the number of $\mathrm{PC}$ and PspA-specific}

ASC.

Female C57BL/6 mice (5/group) were treated with vehicle control or $150 \mathrm{mg} / \mathrm{kg}$ propanil on day 9 and vaccinated on day 0 with $2 \times 10^{8}$ CFU HKSP. (A) Numbers of PspA-specific IgG1, IgG2a, and IgM ASC were determined by ELISPOT assay on day 14. (B) Numbers of PC-specific IgG2b, IgG3, and IgM ASC were determined by ELISPOT assay on day 14. Values represent the mean \pm SD of ASC $/ 1 \times 10^{6}$ B cells. * Significantly different from vehicle control, $\mathrm{p} \leq .05$. 


\section{A. PC15-BSA}
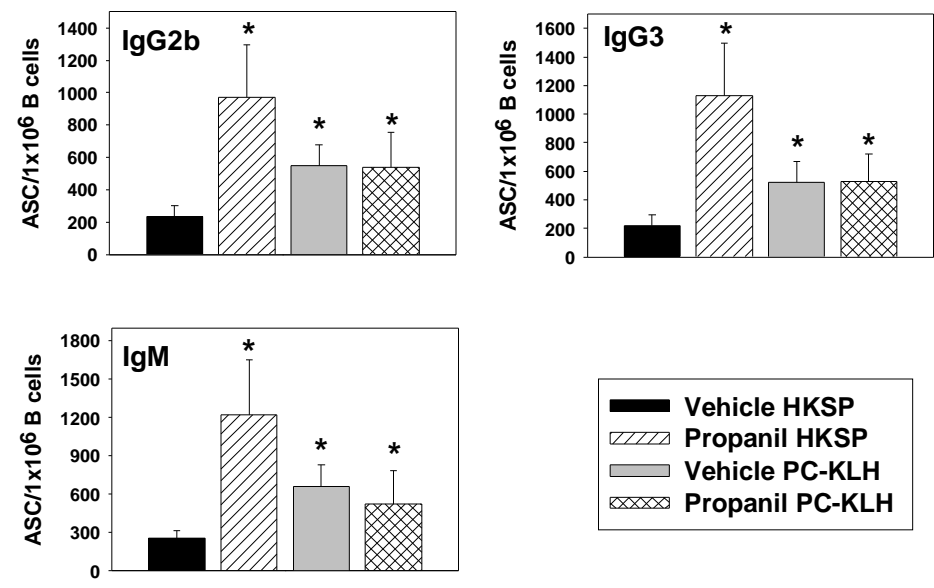

B. PC2-BSA
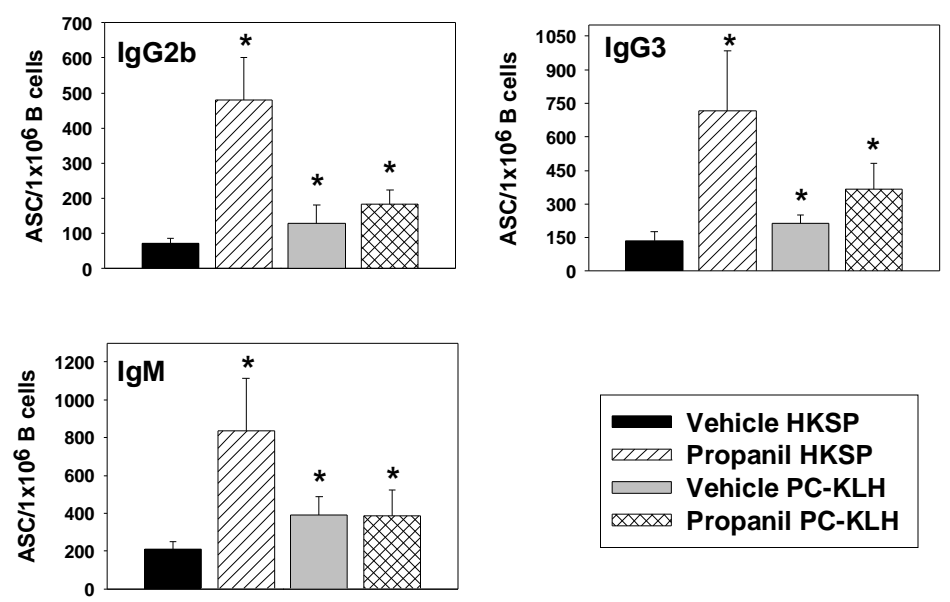

Figure 7. Propanil exposure does not affect the number of PC-specific ASC

\section{following PC-KLH.}

Female C57BL/6 mice (5/group) were treated with vehicle control or $150 \mathrm{mg} / \mathrm{kg}$ propanil and vaccinated on day 0 with $2 \times 10^{8}$ CFU HKSP or PC-KLH. Numbers of PC-specific IgG2b, IgG3, and IgM ASC were determined by ELISPOT assay on day 7. (A) Low affinity B cells were detected using PC(15)-BSA coated plates. (B) High affinity B cells were detected using PC(2)-BSA coated plates. Values represent the mean $\pm \mathrm{SD}$ of ASC $/ 1 \times 10^{6}$ B cells. ${ }^{*}$ Significantly different from vehicle HKSP, $\mathrm{p} \leq .05$. 
CHAPTER 5: EVIDENCE FOR A NOVEL ENDOCRINE DISRUPTOR: THE PESTICIDE PROPANIL REQUIRES THE OVARIES AND STEROID SYNTHESIS TO ENHANCE HUMORAL IMMUNITY 
Evidence for a novel endocrine disruptor: The pesticide Propanil requires the ovaries and steroid synthesis to enhance humoral immunity

\section{Keith D. Salazar* (ksalazar@hsc.wvu.edu) \\ Michael R. Miller $^{+}$(mmiller@hsc.wvu.edu $)$ \\ John B. Barnett* (jbarnett@ hsc.wvu.edu) \\ Rosana Schafer* (rschafer@hsc.wvu.edu)}

*Department of Microbiology, Immunology and Cell Biology, ${ }^{+}$Department of

Biochemistry and Molecular Pharmacology Robert C. Byrd Health Sciences Center, West Virginia University, Morgantown, West Virginia, 26506.

Running title: Pesticide immunomodulation to vaccination

Corresponding author. Rosana Schafer, Ph.D. Department of Microbiology, Immunology and Cell Biology, Health Sciences Center North, P.O. Box 9177, West Virginia University, Morgantown, WV 26506-9177

e-mail: rschafer@hsc.wvu.edu. Telephone: 304-293-3104. Fax: 304-293-7823. 


\begin{abstract}
Steroid hormones are known to affect the humoral immune response to a variety of antigens. However, the mechanisms regulating these effects are poorly understood. The immunotoxic chemical, propanil, and estrogen have similar effects on the immune system including augmentation of humoral immune responses. Propanil enhances the number of phosphorylcholine (PC)-specific IgG2b, IgG3, and IgM antibody secreting cells (ASC) in the spleen 4-6-fold 7 days after vaccination of female C57BL/6 mice with heat-killed Streptococcus pneumoniae (HKSP). Several experiments were performed to test the hypothesis that propanil increases the response via an estrogenic pathway. Ovariectomy abrogated the effect of propanil on the PC-specific ASC response. Both in vitro and in vivo assays indicate that propanil does not bind either ER $\alpha$ or ER $\beta$. Exogenous estradiol administration in ovariectomized mice failed to restore the effect of propanil on the PC response. Treatment of female mice with a pure ER antagonist, ICI 182,780 , or the progesterone antagonist, RU-486, did not inhibit the increase in ASC. These data suggest that estrogen and progesterone do not regulate the effect of propanil. However, complete inhibition of steroid synthesis with the GnRH antagonist, antide, abrogated the increased response in propanil-treated mice, indicating a necessary role for steroid synthesis. Experiments in male mice demonstrated that propanil increased the number of ASC comparable to female mice. However, orchiectomy did not inhibit this effect, suggesting that androgens do not regulate the amplification of the humoral response. These data suggest a novel role for the ovarian hormones in the regulation of the PC-specific antibody response.
\end{abstract}




\section{INTRODUCTION}

Numerous studies have characterized the immunomodulating effects of the steroid hormone $17 \beta$-estradiol (E2) on developing lymphocyte populations in the thymus and bone marrow and on the peripheral humoral immune response. Studies have demonstrated that E2 induces thymic atrophy through a Fas/FasL pathway dependent on both estrogen receptor (ER) $\alpha$ and $\beta$ (Do et al., 2002; Erlandsson et al., 2001; Yao and Hou, 2004). E2 treatment induces thymic atrophy primarily by decreasing the number of $\mathrm{CD} 4^{+} \mathrm{CD} 8^{+}$double positive thymocytes (Screpanti et al., 1989). E2 also inhibits B lymphopoiesis in the bone marrow (Erlandsson et al., 2003; Islander et al., 2003). Specifically, E2 decreases pro-B cell, pre-B cell, and mature B cells of the bone marrow in an ER $\alpha$ and ER $\beta$ dependent manner (Erlandsson et al., 2003). Studies on the effects of E2 on specific immune responses have demonstrated that chronic exposure to E2 increases both the number of splenic antibody secreting cells (ASC) and the serum antibody titers to bacterial and autoantigens (Meyers and Petersen, 1985; Verthelyi and Ahmed, 1998). Recent data suggest that $\mathrm{E} 2$ skews the genetic expression profile of B cells to enhance survival and to lower tolerance, which may contribute to the enhanced antibody response after E2 exposure (Frasor et al., 2003; Grimaldi et al., 2002). It has been proposed that naturally occurring and synthetic compounds capable of acting through an estrogenic pathway may be able to induce the same immunomodulating effects as the endogenous hormone.

Reports on endocrine disrupting chemicals (EDC) that are known estrogen mimics demonstrate that these compounds induce similar immune enhancement as E2 (Sobel et al. 2005; Yurino et al., 2004). One study demonstrated that in vitro exposure to 
bisphenol A (BPA) and diethylstilbesterol (DES) increased IgM secretion from B1 cells (Yurino et al., 2004). In addition, chronic DES exposure accelerated the onset of systemic lupus erythematosus (SLE) in BWF1 mice (Yurino et al., 2004). In another study illustrating the ability of EDC to enhance an autoimmune disease, the organochlorine pesticides chlordecone, methoxychlor, and DDT accelerated the progression of SLE in (NZB x NZW)F 1 mice (Sobel et al., 2005). Additionally, the antiDNA titers were also increased in chlordecone treated animals (Sobel et al., 2005). These reports suggest that EDC have the potential to impact the immune system and accelerate the progression of autoimmune diseases.

The amide class herbicide 3,4-dichloropropionanilide (propanil) is predominantly used for the control of grassy weeds in rice crops. Exposure to propanil causes a diverse array of immunotoxic effects that are similar to those seen in animals treated with E2. Specifically, in vivo exposure to propanil induces thymic atrophy, with reduced double positive and single positive thymocyte populations (Cuff et al., 1996; de la Rosa et al., 2005). The thymic atrophy is associated with an increase in glucocorticoid production (Cuff et al., 1996; de la Rosa et al., 2005). However, administration of the glucocorticoid receptor antagonist RU486 did not completely abrogate the atrophy suggesting that glucocorticoids are only partially responsible for inducing thymic atrophy (de la Rosa $e t$ al., 2005). Propanil also decreases the number of immature $\operatorname{IgM}^{+} \mathrm{B}$ cells and pre-B cells in the bone marrow 7 days post-exposure, however the mechanism is unknown (de la Rosa et al., 2003).

Recently, propanil has been demonstrated to enhance the humoral immune response to a bacterial vaccine (Salazar et al., 2005). Heat-killed Streptococcus 
pneumoniae (HKSP) was used as the model for measuring the antibody response. HKSP elicits a robust $\operatorname{IgG} 2 \mathrm{~b}, \operatorname{IgG} 3$, and $\operatorname{IgM}$ response to the immunodominant T-independent type 2 (TI-2) polysaccharide phosphorylcholine (PC) (Wu et al., 1999). When propanil is administered to mice simultaneously with a HKSP vaccine, the number of splenic ASC specific for PC is increased 4-6 fold over control animals (Salazar et al., 2005). The current studies were designed to investigate the mechanism for the increase in PC antibody production following exposure to propanil.

Only limited studies have reported the endocrine disrupting effects of propanil. Using an in vitro luciferase reporter assay, propanil was found to be weakly antiandrogenic and lacked estrogenic receptor $\alpha$ - and $\beta$-binding activity (Kojima et al., 2004). Another report found that the major metabolite of propanil, 3,4-dichloroaniline (3,4-DCA), binds the androgen receptor in vitro (Bauer et al., 1998). Given the paucity of information describing the potential endocrine disrupting effects of propanil in vivo, one of the goals of this study was to better characterize propanil as an EDC, using both in vivo and in vitro models.

As described above, propanil induces a number of immunotoxic effects also caused by E2. The hypothesis for the present studies was that propanil increased the antibody response to HKSP vaccination through an estrogenic mechanism. The results demonstrate that propanil requires the ovaries and steroid synthesis to induce an increase in the antibody response in female mice. However, the experiments demonstrate that the enhanced antibody response following exposure to propanil occurs independently of the estrogen pathway. These studies suggest that the ovaries may regulate the systemic 
humoral immune response through a novel, estrogen-independent mechanism and that propanil modulates this pathway. 


\section{MATERIALS AND METHODS}

Mice

Six to eight week old C57B1/6 female and male mice were purchased from Hill Top Lab Animals (Scottdale, PA). Ovariectomized (OVX), castrated (CAS), and shamoperated mice were surgically gonadectomized at Hill Top Lab Animals. Mice were housed in microisolator cages in pathogen free conditions at West Virginia University's animal facility. Mice were kept on a $12 \mathrm{hr}$ light-dark cycle and allowed to acclimate to the facility for 1 week. Gonadectomized mice were housed at least 2 weeks following surgery to allow endogenous hormones to decline. Food and water were provided $a d$ libidum. These studies were conducted in accordance with all federal and institutional guidelines for animal use and were approved by the West Virginia University Institutional Animal Care and Use Committee.

\section{Chemicals}

Propanil (3,4-dichloropropionanilide, 99\% pure) was purchased from Chem Service (West Chester, PA). 17 $\beta$-estradiol (E2) was purchased from Sigma Chemical Co. (St. Louis, MO) and diluted in $99 \%$ peanut oil (p.o.) and 1\% EtOH. ICI 182,780 (ICI) was purchased from Tocris Bioscience (Ellisville, MO). ICI was diluted in 95\% p.o. and 5\% EtOH. The GnRH antagonist, antide, was purchased from Bachem (Torrance, CA) and dissolved in $20 \%$ propylene glycol and $0.85 \%$ saline. The progesterone antagonist, RU486, was purchased from Sigma Chemical Co. and dissolved in propylene glycol. 


\section{Bacterial preparation and immunization}

S. pneumoniae strain R36A, an avirulent, nonencapsulated strain, was grown to mid-log phase in Todd-Hewitt broth (Becton Dickinson, Sparks, MD) $+.05 \%$ yeast extract (Becton Dickinson) and stored at $-80^{\circ} \mathrm{C}$. For immunization, stock was cultured in a candle jar for $18 \mathrm{hrs}$ at $37^{\circ} \mathrm{C}$ on blood agar plates (Becton Dickinson). A few characteristic colonies were selected and suspended in $200 \mathrm{ml}$ Todd-Hewitt broth $+.05 \%$ yeast extract. Bacteria were grown at $37^{\circ} \mathrm{C}$ to an absorbance reading at $650 \mathrm{~nm}$ of 0.4 and heat killed for 4 hours in a $60^{\circ} \mathrm{C}$ water bath. A final concentration of $10^{9} \mathrm{CFU} / \mathrm{ml}$ was established in PBS based on colony counts. Sterility was confirmed by culture. Heatkilled stock was stored at $-20^{\circ} \mathrm{C}$ in $1 \mathrm{ml}$ aliquots. Mice were immunized ip with $2 \times 10^{8}$ CFU. This dose of vaccine has previously been demonstrated to elicit an optimal PCspecific antibody response that peaks at day 7 post-vaccination (Wu et al., 1999; Wu et al., 2000).

\section{Animal exposures}

Propanil was dissolved in p.o. for a final concentration of $15 \mathrm{mg} / \mathrm{ml}$ or $20 \mathrm{mg} / \mathrm{ml}$ for all experiments. For the experiments measuring antibody responses, mice (5/group) were treated ip with either $150 \mathrm{mg}$ of propanil/ $\mathrm{kg}$ of body weight $(\mathrm{mg} / \mathrm{kg})$ or vehicle on the same day as vaccination with heat-killed S. pneumoniae (HKSP). The dose of propanil was chosen based on previous studies that demonstrate an increase in the antibody response to $\mathrm{PC}$ in vaccinated mice at $150 \mathrm{mg} / \mathrm{kg}$ (Salazar et al., 2005).

In experiments using E2, ovariectomized mice were injected sc with a daily dose

of E2 $(10 \mu \mathrm{g} / \mathrm{kg})$. Animals received the first dose of E2 $1 \mathrm{hr}$ prior to herbicide or vehicle 
treatment and vaccination. Subsequent E2 treatments were given at the same time daily. Animals were sacrificed $24 \mathrm{hrs}$ following the final E2 exposure.

In experiments using the ER antagonist, ICI 182,780 (10 mg/kg/day), was injected sc into female mice. Animals were treated with the first dose of ICI $1 \mathrm{hr}$ prior to herbicide or vehicle exposure and vaccination. Subsequent ICI exposures were given at the same time daily throughout the course of the experiment.

In experiments using the GnRH antagonist, antide (60 $\mu \mathrm{g} /$ mouse), female mice were injected sc every 48 hours 14 days prior to propanil or vehicle exposure and vaccination (Couse et al., 2003). Subsequent antide treatments were given at the same time every 48 hours throughout the course of the experiment.

For the uterotrophic assays, OVX mice were treated with either a single ip injection of the vehicle or propanil $(150 \mathrm{mg} / \mathrm{kg})$, or 3 daily sc injections of E2 (10 $\mu \mathrm{g} / \mathrm{kg} /$ day). Mice were euthanized 24 hours after the last E2 exposure, and the wet weights of the uteri were recorded.

In experiments using the progesterone receptor antagonist, RU486 (12.5 mg/kg), female mice were injected sc 2 hours prior to propanil treatment, 12 hours following propanil treatment, followed by injections every 24 hours throughout the duration of the experiment. For thymic atrophy experiments, mice were injected with $200 \mathrm{mg} / \mathrm{kg}$ of propanil or vehicle control. The dose of propanil was based on previous studies on propanil-induced thymic atrophy (de la Rosa et al., 2005). Thymic weights were recorded on day 3. For HKSP experiments, mice were treated with $150 \mathrm{mg} / \mathrm{kg}$ of propanil or vehicle control and vaccinated. Splenic antibody responses were measured on day 7. 


\section{Serum estradiol levels}

Serum estradiol levels were determined for mice treated with antide for 14 days using the Estradiol EIA kit (Diagnostic Automation Inc., Calabasas, CA), according to the kit instructions. Briefly, serum samples collected from the saphenous vein or E2 standards were added to the provided 96-well microtiter plates coated with anti-E2 antibody. Anti-E2 antibody conjugated to peroxidase was added, and the wells were incubated for $90 \mathrm{~min}$ at room temperature. The wells were washed and substrate was added to each well for $20 \mathrm{~min}$. The reaction was stopped and read at $450 \mathrm{~nm}$ with a $\mu$ Quant spectrophotometer (Bio-Tek Instruments, Winooski, VT). The level of detection for the assay was $1 \mathrm{pg} / \mathrm{ml}$.

\section{Preparation of splenocytes}

Mice were euthanized with $100 \mu \mathrm{l} \mathrm{Nembutal} \mathrm{Sodium} \mathrm{Solution}(50 \mathrm{mg} / \mathrm{ml}$, Abbott Laboratories, North Chicago, IL) on days 5 or 7 following herbicide exposure and vaccination. Spleen wet weights were recorded. Spleens were mechanically dissociated through Spectra nylon mesh (Spectrum Labs, Rancho Dominguez, CA) in complete cell media containing RPMI-1640 (BioWhitaker, Walkersville, MD), 10\% heat inactivated fetal bovine serum (FBS, Hyclone Laboratories, Inc, Logan, UT), 10 mM HEPES (Sigma), $1 \mathrm{mM} \mathrm{L-} \mathrm{glutamine} \mathrm{(Gibco,} \mathrm{Rockville,} \mathrm{MD),} 5 \times 10^{-5}$ M 2-mercaptoethanol (Sigma), $100 \mathrm{U} / \mathrm{ml}$ penicillin (Gibco), and $100 \mu \mathrm{g} / \mathrm{ml}$ streptomycin (Gibco). Red blood cells in the spleen were lysed with Tris-buffered ammonium chloride. Cell suspensions were washed twice and counted using a hemacytometer. Viability was determined using Trypan blue dye exclusion. 


\section{Measurement of antibody secreting B cells (ASC) in the spleen}

Acrowell $^{\mathrm{TM}} 96$ well filter plates (Pall Life Sciences, Ann Arbor, MI) were coated with $50 \mu \mathrm{l}$ PC-BSA (Biosearch Technologies, Novato, CA) $(10 \mu \mathrm{g} / \mathrm{ml})$ overnight at $4{ }^{\circ} \mathrm{C}$. In all subsequent steps, plates were washed with PBS $+.01 \%$ Tween-20. Plates were blocked with $200 \mu \mathrm{l} /$ well complete medium $+25 \%$ FBS for 2 hours at $37^{\circ} \mathrm{C}$. Plates were washed and cells $(100 \mu \mathrm{l} /$ well $)$ were then added at a concentration of $5 \times 10^{6}$ cells $/ \mathrm{ml}$ or $1 \times 10^{6}$ cells $/ \mathrm{ml}$. All samples were plated in triplicate. Plates were incubated for 4-6 hours at $37^{\circ} \mathrm{C}$ in a $5 \% \mathrm{CO}_{2}$ incubator. After washing, goat anti-mouse alkaline phosphatase (AP) conjugated IgG, IgG2b, IgG3, or IgM antibodies (Southern Biotechnology Associates, Birmingham, AL), diluted 1/250 in PBS $+1 \% \mathrm{BSA}+.05 \%$ Tween-20, were added to the appropriate wells $\left(100 \mu \mathrm{l} /\right.$ well). Plates were incubated overnight at $4^{\circ} \mathrm{C}$ and washed. SIGMAFAST 5-bromo-4-chloro-3-indolyl phosphate/nitro blue tetrazolium tablets (Sigma-Aldrich, St. Louis, MO) were dissolved in distilled water and added at 100 $\mu 1 /$ well. Color development was stopped by washing with distilled water. The number of spots/well was counted using a dissection microscope (Olympus Optical Co., Melville, NY). The number of ASC was calculated by using the mean number of spots from triplicate wells. The number of ASC was normalized to $1 \times 10^{6}$ B cells. Comparable fold increases were noted when normalized to whole spleen (Salazar et al., 2005).

\section{Flow cytometric analysis}

Splenic cells were stained with the appropriate combinations of rat anti-mouse B220-APC (RA3-6B2), rat anti-mouse CD4-FITC (GK1.5), or rat anti-mouse CD8 $\alpha$-PE (53-6.7) (BD PharMingen, San Diego, CA). All steps were performed in PBS

supplemented with $1 \%$ FBS and $0.04 \%$ sodium azide (Sigma). Briefly, 1 x $10^{6}$ cells were 
stained in a total volume of $25 \mu \mathrm{l}$ of antibodies at the appropriate concentrations for 25 minutes on ice in the dark. After incubation, cells were washed twice and fixed in $0.04 \%$ paraformaldehyde overnight at $4^{\circ} \mathrm{C}$ (Fisher Scientific, Pittsburgh, PA). The following day cells were washed twice to remove the paraformaldehyde and resuspended in $1 \mathrm{ml}$ of staining media. For each sample, 10,000 cells were collected for analysis on a BectonDickinson FACScan (Becton Dickinson Immunocytometry Systems, Mansfield, MA). Analysis was performed using WinMDI software (Joseph Trotter, Scripps Institute, San Diego, CA). Population percentages, obtained from flow cytometric analysis, were used to calculate the absolute cell number by multiplying the percentage of cells in a population by the total number of cells harvested per organ. Previous experiments have determined that the number of $\mathrm{CD} 4^{+} \mathrm{T}$ cells, $\mathrm{CD} 8^{+} \mathrm{T}$ cells, and $\mathrm{B}$ cells is not changed after propanil exposure (Salazar et al., 2005).

\section{ER binding assay}

ER competitive binding assays were performed using purified recombinant ER $\alpha$ and ER $\beta$ (Panvera, Madison, WI). Reactions were performed in $10 \mathrm{mM}$ Tris, $1.5 \mathrm{mM}$ EDTA, $1.0 \mathrm{mM}$ dithiothreitol, and $10 \%$ glycerol at $\mathrm{pH}$ 7.4. Reactions containing $1 \mathrm{nmol}$ ER, $10 \mathrm{nmol}\left[{ }^{3} \mathrm{H}\right]-\mathrm{E} 2$, and the indicated concentrations of competing unlabeled E2 or propanil were performed in reaction buffer at $4^{\circ} \mathrm{C}$ for 18 to $20 \mathrm{~h}$. $\left[{ }^{3} \mathrm{H}\right]$-E2 bound to ER was separated from free $\left[{ }^{3} \mathrm{H}\right]-\mathrm{E} 2$ by adding a $60 \%$ hydroxylapatite solution followed by repeated centrifugation and washing. The amount of $\left[{ }^{3} \mathrm{H}\right]-\mathrm{E} 2$ bound to E2 was determined by liquid scintillation.

\section{Ishikawa cells and alkaline phosphatase activity}


Ishikawa cells (a generous gift from Richard B. Hochberg, Yale University Medical School, New Haven, Connecticut) were maintained in MEM medium (Sigma), 10\% fetal bovine serum, as described (Littlefield et al., 1990). Ishikawa cells were treated as described to assess the effect of propanil on estrogen-inducible alkaline phosphatase (Littlefield et al., 1990). Briefly, cultures were rinsed twice with estrogenfree basal medium and maintained in this medium for 24 hours. Cells were then trypsinized and plated into 96 well plates $\left(1 \times 10^{4}\right.$ cells/well) in the presence or absence (negative control) of indicated concentrations of estrogen (positive control) or propanil. All cell treatments were performed in quadruplicate. After $72 \mathrm{hr}$, cultures were treated as described in detail, and alkaline phosphatase activity was determined by measuring the conversion of $p$-nitrophenyl phosphate to $p$-nitrophenol. MTT Cell Proliferation Kit (Roche Applied Science, Indianapolis, IN) was used as specified by the manufacturer to assess effects on cell numbers. Propanil had no effect on the proliferation of Ishikawa cells (data not shown).

\section{Statistics}

One-way analysis of variance (ANOVA) was performed for all statistical analyses using a Tukey-Kramer t-test to perform multiple comparisons between all treatment groups. A significance level of $\mathrm{p} \leq 0.05$ was used for all tests. Statistical analysis was performed using JMP software (SAS Institute Inc., Cary, NC). All experiments were performed 3 or more times with similar results. The figures are representative data from one experiment. 


\section{RESULTS}

\section{Ovariectomization abrogates the antibody increase induced by propanil.}

To test the hypothesis that propanil increases the antibody response after vaccination with HKSP through an estrogenic mechanism, OVX or sham-operated mice were vaccinated with HKSP and treated with propanil or the vehicle. All sham-operated mice exposed to propanil had a significantly increased number of PC-specific ASC compared to sham-operated vehicle-treated mice (Figure 1). PC-specific IgM and the dominant PC isotypes, IgG2b and IgG3, were significantly increased in propanil-treated animals (Figure 1). Spleen cells from these mice were also cultured in vitro for 5 days and the production of antibody measured by specific ELISA. There was an increase in antibody production that corresponded with the increase in ASC (data not shown).

Ovariectomy abrogated the ability of propanil to increase the number of PC-specific ASC in the spleen (Figure 1). Comparable results were obtained when the data were normalized to $1 \times 10^{6}$ splenic B cells (Figure 1) or to the total spleen (data not shown). The number and percentage of $\mathrm{B}$ cells, $\mathrm{CD} 4^{+} \mathrm{T}$ cells and $\mathrm{CD} 8^{+} \mathrm{T}$ cells in the spleen was similar for all groups as determined by flow cytometry (data not shown). These data indicate that the ovaries are required for propanil to induce increases in the PC antibody response.

\section{Propanil does not bind to estrogen receptors in vivo or in vitro.}

To determine if propanil increased the $\mathrm{PC}$ antibody response by binding directly or indirectly with ER $\alpha$, in vivo uterotrophic assays were performed. OVX mice were treated once with $150 \mathrm{mg} / \mathrm{kg}$ of propanil. Positive control animals were treated daily with E2 (He et al., 2003). Uterine weights were recorded 3 days following the first exposure. 
As expected, E2 treatment significantly increased uterine weight (Figure 2). Propanil, however, did not increase the uterine weights compared to vehicle treated animals (Figure 2). This data suggests that propanil does not directly or indirectly activate ER $\alpha$, which is primarily responsible for the E2-induced uterine proliferation (Weihua et al., 2000).

To establish if propanil interacts directly with the $\mathrm{ER} \alpha$ or $\mathrm{ER} \beta$, an in vitro competitive ER binding assay was performed. Propanil did not bind either ER $\alpha$ or ER $\beta$ over a wide range of concentrations (Figure 3), confirming a previous report (Kojima et al., 2004). In addition, propanil was administered to Ishikawa cells, which express both $E R \alpha$ and ER $\beta$. Propanil did not increase estrogen-inducible alkaline phosphatase activity compared to controls, further supporting that propanil does not bind $\operatorname{ER} \alpha$ or $\operatorname{ER} \beta$ (Figure 4).

Administration of exogenous E2 does not restore the enhanced antibody response in propanil-treated OVX mice.

To determine if propanil requires E2 to enhance the antibody response to HKSP, OVX mice were exposed once to either propanil or vehicle control. In addition, half of the propanil-treated and vehicle-treated OVX mice received daily sc E2 for 7 days. All groups were vaccinated with HKSP on day 0. The PC-specific responses from the OVX mice were compared with sham-operated mice. Uterine weights and PC-specific splenic ASC were measured on day 7. Uterine weights of OVX mice were significantly lower than sham-operated vehicle mice (Figure 5A). Exogenous E2 administration restored uterine weights of OVX mice comparable to uterine weights of sham-operated mice (Figure 5A, OVX Vehicle + E2 vs. Vehicle, OVX Propanil + E2 vs. Vehicle). The 
addition of exogenous E2 to propanil-treated OVX mice failed to restore the increase in PC-specific ASC (Figure 5B, OVX Propanil + E2 vs. Propanil). All ovariectomized mice had a similar number of PC-specific ASC as vehicle control animals (Figure 5B). These results suggest that the inability of propanil to enhance the antibody response in OVX mice was not due to the absence of E2.

\section{An ER antagonist does not inhibit the ability of propanil to enhance the antibody response.}

The previous experiment demonstrated that the addition of exogenous E2 did not restore the ability of propanil to enhance the antibody response in OVX mice. However, it is possible that the dose of exogenous E2 given does not accurately mimic the level of E2 in mice with intact ovaries. To determine if signaling through the estrogen receptor is required for the increased immune response, mice were treated with the ER $\alpha$ and ER $\beta$ antagonist ICI 182,780. Normal female mice were vaccinated and treated with propanil or vehicle on day 0 , and given daily treatments with ICI 182,780 . Uterine weights were measured to confirm the efficacy of the ICI treatment and the PC-specific antibody response was determined. The uterine weights of all animals receiving the ER antagonist were significantly reduced compared to control animals (Figure 6A). Treatment with the ER antagonist did not affect the basal PC-specific ASC response in vehicle-treated mice (Vehicle vs. Vehicle + ICI, Figure 6B). Propanil-exposed mice treated with ICI had an increased ASC response comparable to propanil alone (Propanil vs. Propanil + ICI, Figure 6B). These results demonstrate that the ER antagonist did not inhibit the increase in PC-specific ASC in propanil-treated animals, which suggests that signaling through the estrogen receptor pathway is not required for propanil to enhance the antibody response. 


\section{Inhibition of steroid synthesis in propanil-treated mice abrogates the increase in}

ASC.

Chemical inhibition of steroid synthesis was conducted to determine if a gonadal steroid other than estradiol regulates the propanil amplification of the humoral immune response. Animals were treated with the $\mathrm{GnRH}$ antagonist antide for 14 days prior to propanil exposure and HKSP vaccination to ensure complete suppression of ovarian steroid synthesis (Couse et al., 2003). Serum estradiol levels were determined prior to propanil treatment on day 14. All mice had non-detectable levels of estradiol, which is indicative of the efficacy of the antide treatments (data not shown). Uterine weights and the immune response to PC were determined 7 days post-vaccination. Antide-treated animals had significantly decreased uterine weights (Figure 7A). Treatment with antide did not affect the basal PC-specific ASC response (Vehicle vs. Vehicle Antide, Figure 7B). The number of PC-specific ASC in mice treated with antide and exposed to propanil were not significantly different from the vehicle controls (Vehicle vs. Propanil Antide, Figure 7B), but were significantly different from the propanil-treated control animals that had an increased ASC response (Propanil vs. Propanil Antide, Figure 7B). These results demonstrate that steroid synthesis is necessary for the enhanced immune response in the spleens of mice exposed to propanil.

\section{A progesterone receptor antagonist does not inhibit antibody enhancement by}

\section{propanil.}

Progesterone is another steroid hormone that has been shown to affect antibody production. The progesterone antagonist, RU486, was utilized to determine if 
progesterone signaling is required for the increased antibody response. As previously stated, propanil induces thymic atrophy which is partially inhibited by RU486 (de la Rosa et al., 2005). To determine the efficacy of the RU486 treatments, mice were treated with RU486 2 hours prior to propanil or vehicle treatment, and at 12 and 24 hours postexposure. RU486 partially abrogated thymic atrophy as determined by measurement of the thymic weights and by quantification of the $\mathrm{CD} 4^{+} \mathrm{CD} 8^{+}$thymocyte population (Figure 8A and 8B), demonstrating that RU486 is efficacious via the sc route.

To determine if blockade of the progesterone receptor inhibits the increased antibody response, mice were injected with RU486 2 hours prior to propanil exposure and vaccination. Mice were subsequently injected with RU486 12 hours post-exposure and every 24 hours following propanil treatment. Treatment with the progesterone antagonist did not affect the basal PC-specific ASC response in vehicle-treated mice (Vehicle vs. Vehicle + RU486, Figure 8C). Propanil-exposed mice treated with RU486 had an increased ASC response comparable to propanil alone (Propanil vs. Propanil + RU486, Figure 8C). These results demonstrate that the progesterone antagonist did not inhibit the increase in PC-specific ASC in propanil-treated animals, which suggests that progesterone is not required for propanil to enhance the antibody response.

\section{Propanil enhances the antibody response in both normal and orchiectomized males.}

To determine if propanil increased the antibody response in a gender specific manner, male mice were vaccinated and treated with propanil or vehicle (Figure 9). The PC-specific splenic ASC were measured after 7 days. Propanil increased the $\operatorname{IgG} 2 \mathrm{~b}$, IgG3 and IgM PC-specific splenic ASC approximately 3-fold (Vehicle vs. Propanil, Figure 9). Castration did not significantly affect the propanil-induced increase in PC- 
specific ASC. Castrated males treated with propanil produced approximately the same fold increase in PC-specific ASC as normal propanil-treated male mice (Propanil vs. Propanil Castrated, Figure 9). These results suggest that androgens are not involved in the amplification of the immune response after propanil exposure. 


\section{DISCUSSION}

Gonadal steroid regulation of the immune system is poorly understood. The majority of the research into the effects of sex steroids on the humoral immune response involves the hormones estradiol, progesterone, and testosterone. Estradiol has been demonstrated to increase the number of antigen-specific splenic ASC several fold (Verthelyi and Ahmed, 1998). The other major gonadal hormones progesterone and testosterone are generally considered to be immunosuppressive. The data presented here suggest a novel role for the amplification of the TI- 2 humoral immune response by the ovary that is independent of estrogen or progesterone. This report also demonstrates the novel use of propanil exposure to study the mechanism for gonadal steroid regulation of antibody responses.

Previous reports demonstrated that propanil induces a number of immunotoxic effects that suggest a manipulation of the estrogenic pathway (de la Rosa et al., 2003; de la Rosa et al., 2005; Salazar et al., 2005). Propanil has been classified by two studies as non-estrogenic and weakly anti-androgenic, as determined by receptor binding assays (Bauer et al, 1998; Kojima et al., 2004). However, given the heavy usage of propanil and the importance of studying endocrine disruption, extensive characterization of propanil as a potential EDC is warranted. Synthetic chemicals can manipulate the estrogenic pathway in a number of ways including 1) direct binding of ERs, 2) indirect ER activation by stimulating ER phosphorylation, 3) altered expression of the ER, 4) changing the levels of hormone expression, or 5) modifying the intracellular estrogenic signaling pathway (Borgest et al., 2002). 
The uterotrophic assay is the classic method to determine the in vivo estrogenic activity of a chemical. Measuring uterine weights after 3 days of chemical exposure is a sensitive assay for detecting weak ER agonists (O'Connor et al., 1996). In vivo exposure to propanil did not induce an increase in uterine weight. Disadvantages of the uterotrophic assay include the inability to decipher antagonistic or agonistic activity in different organs, a lack of specificity, and the inability to measure ER $\beta$ binding activity (O'Connor et al., 1996; Weihua et al., 2000). For instance, chemicals such as tamoxifen act either as ER antagonists or agonists within different organs or at different concentrations (Watanabe et al., 1997). Therefore, the ER $\alpha$ and ER $\beta$ binding activity of propanil were determined using in vitro assays. Propanil did not compete for E2 binding to either $\mathrm{ER} \alpha$ or $\mathrm{ER} \beta$ nor did it increase estrogen-inducible alkaline phosphatase activity in ER-responsive cells. The results of the uterotrophic assay, ER binding studies, and the ER-inducible alkaline phosphatase assay establish that propanil is not a classic EDC.

Increasing ER expression levels might also affect antibody activity since the ER is found on many immune cells including B cells (Grimaldi et al., 2002). Removal of E2 from circulation would eliminate the ability of ER expressing cells to respond. However, subcutaneous administration of E2 to OVX mice failed to restore the stimulatory effect of propanil on the antibody response to HKSP, which indicates that propanil does not require the presence of E2 to exert its effect on the splenic antibody response. This also suggests that propanil exposure does not induce antibody stimulation by increasing the ability of cells to bind E2. In addition, the data shows that high concentrations of E2 for a short period of time (7 days) do not affect the TI-2 antibody response. 
Chronic low E2 exposure increases splenic ASC (Myers and Petersen, 1985; Verthelyi and Ahmed, 1998). However, high levels of E2, such as during the third trimester of pregnancy, is immunosuppressive (Confavreux et al., 1998). Measuring E2 serum levels is compounded by a number of factors including estrous cycling and the selection of several time points for hormone analysis. An alternative approach to directly measuring estradiol serum levels is to inhibit the effects of E2 by blocking the ER. The ER antagonist ICI 182,780 has been demonstrated to completely attenuate the ability of $\mathrm{ER} \alpha$ and $\mathrm{ER} \beta$ to regulate transcription by 1) impairing receptor dimerization, 2) increasing receptor degradation, thereby lowering ER expression, and 3) disrupting nuclear localization of the ER/ligand complex (Wakeling, 2000). Several reports have shown that administration of ICI $182,7801 \mathrm{hr}$ prior to EDC exposure is sufficient to inhibit the effect of an EDC (Ciana et al., 2001; Jung et al., 2005; Papaconstantinou et al, 2001). Propanil does not appear to trigger antibody stimulation by acting on the estrogenic signaling pathway, as indicated by the failure of ICI 182,780 to inhibit the increased ASC response following propanil treatment. These data strongly suggest that propanil does not affect the TI-2 antibody response via an estrogenic mechanism.

The GnRH antagonist antide was utilized to determine if gonadal steroids regulate the ovarian-dependent stimulation of the antibody response. Antide treatment abrogated the effect of propanil similar to ovariectomy, suggesting that propanil stimulates the antibody response via a gonadal dependent mechanism in females. Antide treatment not only blocks the effects of GnRH, but also decreases the production of LH and FSH from the pituitary and eliminates the secretion of gonadal hormones (Couse $e t$ al, 2003; Fallest et al., 1995). The hypothalamic hormone, GnRH, and the pituitary hormones, LH and 
FSH, have all been demonstrated to regulate the antibody response (Athreya et al., 1993; Jacobson and Ansari, 2004). Since ovariectomized animals have elevated levels of LH and FSH compared to antide-treated animals, but have similar antibody responses following propanil exposure, it can be inferred that LH and FSH do not participate in the increase in the number of PC-specific ASC (Wakeling et al., 1991; Couse et al., 2003).

Other non-estrogenic hormones in the steroid synthesis pathway can regulate the antibody response. Androgens can induce immunosuppression (Brick et al., 1985). As mentioned previously, propanil has some anti-androgenic activity. However, antibody studies evaluating the effects of anti-androgens indicate that they are not immunostimulatory (O'Connor et al., 2002). In addition, removal of the primary source of testosterone in males via castration did not affect the ability of propanil to enhance the antibody response. Altogether, this data does not support an androgenic mechanism.

Progesterone has been demonstrated to be primarily immunosuppressive in pregnant women (Beagley and Gockel, 2003). Observations in pregnant women with autoimmune diseases such as multiple sclerosis have demonstrated that progesterone and estradiol levels are at the highest during the third trimester when the severity of disease decreases (Confavreux et al., 1998). However, some studies have demonstrated that the number of antigen-specific ASC in the vaginal tissue is increased following mucosal immunization and progesterone treatment Johansson et al., 1998). Blockade of the progesterone receptor with RU486 did not have any effect on the stimulation of the antibody response in propanil-treated mice. This suggests that antibody enhancement does not require a progesterone-dependent mechanism. 
Loss of the increased PC response following ovariectomy or inhibition of steroid synthesis may be the result of an indirect effect caused by the loss in homeostatic steroid hormone levels. Immunomodulatory hormones, such as GnRH and E2, are produced locally in lymphoid organs. Studies have shown that the gonads regulate these locally produced lymphoid hormones, suggesting another potential mechanism for ovarian regulation of the humoral immune response. For instance, GnRH has been demonstrated to have immunomodulating effects independent of other hormones. Reports have shown that $\mathrm{GnRH}$ receptor mRNA and GnRH mRNA are expressed in murine spleen cells and human B lymphocytes (Jacobson et al., 1998; Khan et al., 2003; Silveira et al, 2002). In addition, the spleen has been demonstrated to have a higher affinity for GnRH peptide compared to other endocrine and nonendocrine organs including the testes and liver (Khan et al., 2003). Three weeks of exogenous GnRH treatment increases both the total IgG serum levels in female ovariectomized mice and the proliferation of $\mathrm{B}$ and $\mathrm{T}$ lymphocytes in response to LPS and ConA stimulation, respectively (Jacobson and Ansari, 2004).

The classically studied source of GnRH is the hypothalamus, although it is unlikely that hypothalamic produced GnRH can directly affect spleen function since the concentration of $\mathrm{GnRH}$ in the portal blood is low and rapidly metabolized (Eskay et al., 1975). Evidence suggests that the ligand for GnRH receptors on splenic lymphocytes is likely to be derived from another endogenous source and may act in an autocrine or paracrine fashion in non-pituitary organs (Chen et al., 1999). Both GnRH mRNA and GnRH receptor mRNA are altered in splenocytes throughout the estrous cycle, however, the exact mechanism of this regulation is unknown (Jacobson et al., 1998). 
It is possible that the ovaries are involved in regulating the local $\mathrm{GnRH}$ production in the spleen, which contributes to the increased antibody response in propanil-treated animals. This hypothesis might also explain the contrasting results between castrated and ovariectomized animals. There is data which indicates that male and female discrepancies in immune function exist in response to $\mathrm{GnRH}$ treatment following gonadectomy (Jacobson et al., 1999). These data suggest that the sexual disparities exist due to a residual effect caused by hormonal differences experienced early in development.

Additional evidence exists suggesting gonad-mediated hormone regulation in lymphocytes and the spleen. A recent report demonstrated that removal of the ovaries alters the activity of the steroid hormones aromatase and $17 \beta$-hydroxysteroid dehydrogenase locally in the spleens and T cells of mice (Samy et al., 2001). In addition, castration had the opposite effect on the activity of these enzymes (Samy et al., 2001). The role of these steroidogenic pathways in the spleen and $\mathrm{T}$ cells on the humoral immune response has not been evaluated. Propanil may act by disrupting the ovarian control of the steroidogenic enzymes in the spleen leading to altered B cell activation. Analyzing the local spleen-specific and ovary-specific hormone receptor mRNA, hormone mRNA, and the activity of steroid enzymes would yield valuable clues to the mechanism regulating this effect.

In contrast to the results presented here, previous studies have demonstrated that exposure to propanil can decrease the response to a $\mathrm{T}$ dependent and a $\mathrm{T}$-independent antigen (Barnett et. al., 1992; Barnett and Gandy, 1989). In the previous studies, C57B1/6 female mice were exposed i.p. to propanil on day 0, immunized i.v. on day 3 
with the TI-2 antigen DNP-Ficoll, or the T dependent antigen, SRBC, and the plaqueforming cell response in the spleen determined on day 7. In the present studies, propanil was administered i.p. on day 0 and the mice immunized i.p. with HKSP on day 0. The PC-specific ASC response was determined on day 7. It is possible that the different results between the studies in the PC antibody response is due to the nature of the antigen, purified antigen versus whole heat-killed bacteria. However, preliminary studies in the laboratory have demonstrated a similar enhancement of the ASC response to the TI-2 antigen PC-Ficoll when propanil is administered at the time of PC-Ficoll immunization. Therefore, the timing of propanil exposure and immunization may be the critical factor in the ultimate effect that propanil has on the humoral immune response. Preliminary studies demonstrate that propanil can be given 3 days after HKSP immunization and still enhance the PC immune response. In addition, preliminary experiments demonstrate that propanil can also enhance the ASC response in the spleen to a T dependent antigen on HKSP, PspA. The PspA-specific serum antibody titers peak approximately 14 days post-immunization. Propanil must be given on day 9 after immunization to enhance the PspA response. If the animals are exposed to propanil at the time of immunization on day 0 there is no effect on the immune response to PspA on day 14. Taken together, these studies suggest that propanil exposure must occur near the time of the peak antibody response to increase the response. It is not yet known if the ovaries are required for the enhancement of the immune response to PC-Ficoll or PspA.

Altogether, these data support two novel findings. First, propanil enhances the antigen-specific antibody response in females in an ovary-dependent, estrogenindependent manner unlike other EDC reported to date. Second, the data suggests a 
novel role for antibody stimulation by the ovaries following chemical exposure. Future studies will utilize propanil as a unique tool to examine interactions between the immune and endocrine systems with an emphasis on how the ovaries contribute to regulation of humoral immune responses. 


\section{ACKNOWLEDGEMENTS}

This work was supported by the National Institutes of Health grant ES010953.

The Flow Cytometric Core Facility is supported by the National Institutes of Health grant RR16440.

We thank Meenal Elliott, Ph.D. for the S. pneumoniae strain R36A, and Lennie

Samsell and Jeremie A. Walker for excellent technical assistance (Department of

Microbiology, Immunology and Cell Biology, Robert C. Byrd Health Sciences Center, West Virginia University). 


\section{REFERENCES}

1. Athreya, B. H., Pletcher, J., Zulian, F., Weiner, D. B., and Williams, W. V. (1993). Subset-specific effects of sex hormones and pituitary gonadotropins on human lymphocyte proliferation in vitro. Clin.Immunol.Immunopathol. 66, 201-211.

2. Barnett, J.B., and Gandy, J. (1989). The effect of acute propanil exposure on the immune system of C57Bl/6 mice. Fund. Appl. Toxicol. 12, 757-764.

3. Barnett, J., Gandy, J., Wilbourn, D., and Theus, S.A.. (1992). Comparison of the immunotoxicity of propanil and its metabolite, 3,4,-dichloroaniline, in C57Bl/6 mice. Fund. Applied Toxicol. 18, 628-631.

4. Bauer, E. R., Meyer, H. H., Stahlschmidt-Allner, P., and Sauerwein, H. (1998). Application of an androgen receptor assay for the characterisation of the androgenic or antiandrogenic activity of various phenylurea herbicides and their derivatives. Analyst 123, 2485-2487.

5. Beagley, K. W. and Gockel, C. M. (2003). Regulation of innate and adaptive immunity by the female sex hormones oestradiol and progesterone. FEMS Immunol.Med.Microbiol. 38, 13-22.

6. Borgeest, C., Greenfeld, C., Tomic, D., and Flaws, J.A. (2002). The effects of endocrine disrupting chemicals on the ovary. Front. Biosci. 7, 1941-1998. 
7. Brick, J. E., Wilson, D. A., and Walker, S. E. (1985). Hormonal modulation of responses to thymus-independent and thymus-dependent antigens in autoimmune NZB/W mice. J.Immunol. 134, 3693-3698.

8. Chen, H. F., Jeung, E. B., Stephenson, M., and Leung, P. C. (1999). Human peripheral blood mononuclear cells express gonadotropin-releasing hormone $(\mathrm{GnRH})$, GnRH receptor, and interleukin-2 receptor gamma-chain messenger ribonucleic acids that are regulated by GnRH in vitro. J.Clin.Endocrinol.Metab 84, 743-750.

9. Ciana, P., Di Luccio, G., Belcredito, S., Pollio, G., Vegeto, E., Tatangelo, L., Tiveron, C., and Maggi, A. (2001). Engineering of a mouse for the in vivo profiling of estrogen receptor activity. Mol.Endocrinol. 15, 1104-1113.

10. Confavreux, C., Hutchinson, M., Hours, M. M., Cortinovis-Tourniaire, P., and Moreau, T. (1998). Rate of pregnancy-related relapse in multiple sclerosis. Pregnancy in Multiple Sclerosis Group. N.Engl.J.Med. 339, 285-291.

11. Couse, J. F., Yates, M. M., Walker, V. R., and Korach, K. S. (2003). Characterization of the hypothalamic-pituitary-gonadal axis in estrogen receptor (ER) Null mice reveals hypergonadism and endocrine sex reversal in females lacking ERalpha but not ERbeta. Mol.Endocrinol. 17, 1039-1053.

12. Cuff, C. F., Zhao, W., Nukui, T., Schafer, R., and Barnett, J. B. (1996). 3,4Dichloropropionanilide-induced atrophy of the thymus: mechanisms of toxicity and recovery. Fundam.Appl.Toxicol. 33, 83-90. 
13. de la Rosa, P., Barnett, J., and Schafer, R. (2003). Loss of pre-B and $\operatorname{IgM}(+)$ B cells in the bone marrow after exposure to a mixture of herbicides. J.Toxicol.Environ.Health A 66, 2299-2313.

14. de la Rosa, P., Barnett, J. B., and Schafer, R. (2005). Characterization of thymic atrophy and the mechanism of thymocyte depletion after in vivo exposure to a mixture of herbicides. J.Toxicol.Environ.Health A 68, 81-98.

15. Do, Y., Ryu, S., Nagarkatti, M., and Nagarkatti, P. S. (2002). Role of death receptor pathway in estradiol-induced T-cell apoptosis in vivo. Toxicol.Sci. 70, 63-72.

16. Erlandsson, M. C., Jonsson, C. A., Islander, U., Ohlsson, C., and Carlsten, H. (2003). Oestrogen receptor specificity in oestradiol-mediated effects on B lymphopoiesis and immunoglobulin production in male mice. Immunology 108, 346-351.

17. Erlandsson, M. C., Ohlsson, C., Gustafsson, J. A., and Carlsten, H. (2001). Role of oestrogen receptors alpha and beta in immune organ development and in oestrogenmediated effects on thymus. Immunology 103, 17-25.

18. Eskay, R. L., Warberg, J., Mical, R. S., and Porter, J. C. (1975). Prostaglandin E2induced release of LHRH into hypophysial portal blood. Endocrinology 97, 816-824.

19. Fallest, P. C., Trader, G. L., Darrow, J. M., and Shupnik, M. A. (1995). Regulation of rat luteinizing hormone beta gene expression in transgenic mice by steroids and a gonadotropin-releasing hormone antagonist. Biol.Reprod. 53, 103-109. 
20. Frasor, J., Danes, J. M., Komm, B., Chang, K. C., Lyttle, C. R., and Katzenellenbogen, B. S. (2003). Profiling of estrogen up- and down-regulated gene expression in human breast cancer cells: insights into gene networks and pathways underlying estrogenic control of proliferation and cell phenotype. Endocrinology 144, 4562-4574.

21. Grimaldi, C. M., Cleary, J., Dagtas, A. S., Moussai, D., and Diamond, B. (2002). Estrogen alters thresholds for B cell apoptosis and activation. J.Clin.Invest 109, 16251633.

22. He, B., Rhodes-Brower, S., Miller, M. R., Munson, A. E., Germolec, D. R., Walker, V. R., Korach, K. S., and Meade, B. J. (2003). Octamethylcyclotetrasiloxane exhibits estrogenic activity in mice via ERalpha. Toxicol.Appl.Pharmacol. 192, 254-261.

23. Islander, U., Erlandsson, M. C., Hasseus, B., Jonsson, C. A., Ohlsson, C., Gustafsson, J. A., Dahlgren, U., and Carlsten, H. (2003). Influence of oestrogen receptor alpha and beta on the immune system in aged female mice. Immunology 110, 149-157.

24. Jacobson, J. D. and Ansari, M. A. (2004). Immunomodulatory actions of gonadal steroids may be mediated by gonadotropin-releasing hormone. Endocrinology $\mathbf{1 4 5}$, 330-336.

25. Jacobson, J. D., Ansari, M. A., Kinealy, M., and Muthukrishnan, V. (1999). Genderspecific exacerbation of murine lupus by gonadotropin-releasing hormone: potential role of G alpha(q/11). Endocrinology 140, 3429-3437. 
26. Jacobson, J. D., Crofford, L. J., Sun, L., and Wilder, R. L. (1998). Cyclical expression of GnRH and GnRH receptor mRNA in lymphoid organs. Neuroendocrinology 67, $117-125$.

27. Johansson, E. L., Rask, C., Fredriksson, M., Eriksson, K., Czerkinsky, C., and Holmgren, J. (1998). Antibodies and antibody-secreting cells in the female genital tract after vaginal or intranasal immunization with cholera toxin B subunit or conjugates. Infect.Immun. 66, 514-520.

28. Jung, Y. W., Hong, E. J., Choi, K. C., and Jeung, E. B. (2005). Novel progestogenic activity of environmental endocrine disruptors in the upregulation of calbindin-D9k in an immature mouse model. Toxicol.Sci. 83, 78-88.

29. Khan, M. A., Ferro, V. A., and Stimson, W. H. (2003). Use of a highly specific monoclonal antibody against the central variable amino acid sequence of mammalian gonadotropin releasing hormone to evaluate GnRH-I tissue distribution compared with GnRH-I binding sites in adult male rats. Am.J.Reprod.Immunol. 49, 239-248.

30. Kojima, H., Katsura, E., Takeuchi, S., Niiyama, K., and Kobayashi, K. (2004). Screening for estrogen and androgen receptor activities in 200 pesticides by in vitro reporter gene assays using Chinese hamster ovary cells. Environ.Health Perspect. 112, 524-531.

31. Littlefield, B. A., Gurpide, E., Markiewicz, L., McKinley, B., and Hochberg, R. B. (1990). A simple and sensitive microtiter plate estrogen bioassay based on stimulation 
of alkaline phosphatase in Ishikawa cells: estrogenic action of delta 5 adrenal steroids. Endocrinology 127, 2757-2762.

32. Myers, M. J. and Petersen, B. H. (1985). Estradiol induced alterations of the immune system--I. Enhancement of IgM production. Int.J.Immunopharmacol. 7, 207-213.

33. O'Connor, J. C., Cook, J. C., Craven, S. C., Van Pelt, C. S., and Obourn, J. D. (1996). An in vivo battery for identifying endocrine modulators that are estrogenic or dopamine regulators. Fundam.Appl.Toxicol. 33, 182-195.

34. O'Connor, J. C., Frame, S. R., and Ladics, G. S. (2002). Evaluation of a 15-day screening assay using intact male rats for identifying antiandrogens. Toxicol.Sci. 69, 92-108.

35. Papaconstantinou, A. D., Fisher, B. R., Umbreit, T. H., Goering, P. L., Lappas, N. T., and Brown, K. M. (2001). Effects of beta-estradiol and bisphenol A on heat shock protein levels and localization in the mouse uterus are antagonized by the antiestrogen ICI 182,780. Toxicol.Sci. 63, 173-180.

36. Salazar, K. D., De La, R. P., Barnett, J. B., and Schafer, R. (2005). The polysaccharide antibody response after Streptococcus pneumoniae vaccination is differentially enhanced or suppressed by 3,4-dichloropropionanilide and 2,4dichlorophenoxyacetic acid. Toxicol.Sci. 87, 123-133.

37. Samy, T. S., Knoferl, M. W., Zheng, R., Schwacha, M. G., Bland, K. I., and Chaudry, I. H. (2001). Divergent immune responses in male and female mice after trauma- 
hemorrhage: dimorphic alterations in T lymphocyte steroidogenic enzyme activities. Endocrinology 142, 3519-3529.

38. Screpanti, I., Morrone, S., Meco, D., Santoni, A., Gulino, A., Paolini, R., Crisanti, A., Mathieson, B. J., and Frati, L. (1989). Steroid sensitivity of thymocyte subpopulations during intrathymic differentiation. Effects of 17 beta-estradiol and dexamethasone on subsets expressing T cell antigen receptor or IL-2 receptor. J.Immunol. 142, 33783383.

39. Silveira, L. F., Stewart, P. M., Thomas, M., Clark, D. A., Bouloux, P. M., and MacColl, G. S. (2002). Novel homozygous splice acceptor site GnRH receptor (GnRHR) mutation: human GnRHR "knockout". J.Clin.Endocrinol.Metab 87, 29732977.

40. Sobel, E. S., Gianini, J., Butfiloski, E. J., Croker, B. P., Schiffenbauer, J., and Roberts, S. M. (2005). Acceleration of autoimmunity by organochlorine pesticides in (NZB x NZW)F1 mice. Environ.Health Perspect. 113, 323-328.

41. Verthelyi, D. I. and Ahmed, S. A. (1998). Estrogen increases the number of plasma cells and enhances their autoantibody production in nonautoimmune C57BL/6 mice. Cell Immunol. 189, 125-134.

42. Wakeling, A. E. (2000). Similarities and distinctions in the mode of action of different classes of antioestrogens. Endocr.Relat Cancer 7, 17-28.

43. Wakeling, A. E., Dukes, M., and Bowler, J. (1991). A potent specific pure antiestrogen with clinical potential. Cancer Res. 51, 3867-3873. 
44. Watanabe, T., Inoue, S., Ogawa, S., Ishii, Y., Hiroi, H., Ikeda, K., Orimo, A., and Muramatsu, M. (1997). Agonistic effect of tamoxifen is dependent on cell type, EREpromoter context, and estrogen receptor subtype: functional difference between estrogen receptors alpha and beta. Biochem.Biophys.Res.Commun. 236, 140-145.

45. Weihua, Z., Saji, S., Makinen, S., Cheng, G., Jensen, E. V., Warner, M., and Gustafsson, J. A. (2000). Estrogen receptor (ER) beta, a modulator of ERalpha in the uterus. Proc.Natl.Acad.Sci.U.S.A 97, 5936-5941.

46. Wu, Z. Q., Khan, A. Q., Shen, Y., Schartman, J., Peach, R., Lees, A., Mond, J. J., Gause, W. C., and Snapper, C. M. (2000). B7 requirements for primary and secondary protein- and polysaccharide-specific Ig isotype responses to Streptococcus pneumoniae. J.Immunol. 165, 6840-6848.

47. Wu, Z. Q., Vos, Q., Shen, Y., Lees, A., Wilson, S. R., Briles, D. E., Gause, W. C., Mond, J. J., and Snapper, C. M. (1999). In vivo polysaccharide-specific IgG isotype responses to intact Streptococcus pneumoniae are T cell dependent and require CD40- and B7-ligand interactions. J.Immunol. 163, 659-667.

47.Yao, G. and Hou, Y. (2004). Thymic atrophy via estrogen-induced apoptosis is related to Fas/FasL pathway. Int.Immunopharmacol. 4, 213-221.

48. Yurino, H., Ishikawa, S., Sato, T., Akadegawa, K., Ito, T., Ueha, S., Inadera, H., and Matsushima, K. (2004). Endocrine disruptors (Environmental Estrogens) enhance autoantibody production by B1 cells. Toxicol.Sci. 81, 139-147. 

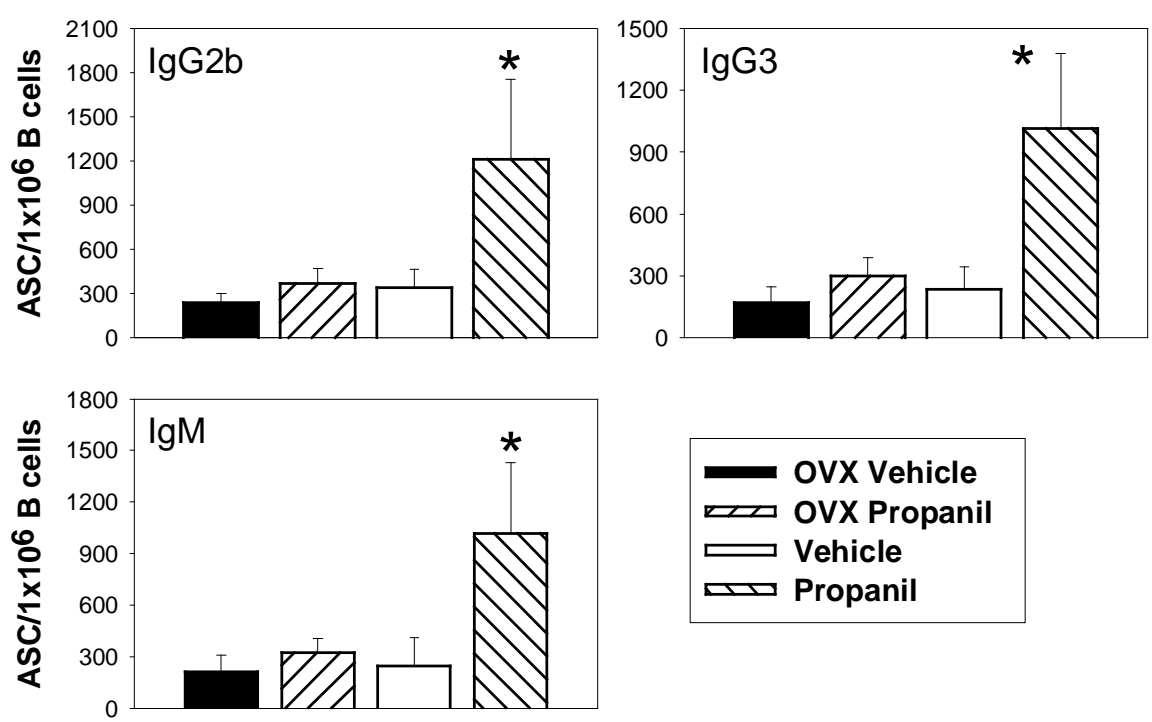

Figure 1. Ovariectomy abrogates the propanil-induced increase in PC-specific splenic ASC.

OVX and sham-operated female C57BL/6 mice (5/group) were treated with $150 \mathrm{mg} / \mathrm{kg}$ propanil or vehicle control and vaccinated with $2 \times 10^{8}$ CFU HKSP. Numbers of PCspecific IgG2b, IgG3, and IgM ASC were determined by ELISPOT assay on day 7.

Values represent the mean \pm SD of ASC $/ 1 \times 10^{6}$ B cells. * Significantly different from all other groups, $\mathrm{p} \leq .05$. 


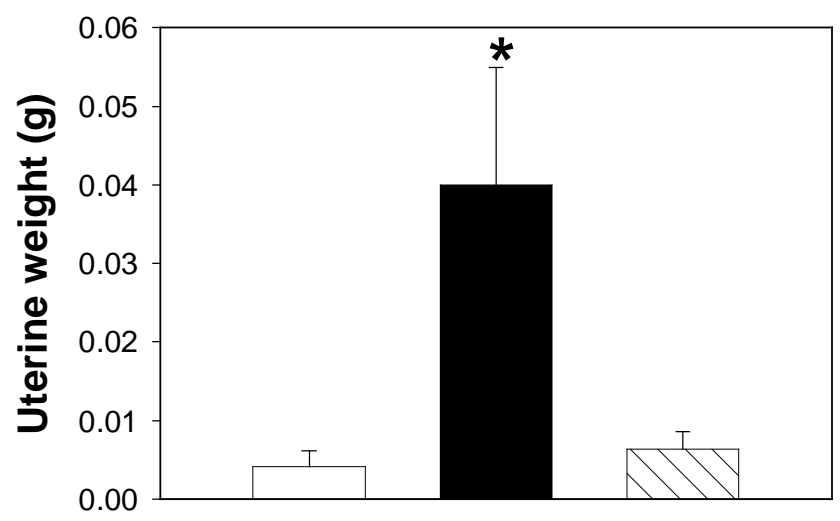

Figure 2. Propanil does not increase uterine weights in OVX mice.

C57BL/6 mice (5/group) were ovariectomized and treated with vehicle control (open bar), $150 \mathrm{mg} / \mathrm{kg}$ propanil (hatched bar), or $10 \mu \mathrm{g} / \mathrm{kg} /$ day of E2 (black bar). Uterine weights were recorded after 3 days. Values represent the mean \pm SD. $*$ Significantly different from vehicle, $\mathrm{p} \leq .05$. 


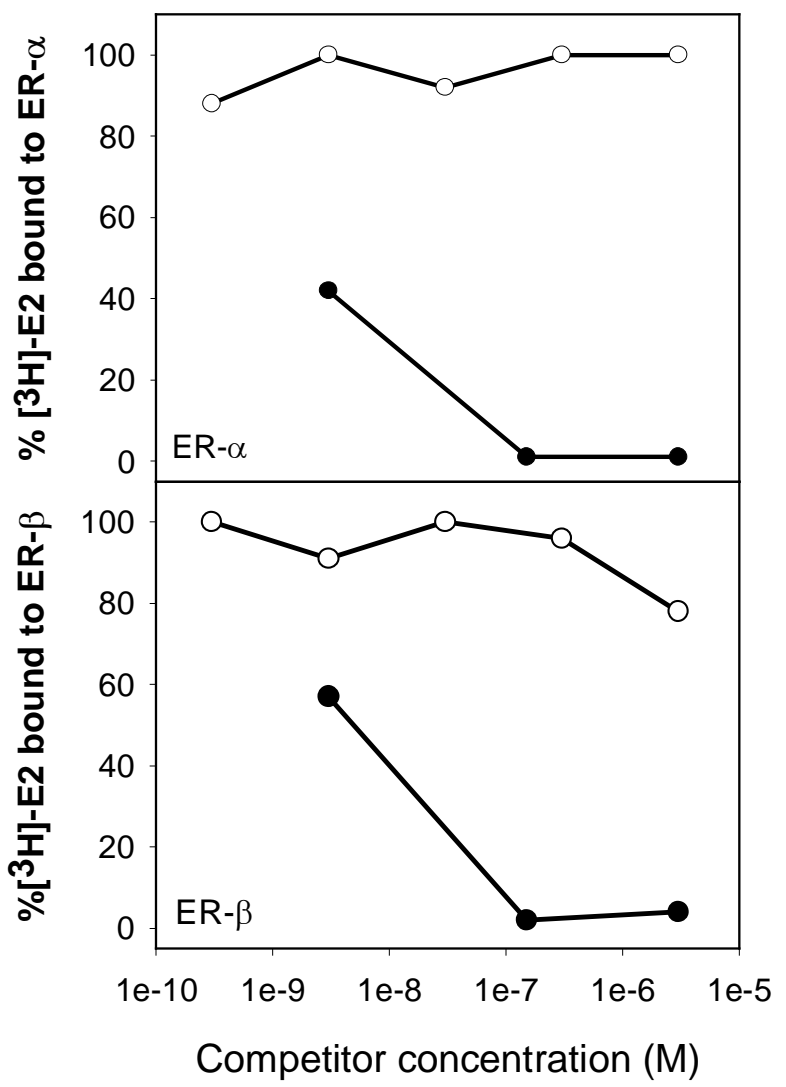

Figure 3. Propanil does not bind to ER $\alpha$ or ER $\beta$.

Competitive binding assays determined the binding of propanil to ER $\alpha$ or ER $\beta$ in the presence of $\left[{ }^{3} \mathrm{H}\right]-\mathrm{E} 2$. Values represent the percent of $\left[{ }^{3} \mathrm{H}\right]-\mathrm{E} 2$ bound to ER in the presence of either propanil (open circles) or unlabeled E2 (closed circles). 


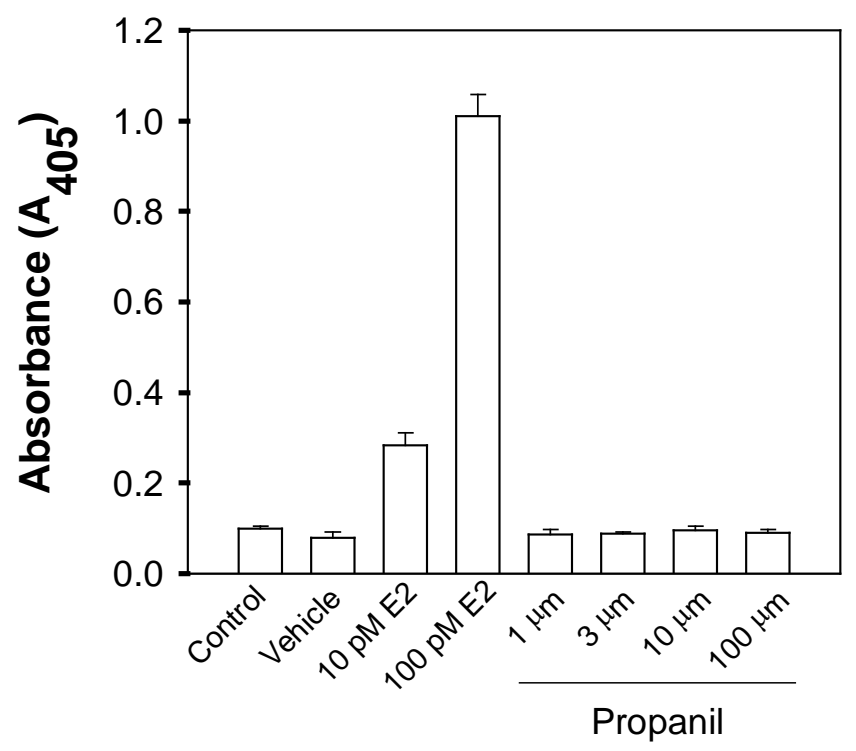

Figure 4. Propanil does not increase estrogen-inducible alkaline phosphatase activity in Ishikawa cells.

Ishikawa cells were treated with propanil $(1 \mu \mathrm{m}, 3 \mu \mathrm{M}, 10 \mu \mathrm{M}$, or $100 \mu \mathrm{M})$ or $\mathrm{E} 2(10 \mathrm{pM}$ or $100 \mathrm{pM})$. Alkaline phosphatase activity was measured after 72 hours. Values represent the mean absorbance recorded in the propanil or E2 treated cells. * Significantly different from vehicle, $\mathrm{p} \leq .05$. 
A.

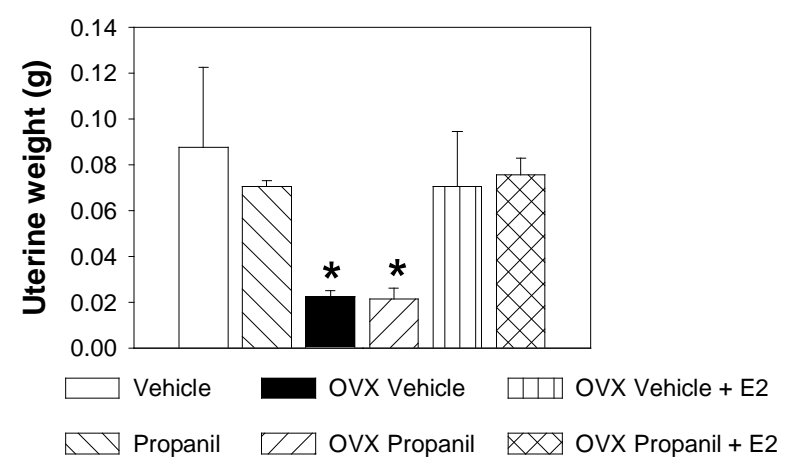

B.
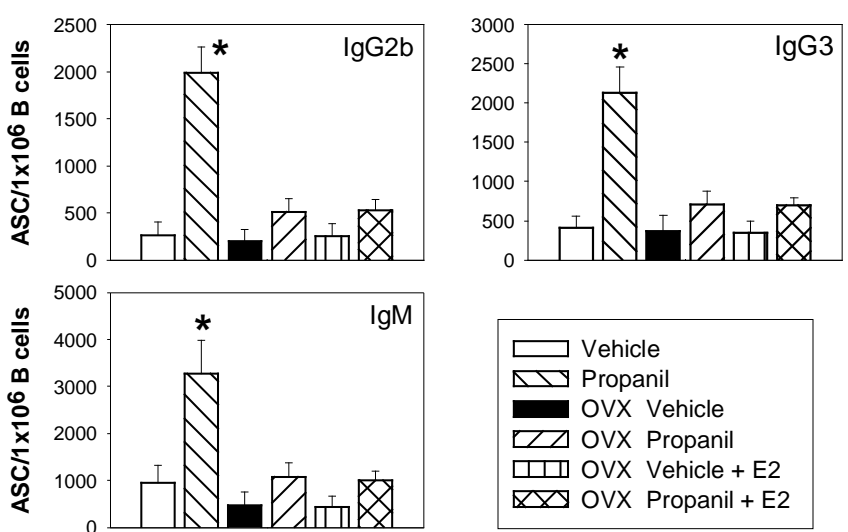

Figure 5. Addition of exogenous E2 does not restore the increase in PC-specific

\section{ASC of propanil-treated animals.}

OVX and sham-operated female C57BL/6 mice (5/group) were treated with $150 \mathrm{mg} / \mathrm{kg}$ propanil or vehicle control and vaccinated with $2 \times 10^{8}$ CFU HKSP. OVX mice were treated with $10 \mu \mathrm{g} / \mathrm{kg} /$ day of E2 or the vehicle. Spleens and uteri were removed after 7 days. (A) Uterine weight. * Significantly different from vehicle control, $\mathrm{p} \leq .05$. (B) Numbers of PC-specific IgG2b, IgG3, and IgM ASC. Values represent the mean \pm SD of ASC $/ 1 \times 10^{6}$ B cells. * Significantly different from vehicle control, $\mathrm{p} \leq .05$. 
A.

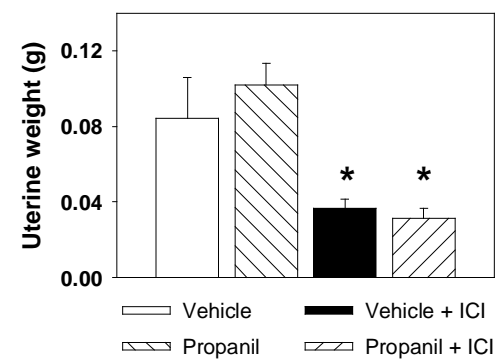

B.
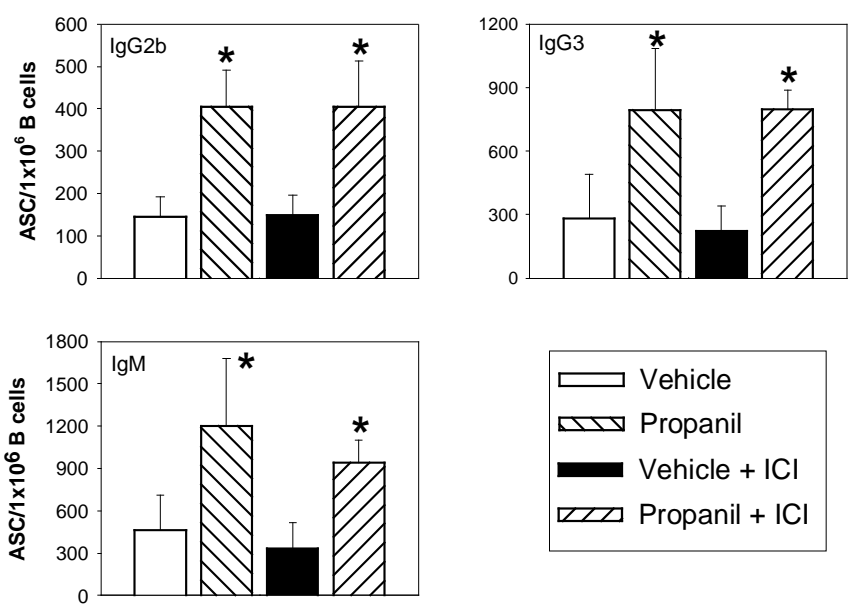

Figure 6. Addition of the ER antagonist ICI 182,780 does not block the increase in ASC in propanil-treated animals.

C57BL/6 mice (5/group) were vaccinated with $2 \times 10^{8}$ CFU HKSP, and treated with 150 $\mathrm{mg} / \mathrm{kg}$ propanil or vehicle control, with or without ICI 182,780 (10 mg/kg/day) or vehicle. Spleens and uteri were removed after 5 days. (A) Uterine weight. * Significantly different from vehicle control, $\mathrm{p} \leq .05$. (B) Numbers of PC-specific IgG2b, IgG3, and IgM ASC. Values represent the mean \pm SD of ASC $1 \times 10^{6}$ B cells. * Significantly different from the respective vehicle control, $\mathrm{p} \leq .05$. 


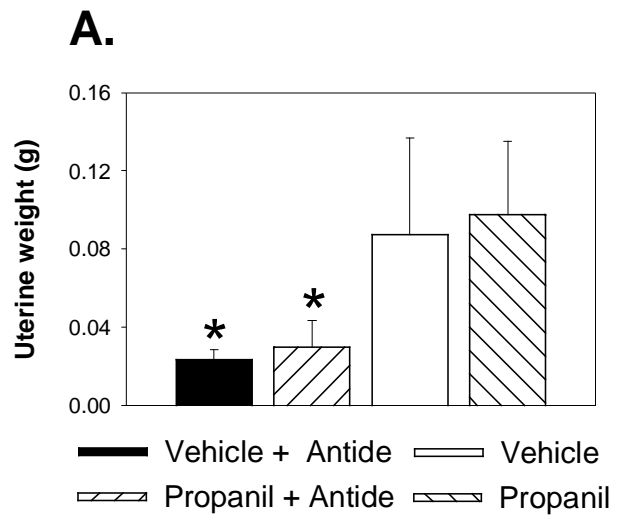

B.
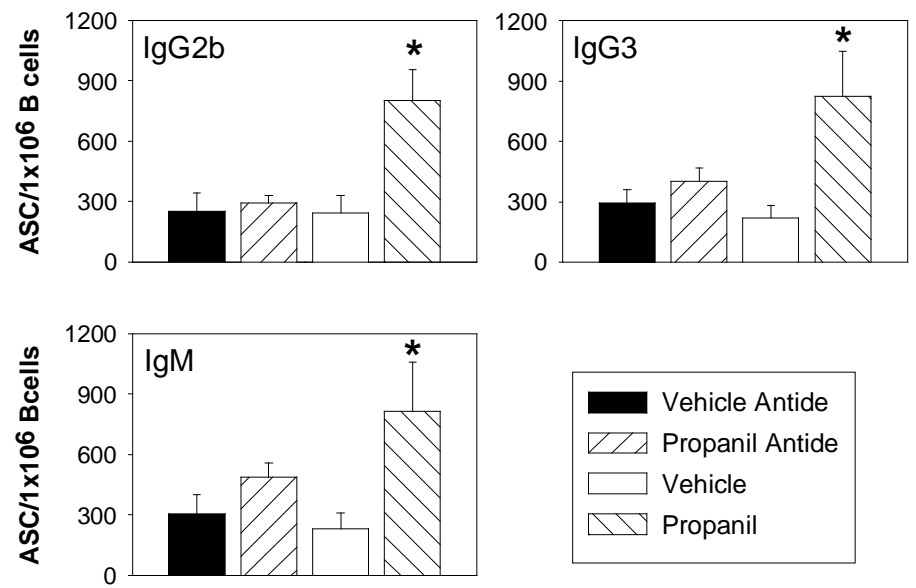

Figure 7. Antide treatment abrogates the propanil-induced increase in PC-specific ASC.

C57BL/6 female mice were treated with antide $(60 \mu \mathrm{g} / \mathrm{mouse})$ or vehicle for 14 days as described in Methods. Mice were vaccinated on day 14 with $2 \times 10^{8}$ CFU HKSP and treated with $150 \mathrm{mg} / \mathrm{kg}$ propanil or vehicle. Spleens and uteri were removed 7 days postvaccination. (A) Uterine weight. * Significantly different from vehicle control, $\mathrm{p} \leq .05$. (B) Numbers of PC-specific IgG2b, IgG3, and IgM ASC. Values represent the mean \pm SD of ASC $/ 1 \times 10^{6}$ B cells. * Significantly different from vehicle control, $\mathrm{p} \leq .05$. 
A.

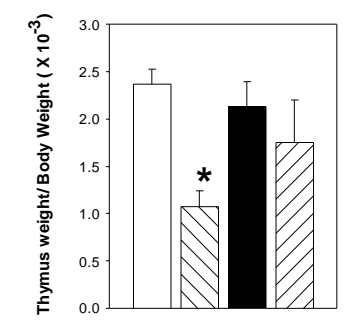

c.
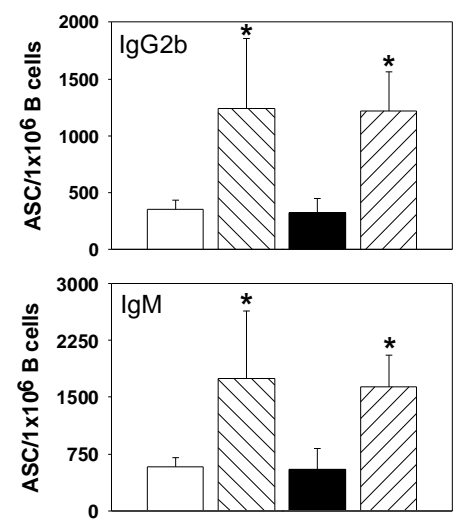

B.
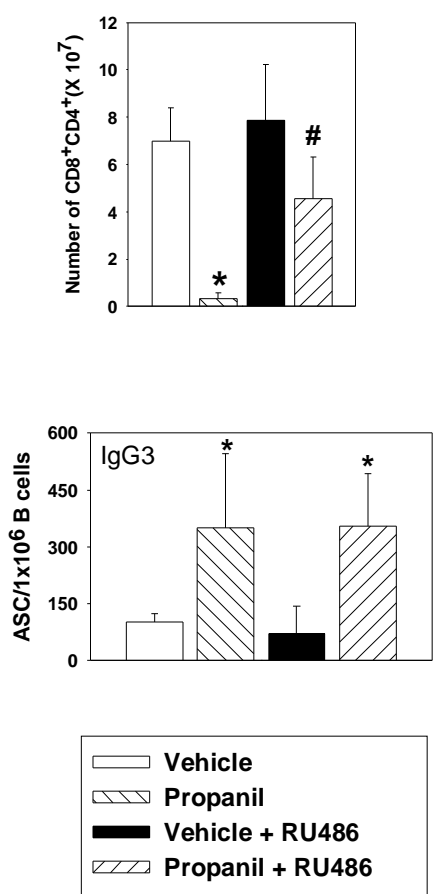

Figure 8. Treatment with the progesterone antagonist RU486 does not inhibit the increase in ASC in propanil-treated animals.

C57BL/6 female mice were treated with RU486 as described in the Methods. Thymic wet weights and thymocyte populations were determined on day 3. (A) Thymus to body weight ratio. * Significantly different from the vehicle control and vehicle + RU486, $\mathrm{p} \leq$ .05. (B) $\mathrm{CD}^{+} \mathrm{CD} 8^{+}$cells. * Significantly different from the vehicle control and vehicle + RU486, $\mathrm{p} \leq .05$. \# Significantly different from vehicle, propanil, and vehicle + RU486, $\mathrm{p} \leq .05$. (C) Numbers of PC-specific IgG2b, IgG3, and IgM ASC were determined by ELISPOT assay on day 7 post-vaccination. Values represent the mean $\pm \mathrm{SD}$ of ASC $/ 1 \times 10^{6} \mathrm{~B}$ cells or per spleen. * Significantly different from the respective vehicle control, $\mathrm{p} \leq .05$. 

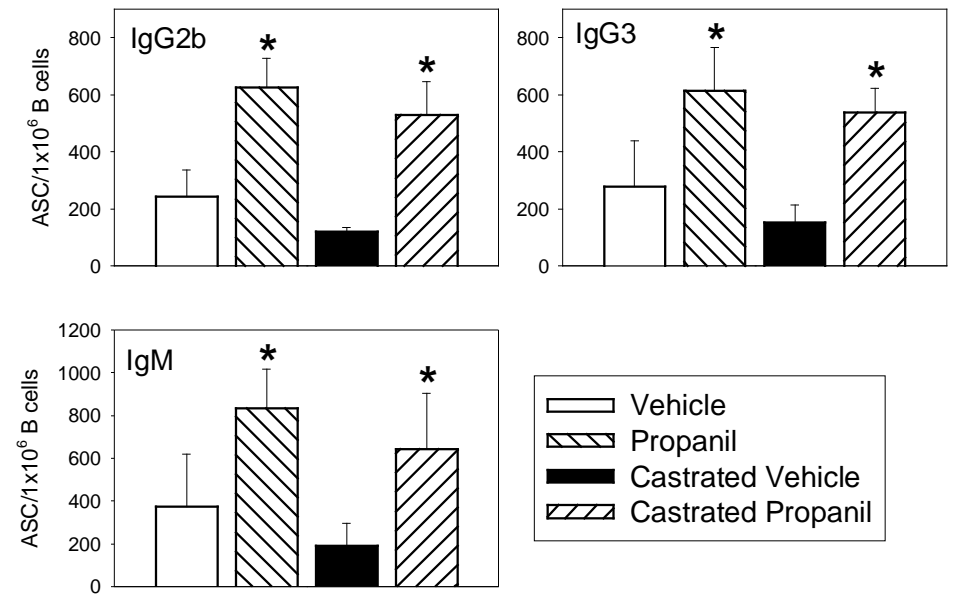

Figure 9. Propanil enhances the antibody response in both normal and orchiectomized males.

Sham-operated and castrated C57BL/6 male mice were vaccinated with $2 \times 10^{8} \mathrm{CFU}$ HKSP and treated with $150 \mathrm{mg} / \mathrm{kg}$ propanil or vehicle control. Spleens were removed after 7 days. Numbers of PC-specific IgG2b, IgG3, and IgM ASC were determined by ELISPOT assay. Values represent the mean $\pm \mathrm{SD}$ of $\mathrm{ASC} / 1 \times 10^{6} \mathrm{~B}$ cells or per spleen. * Significantly different from the respective vehicle control, $\mathrm{p} \leq .05$. 
CHAPTER 6: PROPANIL EXPOSURE DOES NOT

ENHANCE SURVIVAL TO A VIRULENT S. PNEUMONIAE

CHALLENGE FOLLOWING A SUBOPTIMAL

IMMUNIZATION 


\section{INTRODUCTION}

The previous experiments demonstrated that propanil enhances the number of PCspecific ASC in the spleen, but does not affect serum antibody titers. Previous reports have shown that PC-specific antibody is protective against a lethal challenge with $S$. pneumoniae (Briles et al., 1992; Wallick et al., 1983). However, protection is correlated with circulating antibodies in the serum (Fischer et al., 1995). These experiments were conducted to determine if propanil enhances the survival of HKSP immunized animals lethally challenged with $S$. pneumoniae.

Previous studies evaluating the survival of mice following HKSP immunizations have been performed using an immunization schedule of one ip injection on day 0 and a second immunization on day 14 followed by lethal challenge on day 21 (Wallick et al., 1983; Briles et al., 1992; Fischer et al., 1995). However, PC-specific titers peak by day 7 and subsequent immunizations do not significantly increase the PC antibody titers (Wu et al., 2002; Wu et al., 1999). Analysis of the idiotypes produced in response to HKSP immunization demonstrates that the high affinity $\mathrm{T}^{+} 5^{+}$is increased as much as 20 -fold (2 $\mu \mathrm{g} / \mathrm{ml}$ to $40 \mu \mathrm{g} / \mathrm{ml}$ ) following the second immunization in C57BL/6 mice (Ruppert et al., 1980). These studies suggest that the second immunization enhances survival by increasing the percent of high affinity PC-specific antibody produced in C57BL/6 mice rather than increasing the total amount of PC-specific antibodies in the serum.

Previous experiments primarily concentrated on the effect of a single exposure of propanil on a primary antibody response. Therefore, the following experiments utilized a lethal challenge exposure model following a primary immunization. A single primary immunization with HKSP was found to induce a suboptimal level of protection against a 
lethal challenge. Addition of propanil to the primary immunization did not affect mortality outcomes.

\section{METHODS}

\section{Animals}

Six to eight week old C57B1/6 female mice were purchased from Hill Top Lab Animals. Mice were housed in microisolator cages in pathogen free conditions at West Virginia University's animal facility. Mice were kept on a $12 \mathrm{hr}$ light-dark cycle and allowed to acclimate to the facility for 1 week. These studies were conducted in accordance with all federal and institutional guidelines for animal use and were approved by the West Virginia University Institutional Animal Care and Use Committee.

\section{Reagents}

Propanil (3,4-dichloropropionanilide, 99\% pure) was purchased from Chem Service.

\section{Bacterial preparation}

S. pneumoniae strain R36A, an avirulent, nonencapsulated strain, was grown to mid-log phase in Todd-Hewitt broth $+.05 \%$ yeast extract and stored at $-80^{\circ} \mathrm{C}$. For immunization, stock was cultured in a candle jar for $18 \mathrm{hrs}$ at $37^{\circ} \mathrm{C}$ on blood agar plates. A few characteristic colonies were selected and suspended in $200 \mathrm{ml}$ Todd-Hewitt broth $+.05 \%$ yeast extract. Bacteria were grown at $37^{\circ} \mathrm{C}$ to an absorbance reading at $650 \mathrm{~nm}$ of 0.4 and heat killed for 4 hours in a $60^{\circ} \mathrm{C}$ water bath. A final concentration of $10^{9} \mathrm{CFU} / \mathrm{ml}$ was established in PBS based on colony counts. Sterility was confirmed by culture. 
Heat-killed stock was stored at $-20^{\circ} \mathrm{C}$ in $1 \mathrm{ml}$ aliquots. Mice were immunized ip with $2 \times 10^{8} \mathrm{CFU}$.

S. pneumoniae strain D39, an encapsulated virulent strain from which R36a was derived, was grown on blood agar plates for $18 \mathrm{hr}$ at $37^{\circ} \mathrm{C}$. A few colonies were added to Todd-Hewitt broth $+10 \%$ FBS and grown to mid-log phase (approximately $1 \times 10^{8}$ $\mathrm{CFU} / \mathrm{ml}$ ). Bacterial concentration was confirmed by plating. Bacteria was stored in $10 \%$ glycerol at $-80^{\circ} \mathrm{C}$. For lethal challenge, bacteria was thawed, washed in PBS, and resuspended at the appropriate concentration (approximately $2 \times 10^{7} \mathrm{CFU} / \mathrm{ml}$ ).

\section{Animal exposures}

Propanil was dissolved in peanut oil for a final concentration of $15 \mathrm{mg} / \mathrm{ml}$ for all experiments. Mice (4-8/group) were treated ip with either $150 \mathrm{mg}$ of propanil/kg of body weight $(\mathrm{mg} / \mathrm{kg})$ or vehicle on the same day as immunization. On day 7 , mice were challenged either ip or iv with D39. Survival was monitored for 7 days, at which time the experiment was terminated. An $\mathrm{LD}_{50}$ dose of $S$. pneumoniae was experimentally determined prior to these studies.

\section{RESULTS}

\section{IP injected oil enhances survival to a lethal challenge to D39.}

To determine if ip injection of the vehicle affects survival against a lethal challenge of $S$. pneumoniae, 3 groups of mice were vaccinated ip with HKSP and treated with saline, vehicle or propanil. Immunized mice treated with either vehicle or propanil had an increased survival rate $(60 \%)$ compared to immunized alone animals only immunized with HKSP $(0 \%)$ (Figure 1). It is possible that oil may increase survival by 
inducing a general inflammatory reaction. Previous research demonstrated that ip oil exposure increases the number of inflammatory cells in the spleen (data not shown). These data suggest that interpretations from studies using an ip challenge model is complicated by the effects of the vehicle.

\section{IP injected oil does not affect survival to an iv D39 challenge.}

The previous experiment demonstrated that evaluation of the effects of propanil on survival to a lethal challenge requires altering the route of exposure to the virulent bacteria. Previous studies have shown that ip and iv routes of challenge have approximately the same degree of virulence (Briles et al., 1992). Mice were treated with or without the vehicle, immunized ip with HKSP and challenged iv with virulent $S$. pneumoniae. Survival of immunized animals was not affected by ip vehicle treatment (Figure 2). Therefore, the iv route of challenge was chosen for future experimentation.

\section{Propanil treatment does not increase survival in suboptimally immunized mice.}

To determine if the increased number of PC-specific ASC induced by propanil affects survival, vaccinated mice were treated with propanil or vehicle and challenged with $2 \times 10^{6} \mathrm{CFU}$ of D39 on day 7. Results were compared to naïve animals treated with propanil or vehicle. The $\mathrm{CFU}$ of $\mathrm{D} 39$ used was determined to be a $\mathrm{LD}_{50}$ in HKSP vaccinated mice. Immunization with HKSP did not consistently increase survival compared to naïve animals (Figures 3A and 3B). In addition, propanil exposure in naïve animals did not affect survival compared to vehicle treated naïve animals (Figure 3A). Finally, propanil-treatment did not increase survival in immunized mice compared to either naïve mice or vehicle-treated immunized mice (Figures 3A and 3B). 


\section{DISCUSSION}

These experiments begin to address the significance of the increased number of PC-specific ASC in the spleen. The experiments also address the question of whether antibody serum titers or ASC in the spleen are more important for virulent bacterial challenges. These results demonstrate that one vaccination of HKSP is not sufficient to increase survival to a lethal challenge. Furthermore, propanil was not able to enhance survival following a suboptimal immunization.

As previously mentioned, a second immunization with HKSP increases the percent of $\mathrm{T}^{+} 5^{+}$antibodies in the serum. The inability to protect mice following one HKSP injection is likely due to the relatively low concentration of $\mathrm{T}^{+} 5^{+}$antibodies. Previous reports have shown that $\mathrm{T}_{15^{+}}$idiotype antibodies are more effective at protecting against a lethal challenge than other idiotypes produced to PC (Nicoletti et al., 1993; Briles et al., 1982a; Briles et al., 1984). Experiments have shown that passive immunization with $\mathrm{T}^{+} 5^{+}$antibodies increases protection from a lethal ip S. pneumoniae challenge in a dose dependent fashion (Briles et al., 1982a). Given the importance of $\mathrm{T}_{15}{ }^{+}$antibodies for protection, future experiments should evaluate the effect of propanil on PC-specific idiotypes in both the spleen and serum.

Alternative strategies to examine the effect of propanil on mortality include studying the effect of propanil on a secondary immunization. Our previous results demonstrate that propanil treatment at the time of the second immunization results in an increased PC-specific ASC response in the spleen. Challenging propanil and vehicletreated mice that have been immunized twice would determine if propanil increases survival following an optimal immunization. 
Altogether, this data begins to address relevance of an increased local antibody response in resolving a virulent challenge. Immunization with an alternative antigen that may increase serum titers such as PC-Ficoll or PC-KLH would be valuable in exploring the necessity of a corresponding increase in serum titers. In addition, passive immunization with pooled antibody collected from ex vivo splenic cultures from propanil-treated animals would determine the efficacy of the antibodies produced from the amplified response. Altogether, these studies support previous reports demonstrating the importance of serum titers to protect against a lethal challenge. 


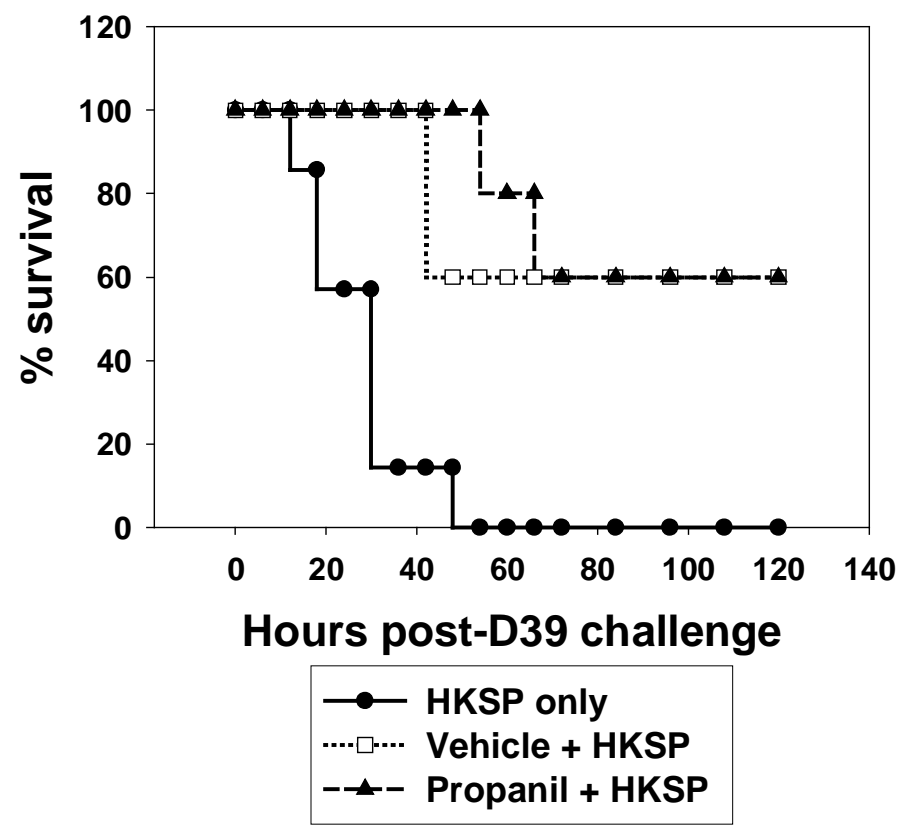

Figure 1. IP oil injection increases survival to a lethal ip $S$. pneumoniae challenge.

Female C57BL/6 mice (5-7/group) were immunized ip with 2x10 ${ }^{8}$ CFU HKSP and treated ip with saline, $150 \mathrm{mg} / \mathrm{kg}$ propanil or vehicle. Mice were challenged ip with a $2 \times 10^{6} \mathrm{CFU}$ D39 S. pneumoniae on day 7. Values represent the percent of surviving mice. 


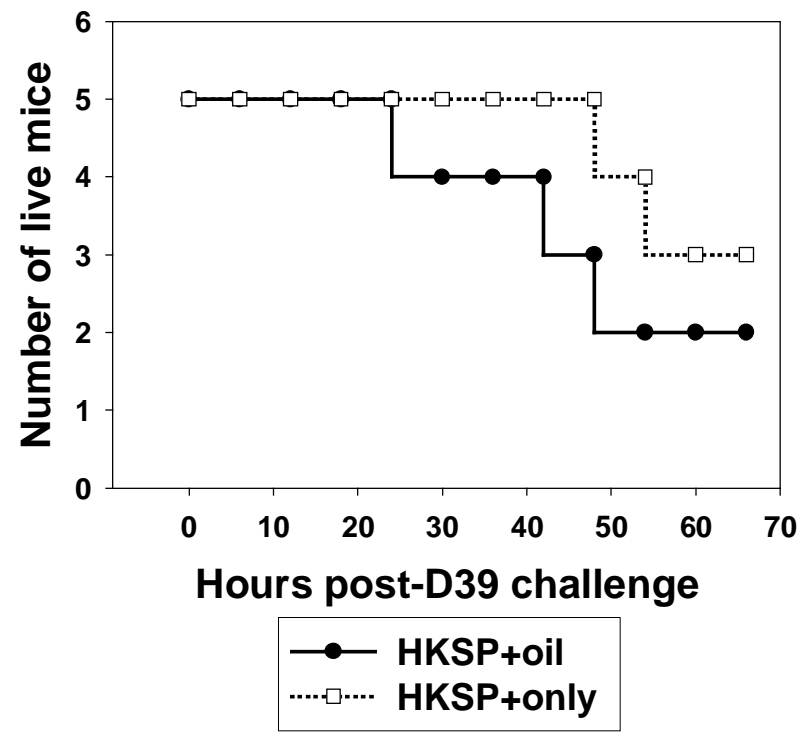

Figure 2. IP oil injection does not affect survival to a lethal iv S. pneumoniae challenge.

Female C57BL/6 mice (5/group) were immunized ip with 2x10 CFU HKSP and treated ip with saline or vehicle. Mice were challenged iv with a $2 \times 10^{6}$ CFU D39 S. pneumoniae on day 7. Values represent the number of surviving mice. 

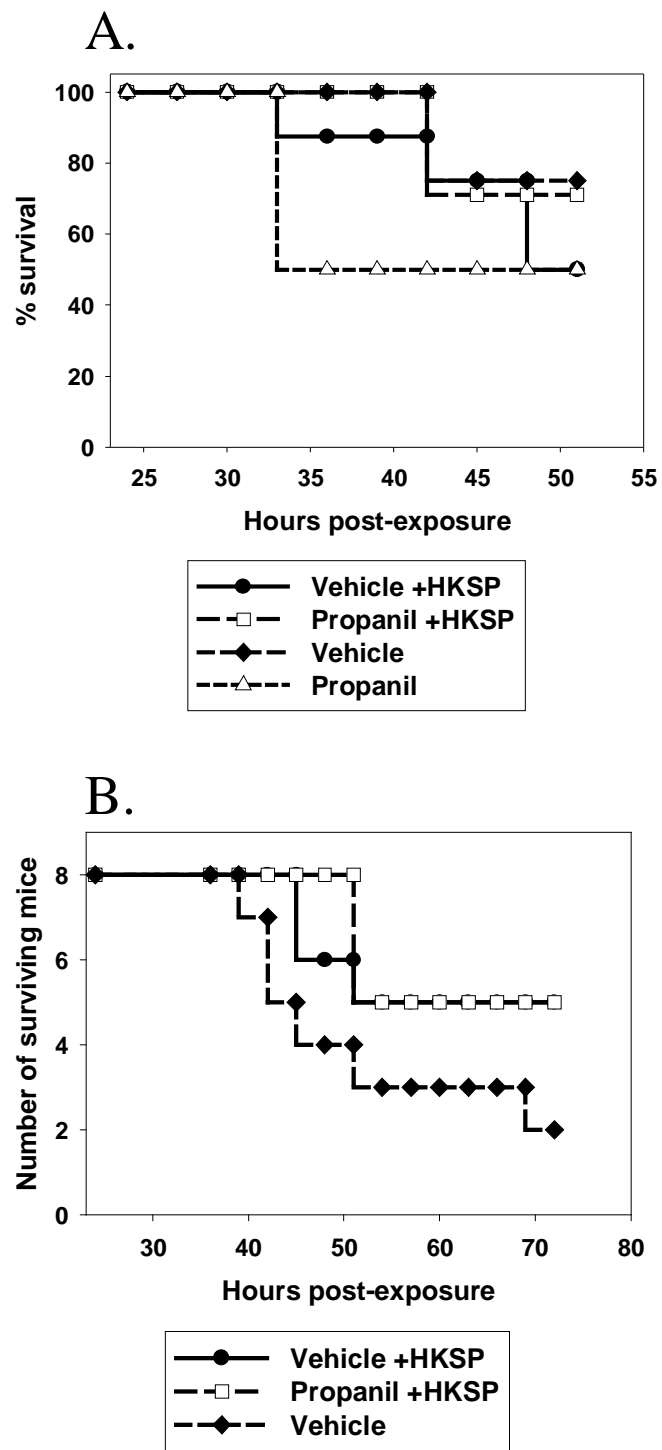

Figure 3. Propanil exposure does not increase survival to a lethal challenge following a suboptimal immunization.

(A) Female C57BL/6 mice (4-8/group) were immunized ip with $2 \times 10^{8}$ CFU HKSP or saline and treated ip with $150 \mathrm{mg} / \mathrm{kg}$ propanil or vehicle. Mice were challenged iv with a $2 \times 10^{6}$ CFU D39 S. pneumoniae on day 7. (A) Values represent the percent of surviving mice. (B) Values represent the number of surviving mice. 


\section{CHAPTER 7: GENERAL DISCUSSION}

\section{Objective}

These studies were designed to 1) examine the effect of an exposure to a mixture of herbicides on the humoral response utilizing the HKSP immunization model, 2) determine the mechanism regulating the propanil-induced enhancement of the PCspecific response induced by propanil, and 3) determine if propanil acts as an adjuvant that enhances the efficacy of an immunization.

\section{Endocrine regulation of the humoral response}

Propanil was found to require ovarian steroid synthesis to enhance the PC-specific response following HKSP immunization. However, the data demonstrates that propanil enhances the humoral response independent of an estrogenic mechanism. In addition, evidence was presented suggesting that progesterone is not involved in the increased response. Castration of male mice did not affect the propanil-induced response in male mice, suggesting an androgenic independent mechanism. This data eliminates the vast majority of published mechanisms by which the gonads directly regulate the antibody response.

A valid hypothesis must account for the two primary observations: 1) the ovaries are required for enhancement, and 2) the testes are not required. These observations suggest that the unknown factor produced by the ovaries required for antibody enhancement is also produced outside of the male gonads, assuming a similar mechanism for antibody enhancement in male and females. There are two hypotheses that may explain the data. 1) Propanil exposure induces the ovaries to produce or suppress protein(s) with a novel function that stimulates the antibody response. The site of protein 
synthesis in males is outside of the gonads. 2) Alternatively, when mice are ovariectomized or steroid synthesis is inhibited, this disrupts local splenic hormone regulation. Propanil may act directly on the splenic hormones. However, disruption of ovarian regulation interferes with the ability of the spleen to respond to propanil. Both hypotheses represent novel roles for the ovarian regulation of the humoral immune response.

The first hypothesis suggests that propanil exposure alters ovarian function either directly or indirectly. There are several difficulties with this hypothesis. Presently, the existing literature has not characterized a protein or hormone associated with ovarian regulation of the antibody response that induces a similar response as observed in the propanil exposure model. Identification of the responsible protein(s) will be difficult since there is not a small group of likely candidates and detection would require a large screen of proteins and mRNA via such techniques such as proteomics and RNA microarrays. Additionally, the data indicates that the protein(s) would be synthesized independent of the testes in males. Locating the responsible protein in males would be more difficult since a target site has not been identified.

The second hypothesis proposes that propanil affects the local endocrineregulated genes in the spleen. As mentioned in Chapter 5, the spleen contains a number of sex hormone mRNAs as well as sex hormone receptor mRNAs and steroidogenic enzymes. The ovaries and testes contribute to regulation of these hormones, receptors, and enzymes (Samy et al., 2001; Jacobson et al., 1998; Jacobson et al., 1999). Notably, the ovaries and testes differentially regulate these local endocrine systems. The significance of global hormones on the immune response is well established. However, 
the impact of local production of endocrine mediators in the spleen and lymphocytes is poorly understood. It is possible that propanil does not affect ovarian function, but instead exerts its effects on the spleen. Removal of the ovaries may disrupt local splenic hormone production, thereby preventing "normal" enhancement of the antibody response by propanil. Addition of the ovarian hormones such as E2 and progesterone to OVX mice prior to propanil exposure would address whether the ovarian hormones act in a supplementary fashion. Although E2 treatments in OVX mice did not restore the enhanced response following propanil exposure, studies suggest that both progesterone and E2 are required for accurate mimicry of ovarian hormone production. For example, complete GNRH and LH feedback regulation in OVX mice requires both progesterone and E2 (Dalkin et al., 1990). Failure of E2 and progesterone supplements in OVX mice to restore the propanil enhancement of the antibody response would suggest that propanil is exerting its effect on the ovaries and not the spleen.

The results gathered by testing either one of these hypotheses would yield novel findings. Since the discovery of endocrine-related hormones and receptors in lymphoid organs, their function is largely unknown. Propanil could be used as a model reagent to study these locally produced hormones and their contribution to immune regulation. Alternatively, discovery of a novel protein or a novel function of an ovarian protein could lead to a number of studies elaborating the role of this protein in normal immune function and disease.

\section{Immune mediators of the enhanced humoral response}

Although it is known that the ovaries are required for the enhanced humoral response, the role of lymphocytes and costimulating molecules is unknown. As 
mentioned in the General Introduction, there are a number of ways the PC-specific antibody response is enhanced. Both the innate and the adaptive immune system regulate the antibody response. Complement receptors enhance the antibody response by lowering the activation requirements of the B cell. APC such as FDC also enhance the antibody response via a CR2 dependent mechanism. As discussed in Chapter 4, propanil is not able to enhance the antibody response to a suboptimal immunization. In addition, affinity analysis suggests that lower affinity PC-specific B cells are not increased. This data suggests that a complement-mediated mechanism does not contribute to the enhanced response.

Other innate immune mechanisms such as MZ macrophages, cytokines and TLR regulate the TI-2 response via different mechanisms. MZ macrophages negatively regulate the PC-specific response. The data indicates that propanil did not affect the number of splenic macrophages. However, measurements of the MZ subpopulation was not performed, therefore this mechanism cannot be eliminated. Cytokines are important for early isotype switching. Since both the IgG isotypes and IgM are increased equally following propanil exposure, enhanced isotype switching is not likely to be responsible for the enhanced response. The available literature has shown that TLR stimulation increases the PC-specific response in a dissimilar manner compared to propanil exposure. However, TLR9 stimulation enhances polysaccharide specific antibody titers (Sen et al., 2006). As previously shown, propanil does not enhance antibody titers. Furthermore, propanil enhancement of the number of splenic ASC is not further increased at later time points. Altogether, the data does not strongly indicate a specific innate immune mechanism for enhanced TI-2 responses following propanil exposure. 
$\mathrm{T}$ cells possess a number of costimulating molecules that enhance the TI-2 antibody response. The inability of propanil to enhance the PC-KLH response on day 7 and the inability of a day 0 propanil-treatment to enhance the PC-specific response on day 3 suggests a role for $\mathrm{T}$ cells in the enhanced response. A direct method for evaluating the role of $\mathrm{T}$ cells is $\mathrm{T}$ cell deletion studies. As mentioned previously in the Discussion of Chapter 4, T cells are not required for normal PC-specific responses after 4 days. It has also been shown that delayed propanil exposure enhances the PC-specific response similarly to simultaneous vaccination and propanil treatment. Conflicting reports present evidence for a necessity of either $\mathrm{CD} 4^{+}$or $\mathrm{CD} 8^{+} \mathrm{T}$ cells in $\mathrm{PC}$ antibody responses (Wu et al., 2002; Kobrynski et al., 2005). An initial study could employ an anti-CD8, anti-CD4, or an anti-CD3 antibody on day 4 following HKSP immunization. Mice could then be exposed to propanil to determine the necessity of the different subpopulations of T cells in the amplified PC-response.

A possible mechanism for $\mathrm{T}$ cell mediated enhancement of the antibody response in propanil-treated mice is via a CD40 dependent pathway. As mentioned in the General Introduction, anti-CD40 treatment enhances the TI-2 antibody response with similar kinetics (Garcia et al., 1999a). In addition, CD40 ligation is also important for TD responses. The number of TI-2 antigen-specific ASC is not increased until day 6 following anti-CD40 treatment (Garcia et al., 1999a). Immunohistochemistry analysis suggests that the increase is the result of extended rounds of proliferation rather than an increase in recruitment of low affinity B cells to the response (Garcia et al., 1999a). In addition, splenomegaly is observed in anti-CD40 treated animals with similar kinetics seen in propanil treated mice (Garcia et al., 1999a). The splenomegaly observed in the 
anti-CD40 treated animals are the result of an increase in white pulp and $\operatorname{IgD}^{+}$cells (Garcia et al., 1999a). Propanil treatment is hypothesized to increase splenomegaly via an influx in undifferentiated cells (de la Rosa, dissertation). Another discrepancy between the two treatments is the predominant IgG1 and IgG3 increase in anti-CD40 treated mice (Garcia et al., 1999a). However, IgM was not measured in this report, making conclusions about the effects on isotype switching difficult. Altogether, these similarities in responses suggest a plausible $\mathrm{T}$ cell dependent mechanism to enhance the TI-2 response. However, a CD40 mechanism could still be plausible if T cells are not involved in the enhanced response. Some studies have shown a T cell independent source for CD40L ligation (Grammer et al., 1999).

Studies exploring the immunological regulation of the antibody response may also aid in determining the mechanism for ovarian regulation by narrowing the search for enzyme or hormone mRNA. Identification of the affected immune cells important for the antibody enhancement will aid in a more precise analysis of the kinetics of activation of individual cells. Understanding the exact time of activation will further narrow the range of time for the mechanism of endocrine mechanism. Using both endocrine directed and immunological approaches will be necessary for efficient identification of the mechanisms involved.

\section{Proliferation vs. polyclonal activation of B cells}

Three primary methods for amplifying the number of ASC is by increasing the proliferation of activated B cells, by increasing the number of B cells recruited activated in the response, or increased differentiation. The evidence presented in Chapters 3 and 4 suggest that polyclonal activation is not the mechanism by which propanil enhances the 
number of ASC. Polyclonal activation is characterized by increased lower affinity B cells, increased number of nonspecific antibodies, and increased recruitment of B cells into the follicles and red pulp of the spleen. An increase in proliferation is characterized by extended rounds of division, which leads to more B cells derived from the same progenitor cell. This results in an increased number of ASC with identical affinity and isotype. The third method for increasing the number of ASC is increased differentiation. This mechanism would suggest an increase in switching. Since all the predominant $\operatorname{IgG}$ isotypes are enhanced equally and $\operatorname{IgM}$ is also enhanced similarly to the $\operatorname{IgG}$ isotypes, this indicates that increased switching is not responsible for the increase in ASC.

Although our data suggests an increase in proliferation rather than polyclonal activation or increased differentiation, more specific experiments are necessary for a more definitive conclusion. More precise affinity analysis could be conducted using idiotype analysis since the affinities of the various idiotypes are known. Identifying the number of T15 and M167 idiotypes in propanil and vehicle-treated animals is another way of conducting affinity analysis. Determining if propanil increases the number of $\mathrm{T} 5^{+} \mathrm{B}$ cells similarly as other idiotypes will provide information on the polyclonal activation. In addition, T15 and M167 analysis provides information on the contribution of B1 B cells and MZ B cells since T15 plasma cells are predominantly derived from B1 cells and M167 are predominantly MZ B cells (Martin et al., 2001). Finally, incorporating immunohistochemistry data and BrdU assays would provide information on the proliferation and recruitment of B cells into the antibody response. These studies would provide a more definitive assessment of polyclonal and proliferative activity following propanil exposure. In addition, determining the method of enhancement would 
aid future experiments studying the immunological and endocrine mechanisms regulating the response.

\section{Correlating serum antibody titers with ASC responses}

An important question remaining from Chapters 3 and 4 is the lack of increased titers despite a several fold increase in the number of splenic ASC. Addressing this issue is important for future studies examining the effect of propanil exposure on a virulent challenge. The ex vivo antibody production from spleens of propanil-treated animals suggests that the increased number of splenic ASC produce antibodies normally. In addition, BM ASC were also demonstrated to contribute to the serum titers. However, splenic ASC in propanil-treated animals do not migrate to the BM in greater numbers. One explanation for the lack of increased titers could be that plasma cells from the spleen must migrate and survive in the $\mathrm{BM}$ in greater numbers to produce an increase in serum titers.

There are several possibilities for a lack of increased BM ASC in propanil-treated animals. The plasma cells may fail to migrate from the spleen to the BM. Alternatively, the BM may be unable to support the increased number of ASC. In order to address the issue of migration in propanil-treated animals, analysis of apoptosis could be performed. Previous studies indicate that splenic ASC that do not migrate to the BM will undergo apoptosis (Smith et al., 1996). To determine if the increased number of splenic ASC are migrating to the $\mathrm{BM}$ or undergoing apoptosis, annexin $\mathrm{V}$ staining could be performed in splenic plasma cells and measured by flow cytometry. Increased levels of annexin expression from propanil-treated ASC compared to vehicle-treated animals would provide evidence suggesting that the increased ASC do not migrate in greater numbers 
because the plasma cells undergo apoptosis. To address the impact of splenic plasma cell migration to the BM on antibody titers, ex vivo production of antibodies could be measured from the BM, spleen and peripheral blood. Comparing the quantity of antibody produced from ASC from each site would address the importance of successful migration of plasma cells from the spleen to the BM to could be measured. Splenic, BM and peripheral blood ASC could be cultured ex vivo and the amount of antibody produced into the supernatant could be quantitated. Directly comparing the amount of antibody produced by these three sources would provide evidence for or against the hypothesis that increased splenic ASC must migrate to the BM to increase serum titers. Altogether, these experiments would provide experimental evidence to address the correlation between serum titers and BM and splenic ASC.

\section{The effect of propanil on a survival to a virulent $S$. pneumoniae challenge}

Determining the effect of propanil exposure on the host's mortality following virulent challenge is important for assessing the relevance of the antibody enhancement model. Several additional experiments would provide more conclusive results concerning propanil's efficacy as an adjuvant. As mentioned in Chapter 6 Introduction, the T15 response is strongly linked to effective clearance of virulent S. pneumoniae. Two immunizations with HKSP are necessary for an optimal immunization. In addition, the T15 response following one injection of HKSP in Balb/c mice is approximately the same as double immunization in C57BL/6 mice (Ruppert et al., 1980).

From this data, two experiments can be derived to evaluate the effect of propanil on an optimal immunization. As demonstrated in Chapter 4, propanil enhances a secondary PC response to HKSP. However, the effect of propanil on the T15 idiotype 
has not been determined in C57BL/6 mice. C57BL/6 mice could be immunized twice with HKSP to elicit an optimum response. Challenging mice treated with propanil during a secondary response would determine if propanil enhances the optimal response.

Alternatively, Balb/c mice could be substituted for C57BL/6 mice in the protection experiments since propanil enhances the response in Balb/c mice similarly to C57BL/6 mice (Schafer, personal communication). From these experiments, the protective effect of a propanil exposure on the optimal antibody response can be determined. Combined with the suboptimal data and serum antibody analysis, these studies would provide the requisite information to draw conclusions about the relevance of the enhanced splenic ASC response.

\section{2,4-D as a model to study plasma cell homing and survival}

The experiments in Chapter 3 demonstrated that 2,4-D reduces both the number of ASC in the BM and serum antibody titers. Although the mechanism is unknown as well as the antigen specificity of the effect, this discovery yielded a novel finding concerning the early importance of BM ASC to the primary TI-2 serum titers. Future studies could use 2,4-D as a model reagent to study BM plasma cells.

The mechanism regulating the 2,4-D induced decrease in BM ASC should be determined prior to employing 2,4-D as a model. Possible mechanisms include 1) defective migration out of the spleen, 2) failure to home properly to the BM, or 3) inability to support plasma cells upon homing to the BM due to disruption of the BM microenvironment. Upon establishing the mechanism of action, 2,4-D could then be used as a specific disruptor of long-lived BM plasma cells.

\section{Summary}


This dissertation presented findings that have implications for both the emerging studies of endocrine-mediated immune interactions and the field of endocrine disruption. As we begin to understand the purpose of the expression of endocrine-related genes in lymphocytes and lymphoid organs as well as the impact of these genes on basic immune function, new tools and models will be needed to address these basic questions. The novel effect of enhancing the number of splenic ASC in conjunction with ovarian steroid synthesis may yield valuable insight into this emerging field. Determining the mechanism by which propanil interacts with both the endocrine and immune system may not only yield new information into how these systems interact, but also, these experiments may reveal that propanil will serve as a useful tool for studying other endocrine-immune interactions.

Secondly, endocrine disruption is of recent concern in the field of toxicology. A large number of ubiquitously occurring compounds have the potential for endocrine disruption. The impact of these newly discovered endocrine disruptors on human health is currently being addressed. However, given the promiscuous binding nature of the ER and the need for rapid, large-scale screening, most studies have focused exclusively on evaluating the affinity of a chemical or compound to the ER. Rapid, comprehensive examinations of other potential nonestrogenic effects of compounds on the endocrine system are absent in the field of toxicology. Although propanil interacts with the endocrine system at high doses in our model, these experiments may be useful in discovering alternative nonestrogenic mechanisms for chemicals to interact with the endocrine system. Once the molecular targets are identified in this propanil exposure model, other chemicals could be rapidly screened for similar effects. As demonstrated in 
our model as well as others, endocrine disruption can affect a number of other biological systems in the host organism. Given the impact of the endocrine system on the overall health of the organism as well as the dependence of the modern economy on the chemical industry, thorough evaluation of these compounds is necessary for sustained human and environmental health. 


\section{GENERAL REFERENCES}

Ambrose, A. M., Larson, P. S., Borzelleca, J. F., and Hennigar, G. R., Jr. (1972).

Toxicologic studies on 3',4'-dichloropropionanilide. Toxicol.Appl.Pharmacol. 23, 650-659.

Ansar, A. S., Dauphinee, M. J., Montoya, A. I., and Talal, N. (1989). Estrogen induces normal murine CD5+ B cells to produce autoantibodies. J.Immunol. 142, 2647-2653.

Ansar, A. S., Penhale, W. J., and Talal, N. (1985). Sex hormones, immune responses, and autoimmune diseases. Mechanisms of sex hormone action. Am.J.Pathol. 121, 531551.

Badawi, A. F., Cavalieri, E. L., and Rogan, E. G. (2000). Effect of chlorinated hydrocarbons on expression of cytochrome P450 1A1, 1A2 and 1B1 and 2- and 4hydroxylation of 17beta-estradiol in female Sprague-Dawley rats. Carcinogenesis 21, 1593-1599.

Bancroft, G. J., Schreiber, R. D., and Unanue, E. R. (1991). Natural immunity: a T-cellindependent pathway of macrophage activation, defined in the scid mouse. Immunol.Rev. 124, 5-24.

Barnes, C. J., Lavy, T. L., and Mattice, J. D. (1987). Exposure of non-applicator personnel and adjacent areas to aerially applied propanil. Bull.Environ.Contam Toxicol. 39, 126-133. 
Barnett, J. B. and Gandy, J. (1989). Effect of acute propanil exposure on the immune response of C57B1/6 mice. Fundam.Appl.Toxicol. 12, 757-764.

Barnett, J. B., Gandy, J., Wilbourn, D., and Theus, S. A. (1992). Comparison of the immunotoxicity of propanil and its metabolite, 3,4-dichloroaniline, in C57B1/6 mice. Fundam.Appl.Toxicol. 18, 628-631.

Benten, W. P., Stephan, C., and Wunderlich, F. (2002). B cells express intracellular but not surface receptors for testosterone and estradiol. Steroids 67, 647-654.

Blakley, B. R. (1986). The effect of oral exposure to the n-butylester of 2,4dichlorophenoxyacetic acid on the immune response in mice. Int.J.Immunopharmacol. 8, 93-99.

Blakley, B. R. (1997). Effect of roundup and tordon 202C herbicides on antibody production in mice. Vet.Hum.Toxicol. 39, 204-206.

Blakley, B. R. and Schiefer, B. H. (1986). The effect of topically applied n-butylester of 2,4-dichlorophenoxyacetic acid on the immune response in mice. J.Appl.Toxicol. 6 , 291-295.

Blyler, G., Landreth, K. S., Lillis, T., Schafer, R., Theus, S. A., Gandy, J., and Barnett, J. B. (1994). Selective myelotoxicity of propanil. Fundam.Appl.Toxicol. 22, 505-510.

Bouman, A., Heineman, M. J., and Faas, M. M. (2005). Sex hormones and the immune response in humans. Hum.Reprod.Update. 11, 411-423. 
Brick, J. E., Wilson, D. A., and Walker, S. E. (1985). Hormonal modulation of responses to thymus-independent and thymus-dependent antigens in autoimmune NZB/W mice. J.Immunol. 134, 3693-3698.

Briles, D. E., Forman, C., and Crain, M. (1992). Mouse antibody to phosphocholine can protect mice from infection with mouse-virulent human isolates of Streptococcus pneumoniae. Infect.Immun. 60, 1957-1962.

Briles, D. E., Forman, C., Hudak, S., and Claflin, J. L. (1982a). Anti-phosphorylcholine antibodies of the T15 idiotype are optimally protective against Streptococcus pneumoniae. J.Exp.Med. 156, 1177-1185.

Briles, D. E., Forman, C., Hudak, S., and Claflin, J. L. (1984). The effects of idiotype on the ability of IgG1 anti-phosphorylcholine antibodies to protect mice from fatal infection with Streptococcus pneumoniae. Eur.J.Immunol. 14, 1027-1030.

Briles, D. E., Nahm, M., Marion, T. N., Perlmutter, R. M., and Davie, J. M. (1982b). Streptococcal group A carbohydrate has properties of both a thymus-independent (TI2) and a thymus-dependent antigen. J.Immunol. 128, 2032-2035.

Brundage, K. M., Schafer, R., and Barnett, J. B. (2004). Altered AP-1 (activating protein1) activity and c-jun activation in T cells exposed to the amide class herbicide 3,4dichloropropionanilide (DCPA). Toxicol.Sci 79, 98-105.

Charles, J. M., Bond, D. M., Jeffries, T. K., Yano, B. L., Stott, W. T., Johnson, K. A., Cunny, H. C., Wilson, R. D., and Bus, J. S. (1996). Chronic dietary 
toxicity/oncogenicity studies on 2,4-dichlorophenoxyacetic acid in rodents.

Fundam.Appl.Toxicol. 33, 166-172.

Charles, J. M., Hanley, T. R., Jr., Wilson, R. D., Van Ravenzwaay, B., and Bus, J. S. (2001). Developmental toxicity studies in rats and rabbits on 2,4dichlorophenoxyacetic acid and its forms. Toxicol.Sci. 60, 121-131.

Clausen, M., Leier, G., and Witte, I. (1990). Comparison of the cytotoxicity and DNAdamaging properties of 2,4-D and U 46 D fluid (dimethylammonium salt of 2,4-D). Arch.Toxicol. 64, 497-501.

Colino, J., Shen, Y., and Snapper, C. M. (2002). Dendritic cells pulsed with intact Streptococcus pneumoniae elicit both protein- and polysaccharide-specific immunoglobulin isotype responses in vivo through distinct mechanisms. J.Exp.Med. 195, 1-13.

Correale, J., Arias, M., and Gilmore, W. (1998). Steroid hormone regulation of cytokine secretion by proteolipid protein-specific $\mathrm{CD} 4+\mathrm{T}$ cell clones isolated from multiple sclerosis patients and normal control subjects. J.Immunol. 161, 3365-3374.

Croix, D. A., Ahearn, J. M., Rosengard, A. M., Han, S., Kelsoe, G., Ma, M., and Carroll, M. C. (1996). Antibody response to a T-dependent antigen requires B cell expression of complement receptors. J.Exp.Med. 183, 1857-1864.

Cuff, C. F., Zhao, W., Nukui, T., Schafer, R., and Barnett, J. B. (1996). 3,4Dichloropropionanilide-induced atrophy of the thymus: mechanisms of toxicity and recovery. Fundam.Appl.Toxicol. 33, 83-90. 
Cundell, D. R., Gerard, N. P., Gerard, C., Idanpaan-Heikkila, I., and Tuomanen, E. I. (1995). Streptococcus pneumoniae anchor to activated human cells by the receptor for platelet-activating factor. Nature $\mathbf{3 7 7}, \mathbf{4 3 5 - 4 3 8 .}$

Dalkin, A. C., Haisenleder, D. J., Ortolano, G. A., Suhr, A., and Marshall, J. C. (1990). Gonadal regulation of gonadotropin subunit gene expression: evidence for regulation of follicle-stimulating hormone-beta messenger ribonucleic acid by nonsteroidal hormones in female rats. Endocrinology 127, 798-806.

Davidson, R. N. and Wall, R. A. (2001). Prevention and management of infections in patients without a spleen. Clin.Microbiol.Infect. 7, 657-660.

De la Rosa, P., Barnett, J., and Schafer, R. (2003). Loss of pre-B and $\operatorname{IgM}(+)$ B cells in the bone marrow after exposure to a mixture of herbicides. J.Toxicol.Environ.Health A 66, 2299-2313.

De la Rosa, P., Barnett, J. B., and Schafer, R. (2005). Characterization of thymic atrophy and the mechanism of thymocyte depletion after in vivo exposure to a mixture of herbicides. J.Toxicol.Environ.Health A 68, 81-98.

Do, Y., Ryu, S., Nagarkatti, M., and Nagarkatti, P. S. (2002). Role of death receptor pathway in estradiol-induced T-cell apoptosis in vivo. Toxicol.Sci. 70, 63-72.

Eidinger, D. and Garrett, T. J. (1972). Studies of the regulatory effects of the sex hormones on antibody formation and stem cell differentiation. J.Exp.Med. 136, 10981116. 
Elo, H. A. and MacDonald, E. (1989). Effects of 2,4-dichlorophenoxyacetic acid (2,4-D) on biogenic amines and their acidic metabolites in brain and cerebrospinal fluid of rats. Arch.Toxicol. 63, 127-130.

Erlandsson, M. C., Jonsson, C. A., Islander, U., Ohlsson, C., and Carlsten, H. (2003). Oestrogen receptor specificity in oestradiol-mediated effects on B lymphopoiesis and immunoglobulin production in male mice. Immunology 108, 346-351.

Erlandsson, M. C., Ohlsson, C., Gustafsson, J. A., and Carlsten, H. (2001). Role of oestrogen receptors alpha and beta in immune organ development and in oestrogenmediated effects on thymus. Immunology 103, 17-25.

Faustini, A., Settimi, L., Pacifici, R., Fano, V., Zuccaro, P., and Forastiere, F. (1996). Immunological changes among farmers exposed to phenoxy herbicides: preliminary observations. Occup.Environ.Med. 53, 583-585.

Fearon, D. T. and Carroll, M. C. (2000). Regulation of B lymphocyte responses to foreign and self-antigens by the CD19/CD21 complex. Annu.Rev.Immunol. 18, 393422.

Feeney, A. J. and Thuerauf, D. J. (1989). Sequence and fine specificity analysis of primary 511 anti-phosphorylcholine antibodies. J.Immunol. 143, 4061-4068.

Fischer, M. B., Goerg, S., Shen, L., Prodeus, A. P., Goodnow, C. C., Kelsoe, G., and Carroll, M. C. (1998). Dependence of germinal center B cells on expression of CD21/CD35 for survival. Science 280, 582-585. 
Fischer, R. T., Longo, D. L., and Kenny, J. J. (1995). A novel phosphocholine antigen protects both normal and X-linked immune deficient mice against Streptococcus pneumoniae. Comparison of the 6-O-phosphocholine hydroxyhexanoate-conjugate with other phosphocholine-containing vaccines. J.Immunol. 154, 3373-3382.

Frost, L. L., Neeley, Y. X., Schafer, R., Gibson, L. F., and Barnett, J. B. (2001). Propanil inhibits tumor necrosis factor-alpha production by reducing nuclear levels of the transcription factor nuclear factor-kappab in the macrophage cell line ic- 21 . Toxicol.Appl.Pharmacol. 172, 186-193.

Gallichan, W. S. and Rosenthal, K. L. (1996). Effects of the estrous cycle on local humoral immune responses and protection of intranasally immunized female mice against herpes simplex virus type 2 infection in the genital tract. Virology 224, 487497.

Galloway, S. M., Armstrong, M. J., Reuben, C., Colman, S., Brown, B., Cannon, C., Bloom, A. D., Nakamura, F., Ahmed, M., Duk, S., and . (1987). Chromosome aberrations and sister chromatid exchanges in Chinese hamster ovary cells: evaluations of 108 chemicals. Environ.Mol.Mutagen. 10 Suppl 10, 1-175.

Garabrant, D. H. and Philbert, M. A. (2002). Review of 2,4-dichlorophenoxyacetic acid (2,4-D) epidemiology and toxicology. Crit Rev.Toxicol. 32, 233-257.

Garcia, d., V, MacLennan, I. C., Holman, M., and Klaus, G. G. (1999a). Anti-CD40 antibody enhances responses to polysaccharide without mimicking $\mathrm{T}$ cell help. Eur.J.Immunol. 29, 3216-3224. 
Garcia, d., V, O'Leary, P., Sze, D. M., Toellner, K. M., and MacLennan, I. C. (1999b). Tindependent type 2 antigens induce B cell proliferation in multiple splenic sites, but exponential growth is confined to extrafollicular foci. Eur.J.Immunol. 29, 1314-1323.

Grammer, A. C., McFarland, R. D., Heaney, J., Darnell, B. F., and Lipsky, P. E. (1999). Expression, regulation, and function of B cell-expressed CD154 in germinal centers. J.Immunol. 163, 4150-4159.

Grimaldi, C. M., Cleary, J., Dagtas, A. S., Moussai, D., and Diamond, B. (2002). Estrogen alters thresholds for B cell apoptosis and activation. J.Clin.Invest 109, 16251633.

Grimaldi, C. M., Jeganathan, V., and Diamond, B. (2006). Hormonal Regulation of B Cell Development: 17beta-Estradiol Impairs Negative Selection of High-Affinity DNA-Reactive B Cells at More Than One Developmental Checkpoint. J.Immunol. 176, 2703-2710.

Grimaldi, C. M., Michael, D. J., and Diamond, B. (2001). Cutting edge: expansion and activation of a population of autoreactive marginal zone B cells in a model of estrogen-induced lupus. J.Immunol. 167, 1886-1890.

Guinamard, R., Okigaki, M., Schlessinger, J., and Ravetch, J. V. (2000). Absence of marginal zone B cells in Pyk-2-deficient mice defines their role in the humoral response. Nat.Immunol. 1, 31-36.

Haas, K. M., Hasegawa, M., Steeber, D. A., Poe, J. C., Zabel, M. D., Bock, C. B., Karp, D. R., Briles, D. E., Weis, J. H., and Tedder, T. F. (2002). Complement receptors 
CD21/35 link innate and protective immunity during Streptococcus pneumoniae infection by regulating IgG3 antibody responses. Immunity. 17, 713-723.

Han, S., Hathcock, K., Zheng, B., Kepler, T. B., Hodes, R., and Kelsoe, G. (1995). Cellular interaction in germinal centers. Roles of CD40 ligand and B7-2 in established germinal centers. J.Immunol. 155, 556-567.

Harms, G., Hardonk, M. J., and Timens, W. (1996). In vitro complement-dependent binding and in vivo kinetics of pneumococcal polysaccharide TI-2 antigens in the rat spleen marginal zone and follicle. Infect.Immun. 64, 4220-4225.

Hill, R. H., Jr., Head, S. L., Baker, S., Gregg, M., Shealy, D. B., Bailey, S. L., Williams, C. C., Sampson, E. J., and Needham, L. L. (1995). Pesticide residues in urine of adults living in the United States: reference range concentrations. Environ.Res. 71, 99-108.

Izmerov, N. F. (1984). Propanide. Sci.Rev.Soviet Literature Tox.Haz.Chem. 76, 1-24.

Jacob, J., Kassir, R., and Kelsoe, G. (1991). In situ studies of the primary immune response to (4-hydroxy-3-nitrophenyl)acetyl. I. The architecture and dynamics of responding cell populations. J.Exp.Med. 173, 1165-1175.

Jacobi, H. and Witte, I. (1991). Synergistic effects of U46 D fluid (dimethylammonium salt of 2,4-D) and $\mathrm{CuCl} 2$ on cytotoxicity and DNA repair in human fibroblasts. Toxicol.Lett. 58, 159-167. 
Jacobson, J. D., Ansari, M. A., Kinealy, M., and Muthukrishnan, V. (1999). Genderspecific exacerbation of murine lupus by gonadotropin-releasing hormone: potential role of G alpha(q/11). Endocrinology 140, 3429-3437.

Jacobson, J. D., Crofford, L. J., Sun, L., and Wilder, R. L. (1998). Cyclical expression of GnRH and GnRH receptor mRNA in lymphoid organs. Neuroendocrinology 67, 117125.

Johansson, E. L., Rask, C., Fredriksson, M., Eriksson, K., Czerkinsky, C., and Holmgren, J. (1998). Antibodies and antibody-secreting cells in the female genital tract after vaginal or intranasal immunization with cholera toxin B subunit or conjugates. Infect.Immun. 66, 514-520.

Khan, A. Q., Chen, Q., Wu, Z. Q., Paton, J. C., and Snapper, C. M. (2005). Both innate immunity and type 1 humoral immunity to Streptococcus pneumoniae are mediated by MyD88 but differ in their relative levels of dependence on toll-like receptor 2. Infect.Immun. 73, 298-307.

Khan, A. Q., Lees, A., and Snapper, C. M. (2004). Differential regulation of IgG anticapsular polysaccharide and antiprotein responses to intact Streptococcus pneumoniae in the presence of cognate CD4+ T cell help. J.Immunol. 172, 532-539.

Khan, A. Q., Shen, Y., Wu, Z. Q., Wynn, T. A., and Snapper, C. M. (2002). Endogenous pro- and anti-inflammatory cytokines differentially regulate an in vivo humoral response to Streptococcus pneumoniae. Infect.Immun. 70, 749-761. 
Knopp, D. and Schiller, F. (1992). Oral and dermal application of 2,4-

dichlorophenoxyacetic acid sodium and dimethylamine salts to male rats:

investigations on absorption and excretion as well as induction of hepatic mixedfunction oxidase activities. Arch.Toxicol. 66, 170-174.

Kobrynski, L. J., Sousa, A. O., Nahmias, A. J., and Lee, F. K. (2005). Cutting edge: antibody production to pneumococcal polysaccharides requires CD1 molecules and CD8+ T cells. J.Immunol. 174, 1787-1790.

Kocar, I. H., Yesilova, Z., Ozata, M., Turan, M., Sengul, A., and Ozdemir, I. (2000). The effect of testosterone replacement treatment on immunological features of patients with Klinefelter's syndrome. Clin.Exp.Immunol. 121, 448-452.

Kruetzmann, S., Rosado, M. M., Weber, H., Germing, U., Tournilhac, O., Peter, H. H., Berner, R., Peters, A., Boehm, T., Plebani, A., Quinti, I., and Carsetti, R. (2003). Human immunoglobulin M memory B cells controlling Streptococcus pneumoniae infections are generated in the spleen. J.Exp.Med. 197, 939-945.

Ladics, G. S., Smith, C., Nicastro, S. C., Loveless, S. E., Cook, J. C., and O'Connor, J. C. (1998). Evaluation of the primary humoral immune response following exposure of male rats to 17 beta-estradiol or flutamide for 15 days. Toxicol.Sci. 46, 75-82.

Leemans, R., Harms, G., Rijkers, G. T., and Timens, W. (1999). Spleen autotransplantation provides restoration of functional splenic lymphoid compartments and improves the humoral immune response to pneumococcal polysaccharide vaccine. Clin.Exp.Immunol. 117, 596-604. 
Lin, N. and Garry, V. F. (2000). In vitro studies of cellular and molecular developmental toxicity of adjuvants, herbicides, and fungicides commonly used in Red River Valley, Minnesota. J.Toxicol.Environ.Health A 60, 423-439.

Linnainmaa, K. (1983). Sister chromatid exchanges among workers occupationally exposed to phenoxy acid herbicides 2,4-D and MCPA. Teratog.Carcinog.Mutagen. 3, 269-279.

Liu, Y. J., Zhang, J., Lane, P. J., Chan, E. Y., and MacLennan, I. C. (1991). Sites of specific B cell activation in primary and secondary responses to T cell-dependent and T cell-independent antigens. Eur.J.Immunol. 21, 2951-2962.

Lu, F. X., Abel, K., Ma, Z., Rourke, T., Lu, D., Torten, J., McChesney, M., and Miller, C. J. (2002). The strength of B cell immunity in female rhesus macaques is controlled by CD8+ $\mathrm{T}$ cells under the influence of ovarian steroid hormones. Clin.Exp.Immunol. 128, $10-20$.

Malerba, I., Castoldi, A. F., Parent-Massin, D., and Gribaldo, L. (2002). In vitro myelotoxicity of propanil and 3,4-dichloroaniline on murine and human CFU-E/BFUE progenitors. Toxicol.Sci. 69, 433-438.

Manz, R. A., Arce, S., Cassese, G., Hauser, A. E., Hiepe, F., and Radbruch, A. (2002). Humoral immunity and long-lived plasma cells. Curr.Opin.Immunol. 14, 517-521.

Martin, F., Oliver, A. M., and Kearney, J. F. (2001). Marginal zone and B1 B cells unite in the early response against T-independent blood-borne particulate antigens. Immunity. 14, 617-629. 
Mattsson, J. L., Charles, J. M., Yano, B. L., Cunny, H. C., Wilson, R. D., and Bus, J. S. (1997). Single-dose and chronic dietary neurotoxicity screening studies on 2,4dichlorophenoxyacetic acid in rats. Fundam.Appl.Toxicol. 40, 111-119.

McClure, G. Y., Helm, R. M., Stine, K., Burks, A. W., Jones, S. M., and Gandy, J. (2001). Evaluation of immune parameters in propanil-exposed farm families. Arch.Environ.Contam Toxicol. 41, 104-111.

McMillan, D. C., Bradshaw, T. P., Hinson, J. A., and Jollow, D. J. (1991). Role of metabolites in propanil-induced hemolytic anemia. Toxicol.Appl.Pharmacol. 110, 7078.

McMillan, D. C., Freeman, J. P., and Hinson, J. A. (1990a). Metabolism of the arylamide herbicide propanil. I. Microsomal metabolism and in vitro methemoglobinemia. Toxicol.Appl.Pharmacol. 103, 90-101.

McMillan, D. C., McRae, T. A., and Hinson, J. A. (1990b). Propanil-induced methemoglobinemia and hemoglobin binding in the rat. Toxicol.Appl.Pharmacol. 105, 503-507.

McMillan, D. C., Shaddock, J. G., Heflich, R. H., Casciano, D. A., and Hinson, J. A. (1988). Evaluation of propanil and its N-oxidized derivatives for genotoxicity in the Salmonella typhimurium reversion, Chinese hamster ovary/hypoxanthine guanine phosphoribosyl transferase, and rat hepatocyte/DNA repair assays. Fundam.Appl.Toxicol. 11, 429-439. 
McMurray, R. W., Suwannaroj, S., Ndebele, K., and Jenkins, J. K. (2001). Differential effects of sex steroids on T and B cells: modulation of cell cycle phase distribution, apoptosis and bcl-2 protein levels. Pathobiology 69, 44-58.

Mongini, P. K., Vilensky, M. A., Highet, P. F., and Inman, J. K. (1997). The affinity threshold for human B cell activation via the antigen receptor complex is reduced upon co-ligation of the antigen receptor with CD21 (CR2). J.Immunol. 159, 37823791.

Morse, D. L., Baker, E. L., Jr., Kimbrough, R. D., and Wisseman, C. L., III (1979). Propanil-chloracne and methomyl toxicity in workers of a pesticide manufacturing plant. Clin.Toxicol. 15, 13-21.

Munro, I. C., Carlo, G. L., Orr, J. C., Sund, K. G., Wilson, R. M., Kennepohl, E., Lynch, B. S., Jablinske, M., and Lee, N. L. (2002). A comprehensive, integrated review and evaluation of the scientific evidence relating to the safety of the herbicide 2,4-D. J.Am.Coll.Toxicol. 11, 559-663.

Myers, M. J. and Petersen, B. H. (1985). Estradiol induced alterations of the immune system--I. Enhancement of IgM production. Int.J.Immunopharmacol. 7, 207-213.

Nicoletti, C., Yang, X., and Cerny, J. (1993). Repertoire diversity of antibody response to bacterial antigens in aged mice. III. Phosphorylcholine antibody from young and aged mice differ in structure and protective activity against infection with Streptococcus pneumoniae. J.Immunol. 150, 543-549. 
O'Connor, J. C., Frame, S. R., and Ladics, G. S. (2002). Evaluation of a 15-day screening assay using intact male rats for identifying antiandrogens. Toxicol.Sci. 69, 92-108.

Pelletier, O., Ritter, L., Caron, J., and Somers, D. (1989). Disposition of 2,4dichlorophenoxyacetic acid dimethylamine by Fischer 344 rats dosed orally and dermally. J.Toxicol.Environ.Health 28, 221-234.

Perlmutter, R. M., Crews, S. T., Douglas, R., Sorensen, G., Johnson, N., Nivera, N., Gearhart, P. J., and Hood, L. (1984). The generation of diversity in phosphorylcholine-binding antibodies. Adv.Immunol. 35, 1-37.

Peset Llopis, M. J., Harms, G., Hardonk, M. J., and Timens, W. (1996). Human immune response to pneumococcal polysaccharides: complement-mediated localization preferentially on CD21-positive splenic marginal zone B cells and follicular dendritic cells. J.Allergy Clin.Immunol. 97, 1015-1024.

Qin, D., Wu, J., Carroll, M. C., Burton, G. F., Szakal, A. K., and Tew, J. G. (1998). Evidence for an important interaction between a complement-derived CD21 ligand on follicular dendritic cells and CD21 on B cells in the initiation of $\mathrm{IgG}$ responses. J.Immunol. 161, 4549-4554.

Ramachandra, L., Chu, R. S., Askew, D., Noss, E. H., Canaday, D. H., Potter, N. S., Johnsen, A., Krieg, A. M., Nedrud, J. G., Boom, W. H., and Harding, C. V. (1999). Phagocytic antigen processing and effects of microbial products on antigen processing and T-cell responses. Immunol.Rev. 168, 217-239. 
Richards, S. M., McClure, G. Y., Lavy, T. L., Mattice, J. D., Keller, R. J., and Gandy, J. (2001). Propanil (3,4-dichloropropionanilide) particulate concentrations within and near the residences of families living adjacent to aerially sprayed rice fields. Arch.Environ.Contam Toxicol. 41, 112-116.

Rosenberg, N. and Kincade, P. W. (1994). B-lineage differentiation in normal and transformed cells and the microenvironment that supports it. Curr.Opin.Immunol. 6, 203-211.

Roubinian, J. R., Talal, N., Greenspan, J. S., Goodman, J. R., and Siiteri, P. K. (1978). Effect of castration and sex hormone treatment on survival, anti-nucleic acid antibodies, and glomerulonephritis in NZB/NZW F1 mice. J.Exp.Med. 147, 15681583.

Roubinian, J. R., Talal, N., Greenspan, J. S., Goodman, J. R., and Siiteri, P. K. (1979). Delayed androgen treatment prolongs survival in murine lupus. J.Clin.Invest 63, 902911.

Ruppert, V. J., Williams, K., and Claflin, J. L. (1980). Specific clonal regulation in the response to phosphocholine. I. Genetic analysis of the response of a distinct idiotype (M511 Id). J.Immunol. 124, 1068-1074.

Salazar, K. D., De la Rosa, P., Barnett, J. B., and Schafer, R. (2005). The Polysaccharide Antibody Response after Streptococcus pneumoniae Vaccination Is Differentially Enhanced or Suppressed by 3,4-Dichloropropionanilide and 2,4Dichlorophenoxyacetic Acid. Toxicol.Sci. 87, 123-133. 
Samy, T. S., Knoferl, M. W., Zheng, R., Schwacha, M. G., Bland, K. I., and Chaudry, I. H. (2001). Divergent immune responses in male and female mice after traumahemorrhage: dimorphic alterations in T lymphocyte steroidogenic enzyme activities. Endocrinology 142, 3519-3529.

Sauerhoff, M. W., Braun, W. H., Blau, G. E., and Gehring, P. J. (1977). The fate of 2,4dichlorophenoxyacetic acid (2,4-D) following oral administration to man. Toxicology 8, 3-11.

Screpanti, I., Morrone, S., Meco, D., Santoni, A., Gulino, A., Paolini, R., Crisanti, A., Mathieson, B. J., and Frati, L. (1989). Steroid sensitivity of thymocyte subpopulations during intrathymic differentiation. Effects of 17 beta-estradiol and dexamethasone on subsets expressing T cell antigen receptor or IL-2 receptor. J.Immunol. 142, 33783383.

Sen, G., Chen, Q., and Snapper, C. M. (2006). Immunization of aged mice with a pneumococcal conjugate vaccine combined with an unmethylated $\mathrm{CpG}$-containing oligodeoxynucleotide restores defective immunoglobulin $\mathrm{G}$ antipolysaccharide responses and specific CD4+-T-cell priming to young adult levels. Infect.Immun. 74, 2177-2186.

Sen, G., Khan, A. Q., Chen, Q., and Snapper, C. M. (2005). In Vivo Humoral Immune Responses to Isolated Pneumococcal Polysaccharides Are Dependent on the Presence of Associated TLR Ligands. J.Immunol. 175, 3084-3091. 
Sharer, M., Park, J. H., Voice, T. C., and Boyd, S. A. (2003). Aging effects on the sorption-desorption characteristics of anthropogenic organic compounds in soil. J.Environ.Qual. 32, 1385-1392.

Shih, T. A., Roederer, M., and Nussenzweig, M. C. (2002). Role of antigen receptor affinity in T cell-independent antibody responses in vivo. Nat.Immunol. 3, 399-406.

Singleton, S. D. and Murphy, S. D. (1973). Propanil (3,4-dichloropropionanilide)induced methemoglobin formation in mice in relation to acylamidase activity. Toxicol.Appl.Pharmacol. 25, 20-29.

Smith, K. G., Hewitson, T. D., Nossal, G. J., and Tarlinton, D. M. (1996). The phenotype and fate of the antibody-forming cells of the splenic foci. Eur.J.Immunol. 26, 444448.

Szekeres-Bartho, J. and Wegmann, T. G. (1996). A progesterone-dependent immunomodulatory protein alters the Th1/Th2 balance. J.Reprod.Immunol. 31, 8195.

Timens, W., Boes, A., Rozeboom-Uiterwijk, T., and Poppema, S. (1989). Immaturity of the human splenic marginal zone in infancy. Possible contribution to the deficient infant immune response. J.Immunol. 143, 3200-3206.

Tu, A. H., Fulgham, R. L., McCrory, M. A., Briles, D. E., and Szalai, A. J. (1999). Pneumococcal surface protein A inhibits complement activation by Streptococcus pneumoniae. Infect.Immun. 67, 4720-4724. 
Tuomanen, E. I., Austrian, R., and Masure, H. R. (1995). Pathogenesis of pneumococcal infection. N.Engl.J.Med. 332, 1280-1284.

U.S.ENVIRONMENTAL PROTECTION AGENCY OFFICE OF PESTICIDE PROGRAMS SPECIAL REVIEW AND REREGISTRATION DIVISION. Reregistration Eligibility Decision for Propanil. (2003).

http://www.epa.gov/REDs/propanil_red.pdf

\section{U.S.ENVIRONMENTAL PROTECTION AGENCY OFFICE OF PESTICIDE} PROGRAMS SPECIAL REVIEW AND REREGISTRTION DIVISION. Reregistration Eligibility Decision for 2,4-D. (2005). http://www.epa.gov/oppsrrd1/REDs/24d_red.pdf

van den Eertwegh, A. J., Laman, J. D., Schellekens, M. M., Boersma, W. J., and Claassen, E. (1992). Complement-mediated follicular localization of T-independent type-2 antigens: the role of marginal zone macrophages revisited. Eur.J.Immunol. 22, 719-726.

Van Ravenzwaay, B., Hardwick, T. D., Needham, D., Pethen, S., and Lappin, G. J. (2003). Comparative metabolism of 2,4-dichlorophenoxyacetic acid (2,4-D) in rat and dog. Xenobiotica 33, 805-821.

Veeh, R., Inskeep, W., and Camper AK (1996). Soil depth and temperature effects on microbial degradation of 2,4-D. Journal of Environmental Quality 25, 5-12. 
Verthelyi, D. I. and Ahmed, S. A. (1998). Estrogen increases the number of plasma cells and enhances their autoantibody production in nonautoimmune C57BL/6 mice. Cell Immunol. 189, 125-134.

Vinuesa, C. G., Sunners, Y., Pongracz, J., Ball, J., Toellner, K. M., Taylor, D., MacLennan, I. C., and Cook, M. C. (2001). Tracking the response of Xid B cells in vivo: TI-2 antigen induces migration and proliferation but Btk is essential for terminal differentiation. Eur.J.Immunol. 31, 1340-1350.

Vos, Q., Lees, A., Wu, Z. Q., Snapper, C. M., and Mond, J. J. (2000). B-cell activation by T-cell-independent type 2 antigens as an integral part of the humoral immune response to pathogenic microorganisms. Immunol.Rev. 176, 154-170.

Wallick, S., Claflin, J. L., and Briles, D. E. (1983). Resistance to Streptococcus pneumoniae is induced by a phosphocholine-protein conjugate. J.Immunol. 130, 2871-2875.

Watson, V. A., Barnett, J. B., and Schafer, R. (2000). In vivo cytokine production and resistance to infection after acute exposure to 3,4-dichloropropionaniline. J.Toxicol.Environ.Health A 60, 391-406.

Wauchope, R. D., Burt, J. P., Augustijn Beckers, P. W. M., Hornsby, A. G., and Buttler, T. M. (1992). SCS/ARS/CES Pesticide properties database for environmental decision making. Rev.Environ.Contam.Toxicol. 123, 10-12.

Whipple, E. C., Shanahan, R. S., Ditto, A. H., Taylor, R. P., and Lindorfer, M. A. (2004). Analyses of the in vivo trafficking of stoichiometric doses of an anti-complement 
receptor 1/2 monoclonal antibody infused intravenously in mice. J.Immunol. 173, 2297-2306.

Whitmore, A. C., Neely, H. R., Diz, R., and Flood, P. M. (2004). Rapid induction of splenic and peritoneal B-1a cells in adult mice by thymus-independent type- 2 antigen. J.Immunol. 173, 5406-5414.

Wiens, G. D., Brown, M., and Rittenberg, M. B. (2003). Repertoire shift in the humoral response to phosphocholine-keyhole limpet hemocyanin: $\mathrm{VH}$ somatic mutation in germinal center B cells impairs T15 Ig function. J.Immunol. 170, 5095-5102.

Williams, C. H. and Jacobson, K. H. (1966). An acylamidase in mammalian liver hydrolyzing the herbicide 3,4-dichloropropionanilide. Toxicology and Applied Pharmacology 9, 495-500.

Wortham, C., Grinberg, L., Kaslow, D. C., Briles, D. E., McDaniel, L. S., Lees, A., Flora, M., Snapper, C. M., and Mond, J. J. (1998). Enhanced protective antibody responses to PspA after intranasal or subcutaneous injections of PspA genetically fused to granulocyte-macrophage colony-stimulating factor or interleukin-2. Infect.Immun. 66, 1513-1520.

Wu, P. and Ward, R. E. (1993). Ig repertoire expression of BALB/c primary and secondary B cell precursors specific for phosphorylcholine. J.Immunol. 150, 38623872.

Wu, Z. Q., Khan, A. Q., Shen, Y., Schartman, J., Peach, R., Lees, A., Mond, J. J., Gause, W. C., and Snapper, C. M. (2000). B7 requirements for primary and secondary 
protein- and polysaccharide-specific Ig isotype responses to Streptococcus pneumoniae. J.Immunol. 165, 6840-6848.

Wu, Z. Q., Khan, A. Q., Shen, Y., Wolcott, K. M., Dawicki, W., Watts, T. H., Mittler, R. S., and Snapper, C. M. (2003). 4-1BB (CD137) differentially regulates murine in vivo protein- and polysaccharide-specific immunoglobulin isotype responses to Streptococcus pneumoniae. Infect.Immun. 71, 196-204.

Wu, Z. Q., Shen, Y., Khan, A. Q., Chu, C. L., Riese, R., Chapman, H. A., Kanagawa, O., and Snapper, C. M. (2002). The mechanism underlying T cell help for induction of an antigen-specific in vivo humoral immune response to intact Streptococcus pneumoniae is dependent on the type of antigen. J.Immunol. 168, 5551-5557.

Wu, Z. Q., Vos, Q., Shen, Y., Lees, A., Wilson, S. R., Briles, D. E., Gause, W. C., Mond, J. J., and Snapper, C. M. (1999). In vivo polysaccharide-specific IgG isotype responses to intact Streptococcus pneumoniae are $\mathrm{T}$ cell dependent and require. J.Immunol. 163, 659-667.

Xie, Y. C., Schafer, R., and Barnett, J. B. (1997a). Inhibitory effect of 3,4-dichloropropionaniline on cytokine production by macrophages is associated with LPSmediated signal transduction. J.Leukoc.Biol. 61, 745-752.

Xie, Y. C., Schafer, R., and Barnett, J. B. (1997b). The immunomodulatory effects of the herbicide propanil on murine macrophage interleukin-6 and tumor necrosis factoralpha production. Toxicol.Appl.Pharmacol. 145, 184-191. 
Yurino, H., Ishikawa, S., Sato, T., Akadegawa, K., Ito, T., Ueha, S., Inadera, H., and Matsushima, K. (2004). Endocrine disruptors (environmental estrogens) enhance autoantibody production by B1 cells. Toxicol.Sci. 81, 139-147.

Zandvoort, A. and Timens, W. (2002). The dual function of the splenic marginal zone: essential for initiation of anti-TI-2 responses but also vital in the general first-line defense against blood-borne antigens. Clin.Exp.Immunol. 130, 4-11.

Zeljezic, D. and Garaj-Vrhovac, V. (2004). Chromosomal aberrations, micronuclei and nuclear buds induced in human lymphocytes by 2,4-dichlorophenoxyacetic acid pesticide formulation. Toxicology 200, 39-47.

Zhao, W., Schafer, R., and Barnett, J. B. (1998). Cytokine production by C57BL/6 mouse spleen cells is selectively reduced by exposure to propanil. J.Toxicol.Environ.Health A 55, 107-120.

Zhao, W., Schafer, R., and Barnett, J. B. (1999). Propanil affects transcriptional and posttranscriptional regulation of IL-2 expression in activated EL-4 cells. Toxicol.Appl.Pharmacol. $154,153-159$.

Zhao, W., Schafer, R., Cuff, C. F., Gandy, J., and Barnett, J. B. (1995). Changes in primary and secondary lymphoid organ T-cell subpopulations resulting from acute in vivo exposure to propanil. J.Toxicol.Environ.Health 46, 171-181. 